\title{
Invited review: Nitrogen in ruminant nutrition: A review of measurement techniques
}

\author{
A. N. Hristov, ${ }^{1 *}$ A. Bannink, ${ }^{2}$ L. A. Crompton, ${ }^{3}$ P. Huhtanen, ${ }^{4}$ M. Kreuzer, ${ }^{5}$ M. McGee, ${ }^{6}$ P. Nozière, ${ }^{7}$ \\ C. K. Reynolds, ${ }^{3}$ A. R. Bayat, ${ }^{8}$ D. R. Yáñez-Ruiz, ${ }^{9}$ J. Dijkstra, ${ }^{10}$ E. Kebreab,,${ }^{11}$ A. Schwarm,${ }^{5} \dagger$ \\ K. J. Shingfield, ${ }^{8,12} \ddagger$ and Z. Yu ${ }^{13}$ \\ ${ }^{1}$ Department of Animal Science, The Pennsylvania State University, University Park 16802 \\ ${ }^{2}$ Wageningen Livestock Research, Wageningen University \& Research, PO Box 338, 6700 AH Wageningen, the Netherlands \\ ${ }^{3}$ School of Agriculture, Policy and Development, Centre for Dairy Research, University of Reading, PO Box 237 Earley Gate, Reading RG6 6AR, \\ United Kingdom \\ ${ }^{4}$ Department of Agricultural Science, Swedish University of Agricultural Sciences, S-90, Umeå, Sweden \\ ${ }^{5}$ ETH Zurich, Institute of Agricultural Sciences, Universitaetstrasse 2, 8092 Zurich, Switzerland \\ ${ }^{6}$ Teagasc, Animal \& Grassland Research and Innovation Centre, Grange, Dunsany, Co. Meath, Ireland C15 PW93 \\ ${ }^{7}$ Université Clermont Auvergne, INRA, VetAgro Sup, UMR Herbivores, F-63122 Saint-Genès-Champanelle, France \\ ${ }^{8}$ Milk Production Solutions, Production Systems, Natural Resources Institute Finland (Luke), FI 31600 Jokioinen, Finland \\ ${ }^{9}$ Estación Experimental del Zaidín (CSIC), Profesor Albareda, 1, 18008, Granada, Spain \\ ${ }^{10}$ Animal Nutrition Group, Wageningen University \& Research, PO Box 338, $6700 \mathrm{AH}$, Wageningen, the Netherlands \\ ${ }^{11}$ Department of Animal Science, University of California, Davis 95616 \\ ${ }^{12}$ Institute of Biological, Environmental and Rural Sciences, Aberystwyth University, Aberystwyth, SY23 3EB, United Kingdom \\ ${ }^{13}$ Department of Animal Sciences, The Ohio State University, Columbus 43210
}

\section{ABSTRACT}

Nitrogen is a component of essential nutrients critical for the productivity of ruminants. If excreted in excess, $\mathrm{N}$ is also an important environmental pollutant contributing to acid deposition, eutrophication, human respiratory problems, and climate change. The complex microbial metabolic activity in the rumen and the effect on subsequent processes in the intestines and body tissues make the study of $\mathrm{N}$ metabolism in ruminants challenging compared with nonruminants. Therefore, using accurate and precise measurement techniques is imperative for obtaining reliable experimental results on $\mathrm{N}$ utilization by ruminants and evaluating the environmental impacts of $\mathrm{N}$ emission mitigation techniques. Changeover design experiments are as suitable as continuous ones for studying protein metabolism in ruminant animals, except when changes in body weight or carryover effects due to treatment are expected. Adaptation following a dietary change should be allowed for at least 2 (preferably 3 ) wk, and extended adaptation periods may be required if body pools can temporarily supply the nutrients studied. Dietary protein degradability in the rumen and intestines are feed

Received October 10, 2018.

Accepted February 27, 2019.

*Corresponding author: anh13@psu.edu

$\dagger$ Present address: Department of Animal and Aquacultural Sciences, Norwegian University of Life Sciences, Arboretveien 6, 1433 Ås, Norway.

$\ddagger$ Deceased. characteristics determining the primary AA available to the host animal. They can be estimated using in situ, in vitro, or in vivo techniques with each having inherent advantages and disadvantages. Accurate, precise, and inexpensive laboratory assays for feed protein availability are still needed. Techniques used for direct determination of rumen microbial protein synthesis are laborious and expensive, and data variability can be unacceptably large; indirect approaches have not shown the level of accuracy required for widespread adoption. Techniques for studying postruminal digestion and absorption of nitrogenous compounds, urea recycling, and mammary AA metabolism are also laborious, expensive (especially the methods that use isotopes), and results can be variable, especially the methods based on measurements of digesta or blood flow. Volatile loss of $\mathrm{N}$ from feces and particularly urine can be substantial during collection, processing, and analysis of excreta, compromising the accuracy of measurements of totaltract $\mathrm{N}$ digestion and body $\mathrm{N}$ balance. In studying ruminant $\mathrm{N}$ metabolism, nutritionists should consider the longer term fate of manure $\mathrm{N}$ as well. Various techniques used to determine the effects of animal nutrition on total $\mathrm{N}$, ammonia- or nitrous oxide-emitting potentials, as well as plant fertilizer value, of manure are available. Overall, methods to study ruminant $\mathrm{N}$ metabolism have been developed over $150 \mathrm{yr}$ of animal nutrition research, but many of them are laborious and impractical for application on a large number of animals. The increasing environmental concerns associated with livestock production systems necessitate more accurate and reliable methods to determine ma- 
nure $\mathrm{N}$ emissions in the context of feed composition and ruminant $\mathrm{N}$ metabolism.

Key words: nitrogen, metabolism, environment, technique, ruminant animal, manure

\section{INTRODUCTION}

Since the discovery of the Haber-Bosch process, N has played a pivotal role in agricultural production and is a key nutrient influencing crop yields. Globally, demands for $\mathrm{N}$ fertilizer are growing (in parallel with the growing human population) and were expected to reach 119.4 million t in 2018 (FAO, 2015). Being a component of essential nutrients, $\mathrm{N}$ is critically important for animal growth and productivity. Ruminant livestock, however, are relatively inefficient utilizers of feed $\mathrm{N}$. In research trials with dairy cows, milk $\mathrm{N}$ efficiency varied from 14 to $45 \%$ [average of 25 and $28 \%$ (SD = 4.1 and $3.6 \%$ ) for North American and North European data, respectively] as reported in a meta-analysis by Huhtanen and Hristov (2009). Nitrogen mass balance data for dairy farms and beef feedlots showed the efficiency of feed $\mathrm{N}$ conversion into milk or BW gain of 27 and 14\%, respectively (Hristov et al., 2011). Nitrogen not retained in animal tissues or secreted in milk is excreted in urine and feces, contributing to water pollution, gaseous $\mathrm{N}$ emissions, and small particulate matter formation in the atmosphere (Külling et al., 2001; Hristov, 2011; Hristov et al., 2011; Cameron et al., 2013). Urinary $\mathrm{N}$ is much more labile and susceptible to fast leaching and volatilization losses than fecal N. The large variation in urinary $\mathrm{N}$ excretion, compared with fecal N, presents an opportunity to manipulate diets to reduce urinary $\mathrm{N}$ excretion (Dijkstra et al., 2018). Therefore, understanding $\mathrm{N}$ metabolism and studying processes and practices that can improve the efficiency of $\mathrm{N}$ utilization for productive purposes have been a primary focus of ruminant nutrition research for over a century (Bergen, 2007; Schwab and Broderick, 2017). More recent research has gravitated toward mitigation of $\mathrm{N}$ emissions (i.e., ammonia, nitrate, and nitrous oxide) to the environment. Using the most accurate and precise measurement techniques is critical for obtaining reliable experimental results on $\mathrm{N}$ utilization by ruminants, for assessing the efficiency of $\mathrm{N}$ emission mitigation technologies, and for proper evaluation and interpretation of published data.

This review is intended to provide an in-depth analysis of the methods currently used to study $\mathrm{N}$ digestion and metabolism in ruminants and the fate of manure N. The review is based on the broad yet complementary expertise of the international consortium of scientists participating in the Global Network project within the Feed and Nutrition Network, which is part of the Livestock Research Group of the Global Research Alliance for Agricultural Greenhouse Gases (https://globalresearchalliance.org/research/livestock/ networks/feed-nutrition-network; accessed October 1, 2018).

\section{EXPERIMENTAL DESIGN}

Several excellent papers (Tempelman, 2004; StPierre, 2007; McNamara et al., 2016) and classic texts such as Cochran and Cox (1992) have reviewed experimental designs used in animal research. The goal of this section is not to repeat what has already been discussed elsewhere, but to focus primarily on the specific aspects of studies designed to investigate $\mathrm{N}$ metabolism in $\mathrm{ru}-$ minant animals.

\section{Short- vs. Long-Term Experiments}

Nutritional experiments with ruminant animals mostly fall within 2 categories, so-called continuous design experiments (for example, randomized block design), usually of prolonged duration, and changeover or crossover (typically, Latin square) design experiments of a limited number of subsequent experimental periods. Both types of designs have advantages and disadvantages.

The continuous design allows evaluation of the effects of treatment on variables over a longer study period, with BW changes being a typical example. The main disadvantage of this design is that variability among individual animals can be high. Even when animals are carefully selected and blocked, and a covariate period is used, individual animals can vary greatly in their feed intake, production, or other responses to treatment in time. Data collection during a covariate period, during which animals are receiving a uniform treatment, is recommended for continuous design experiments. The length of the covariate period should be sufficient (at least $14 \mathrm{~d}$, see next section) to allow adaptation to the background diet. In addition, variables for which data are collected during the covariate period should correspond to variables studied in the main experiment. In some situations, however, the inclusion of a covariate period is not possible, an example being experiments with transition dairy cows, and another blocking criterion (or criteria) should be used instead (e.g., 100- or 305-d milk yield in the previous lactation). Moreover, if treatment by block interaction (e.g., block being parity) is of interest, use of a covariate hampers analysis of this interaction.

The advantage of changeover designs is that all animals receive all treatments and can serve as their 
own control, unless the design is incomplete. Thus, the statistical power of this type of design is almost always greater, at a comparable number of experimental units, than that of a continuous design because animal variation is accounted for. The main disadvantage of changeover designs is that experimental periods are usually of a short duration and animals may change their nutrient metabolism or production parameters (or both) during the experiment (such as the case with lactating dairy cows or growing animals). Another issue is carryover effects of treatments; for example, a milk yield decrease, as a consequence of MP deficiency, may not fully recover or recover over extended periods (Zanton, 2016), with compensatory growth in cattle being another example. In less severe cases, carryover effects can be minimized by using designs balanced for carryover effects, extending experimental periods, and including washout periods (7 to 14 d; van Gastelen et al., 2017; Rossi et al., 2018). Huhtanen and Hetta (2012) conducted a meta-analysis of published continuous (354 diets) and changeover (632 diets) design studies and concluded that, except when treatments result in large differences in DMI $(>5 \mathrm{~kg} / \mathrm{d})$, both designs are similarly accurate in evaluating the effects of nutritional treatments on feed intake and milk production in dairy cows. Analysis of a smaller subset of changeover experiments in that study showed no significant carryover effects. Another attempt to elucidate the effect of experimental design on production responses in dairy cows, as related to dietary protein, was a meta-analysis by Zanton (2016). This author concluded that design had no effect on DMI, milk fat and protein yields, or milk $\mathrm{N}$ efficiency in response to dietary $\mathrm{CP}$, but that design influenced milk yield and consequently feed efficiency. One issue with the latter analysis, less evident in the meta-analysis of Huhtanen and Hetta (2012), was the different DIM of the cows on the 2 types of experimental design, which is an important variable in studies focusing on production effects of dietary protein.

\section{Experimental Unit}

Defining the experimental unit is as important as the experimental design in animal studies. In nutritional studies, the individual animal is usually the experimental unit. Groups of animals, however, can also represent an experimental unit. The type of animal should be representative of the population to which results from the study would be applicable or recommended. Most experimental data obtained for one species or category of animals cannot be applied to another species or category; data from sheep are not generally applicable to cattle, and data from beef cattle are not generally applicable to lactating dairy cows. Then, within a spe- cies or a category, researchers should select a group of healthy animals with production, type of diet, and DMI being representative of the target population of animals (i.e., passage rate and digestive metabolism of a high-producing dairy cow, for example, would be much different from those of a low-producing or dry cow).

The number of experimental units should be sufficient to detect statistical differences for the main variables of interest. Typically, power analysis is used to determine the sample size, replications, or experimental units. Power analysis, however, is useful only when variability and expected magnitude of the response for a measurement are known. For some nutritional measurements, variability can be very high. Titgemeyer (1997) examined 126 studies published in the Journal of Animal Science and calculated that to detect a 5- or 10-percentage-unit significant $(P<0.05)$ difference in totaltract $\mathrm{N}$ digestibility, 3 to 4 experimental units would be sufficient. To detect the same magnitude of difference in rumen $\mathrm{N}$ degradability or duodenal $\mathrm{N}$ flow, however, 5 to 15 and 6 to 20 experimental units were required, respectively. The large variability in the digesta flow data in the Titgemeyer (1997) analysis can be partially explained by the predominantly single-marker approach used in the original studies. This variability can be decreased by using dual- or triple-marker techniques for estimating digesta flow kinetics (Huhtanen et al., 2010; see discussion in Invasive or Direct Methods for Assessing Feed Protein Degradability and Microbial Protein Synthesis). Titgemeyer (1997) also made the point that researchers should be aware of "unrealistic" values. A typical example of an unrealistic value that may occur in $\mathrm{N}$ metabolism studies would be a high $\mathrm{N}$ retention (discussed in Whole-Animal Nitrogen Balance Studies).

If treatment is applied to a group of animals in a pen or corral, the group is considered the experimental unit. As pointed out by St-Pierre (2007), the number of experimental units to achieve a statistical significance in a group study is lower due to lower variability among groups than variability among animals within a group. As with the study of individual animals, that of groups or pens must be replicated for valid statistical analysis. Within a group of animals, however, some measurements may be collected on an individual animal basis. Examples are blood metabolites, milk yield, and milk protein content. Nevertheless, these data must still be analyzed statistically with group as the unit of replication instead of individual animals. The argument brought up by Robinson (2016) that the "experimental unit is the smallest unit in which an individual treatment can be measured" is invalid when dietary treatments are applied to animals within a pen not individually but as a group (for example, via a common trough), as eloquently discussed in Bello et al. (2016). 
Another type of experiment is the so-called "field study." These are experiments conducted on commercial animal farms. Field studies may be attractive given their broader scope of inference on treatment effects across a far wider range of conditions compared with university or institute research farms. Also, greater power may be achieved in field studies when examining effects of nutrition on binary traits (i.e., reproduction, animal health). Generally, however, field studies are more difficult to conduct in a reproducible manner and publish in peer-reviewed journals. This is because these studies are done on working farms where conditions are likely to change daily, and the researcher has less control on the experimental conditions. Replication and variation over time are other factors that usually are not well controlled or managed in field studies. Similar to the group studies described above, groups or pens of animals can be the replication in a single-farm field study, or farms can be replicated in a multi-farm study scenario. In any case, field studies rarely produce convincing and statistically sound results in nutritional research. However, when treatments are replicated across several individual farms, the range of response to a specific treatment may be observed under practical circumstances (Morris, 1999). An excellent overview of the challenges and recommendations for field studies with dairy cattle is provided in Tempelman (2004).

\section{Duration of Treatment or Experimental Periods}

Rumen microbial populations profoundly change with changing diet composition (Fernando et al., 2010) and the rumen ecosystem requires time to recover from or adjusts to changes in diet regimens (Tajima et al., 2000; Monteils et al., 2012). It is generally assumed that the length of a typical adaptation period within changeover design experiments, 14 to $21 \mathrm{~d}$, is sufficient for the manifestation of treatment effects on DMI and digestibility (Grant et al., 2015; Machado et al., 2016; Farenzena et al., 2017). However, evidence indicates that this duration can be shorter for components of the rumen ecosystem. Weimer et al. (2010), for example, reported rapid recovery of ruminal $\mathrm{pH}$ and VFA, but that a more prolonged period (about a week) was needed for recovery of the bacterial community composition, following a near-complete exchange of the ruminal contents of 2 dairy cows. Dieho et al. (2017) demonstrated rapid recovery of the microbiota within $10 \mathrm{~d}$ following a differential concentrate buildup after calving. Similarly, Machado et al. (2016) observed stabilization of the bacterial community in the liquid phase of ruminal contents within 3 to $9 \mathrm{~d}$ following a diet switch. There are, however, large differences between microbial communities associated with the liquid or solid phases of ruminal contents (Henderson et al., 2013) and these communities may respond differently to dietary treatments. The length of data collection/measurements in a continuous design experiment is usually several weeks, which is sufficient for the manifestation of treatment effect, but may be insufficient if BW change is of interest. Similar to changeover design experiments, data or measurement collection in continuous experiments should start following a proper adaptation to treatment for at least $14 \mathrm{~d}$. In experiments with lactating ruminant, depending on the research objectives, treatment effects may be studied over a part of a lactation, a full lactation (as in Wu and Satter, 2000), or several lactations, with the latter rarely occurring in nutritional studies due to funding and facility limitations.

Some specifics should be considered when designing experiments to study $\mathrm{N}$ or AA metabolism in ruminant animals. Evolution has given ruminants a mechanism to preserve and reuse $\mathrm{N}$ through recycling urea synthesized in the liver back to the digestive tract. This mechanism allows microbial fermentation in the rumen to proceed in times when dietary N supply is low. Reynolds and Kristensen (2008) provided a review of the factors regulating urea recycling, and the mechanism involved is discussed in detail later in this review. The important point for designing nutritional experiments is that ruminants, through their rumen microbial ecosystem, can manage temporary low dietary-N supply periods. However, in comparison with preformed AA and small peptides available for microbial metabolism, microbial protein synthesis (MPS) and yield are decreased when ammonia is the major source of $\mathrm{N}$ (reviewed by Dijkstra et al., 1998). The resulting deficiency of AA absorbed from the gut, either of dietary or microbial origin, will cause decreased performance or BW loss. In dairy cows, muscle tissues are a source of AA for glucose and protein synthesis (NRC, 2001). A full-lactation study with high-producing dairy cows (Wu and Satter, 2000) clearly showed that an isoenergetic, but $\mathrm{N}$-deficient, diet will not only decrease milk yield, but will also cause BW loss up to lactation wk 16. Similar trends for BW loss with MP-deficient diets have been shown in continuous design experiments with dairy cows producing around $40 \mathrm{~kg}$ of milk/d (Lee et al., 2012b; Giallongo et al., 2015a). Earlier studies suggested repletion and depletion of body protein reserves in dairy cows for up to 5 mo (Paquay et al., 1972). These authors estimated labile protein reserves of over $15 \mathrm{~kg}$, whereas a later study by Botts et al. (1979) suggested protein reserves of Holstein cows ranging from 25 to $27 \%$ of body protein. Although, typically, cows will lose mainly fat in early lactation (Andrew et al., 1994), when protein is deficient, factors such as DMI, milk and milk protein yields, and specific AA deficiencies 
may contribute to the composition of BW loss. Metaanalyses by Huhtanen and Hetta (2012) and Zanton (2016) discussed short- versus long-term studies and concluded that, in some situations, the experimental design may influence production responses (i.e., large differences in DMI or extensive mobilization of body reserves). Therefore, the full effects of nutritional treatments that cause AA deficiency and consequent BW loss cannot be reliably studied in changeover design experiments.

Experiments designed to study a specific nutrient need to address the potential existence of endogenous pools of that nutrient or its precursors, as is the case with His. Histidine is unique among the EAA by having labile body pools (i.e., intramuscular dipeptides carnosine and anserine, and circulating blood hemoglobin) that could provide a source of His during short periods of deficiency (Lapierre et al., 2008). The importance of experimental design to evaluate effects of His supplementation was illustrated in 2 experiments: one 70-d, continuous (Lee et al., 2012b) and one changeover design with 28-d experimental periods (Lee et al., 2015) aimed to study dietary protein effects in lactating dairy cows. Identical diets were fed in both experiments, cows produced similar amount of milk true protein, and the experiments were conducted simultaneously. As shown in Figure 1, the average, covariate-adjusted plasma His concentration in the MP-deficient diets was $42 \%$ lower than that of the control, MP-adequate diet, in the continuous design experiment, but was not different from the control in the changeover experiment.

In conclusion, both continuous and changeover design experiments are suitable for studying protein

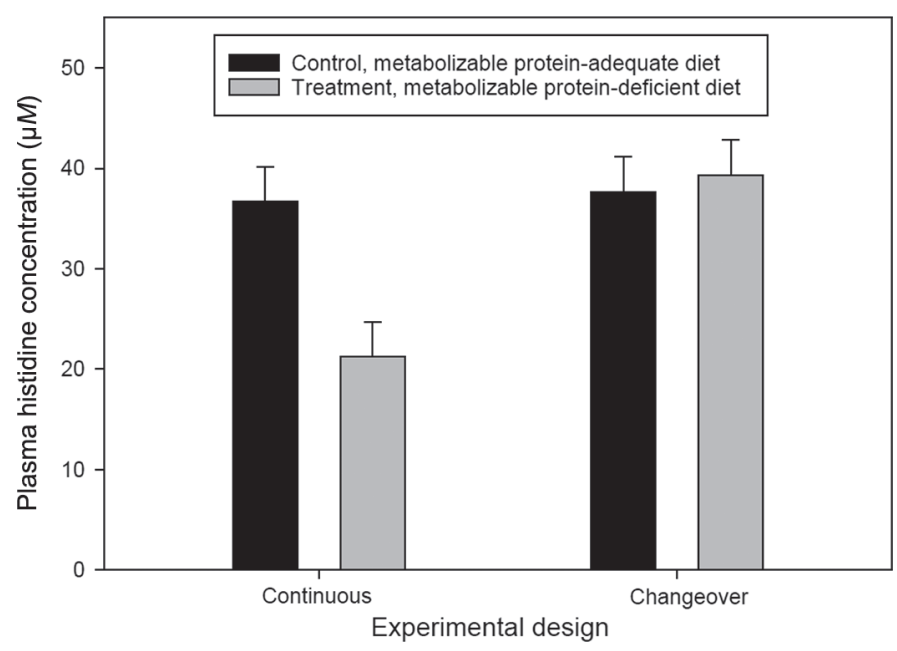

Figure 1. Plasma histidine concentration in dairy cows fed diets adequate or deficient in MP in continuous or changeover design experiments (data from Lee et al., 2012b and 2015; means \pm SEM). metabolism in ruminant animals. In cases where carryover effects are expected due to treatment, changeover experiments may not be appropriate, unless adaptation to treatment, within an experimental period, is sufficiently long (provided that effects are not confounded by lactation stage, animal age, or nutritional state). Adaptation periods following a dietary change should be long enough, at least 2 , and preferably $3 \mathrm{wk}$, to allow stabilization of the rumen ecosystem and ruminant metabolism before experimental data are collected; length of time required for adaptation will also depend on the nature and severity of the treatment. Extended adaptation periods may be required if body reserves can supply or store the nutrient(s) of interest, as is the case with His.

\section{TECHNIQUES OF STUDYING RUMINAL DEGRADATION OF NITROGENOUS COMPOUNDS}

\section{In Situ}

The in situ method has been widely used to estimate ruminal degradation of DM and CP (Hvelplund and Weisbjerg, 1998). Due to various limitations, no in vitro method has been generally accepted as a satisfactory alternative (Stern et al., 1997; Hvelplund and Weisbjerg, 1998; Olaisen et al., 2003; Mohamed and Chaudhry, 2008). The in situ technique relies on the assumption that disappearance of substrate from synthetic porous bags incubated in the rumen represents actual substrate degradation by rumen microorganisms and determines the extent and rate of degradation (Orskov and McDonald, 1979). Bags with a known amount of feed material are incubated in the rumen of cannulated animals for different duration. After incubation, bags are retrieved, washed, and the residues weight is used to calculate nutrient degradation at different time points, which result in the general degradability profile:

$$
\text { in situ degradation }(\mathrm{g} / \mathrm{g})=\mathrm{a}+\mathrm{b}\left(1-\mathrm{e}^{-\mathrm{kd} \times \mathrm{t}}\right) \text {, }
$$

where $\mathrm{a}=$ zero-time intercept $(\mathrm{g} / \mathrm{g}), \mathrm{b}=$ potentially degradable fraction $(\mathrm{g} / \mathrm{g}), \mathrm{kd}=$ fractional rate of degradation $\left(h^{-1}\right)$, and $t=$ incubation time $(h)$.

A wide variety of mathematical models are available to describe in situ degradability data (Lopez et al., 1999). To account for feed outflow from the rumen (which hence escapes rumen degradation), effective degradability $(\mathbf{E D} ; \mathrm{g} / \mathrm{g})$ is classically estimated as

$$
\mathrm{ED}=\mathrm{a}+(\mathrm{b} \times \mathrm{kd}) \div(\mathrm{kd}+\mathrm{kp})
$$

where $\mathrm{kp}=$ fractional rate of particle outflow $\left(\mathrm{h}^{-1}\right)$. 
This method is the reference method to calculate rumen CP degradation in protein evaluation systems for ruminants in several countries, with $\mathrm{kp}$ (for dairy cows) varying from 0.04 to $0.08 \mathrm{~h}^{-1}$ depending on the system (Madsen, 1985; Vérité and Peyraud, 1989; Tamminga et al., 1994; NRC, 2001). This basic model has been adapted in recent systems (Volden, 2011; Van Duinkerken et al., 2011; INRA, 2018) to account for different $\mathrm{kp}$ according to the dietary fractions, and to let these kp vary with feed intake level and dietary composition.

Several factors that may affect in situ degradability should be considered when interpreting results or designing new experiments. These include host animal species, diet, feed intake, sample processing, particle size/form/fine particle losses, sample size to bag surface area ratio, bag pore size, data modeling, microbial $\mathrm{N}$ contamination of bag residues, and incubation sequence. Factors related to particle size and losses affect the estimation of degradability of concentrate feeds to a greater extent than other factors (Madsen and Hvelplund, 1994), whereas microbial contamination and duration of incubation are more relevant for forages (Klopfenstein et al., 2001). Recommendations for conducting in situ experiments have been published (Broderick and Cochran, 2000; NRC, 2001; Krizsan et al., 2015). These general recommendations have to be adjusted to the specific research needs. Furthermore, clarifications in relation to some of the technique's limitations are worth considering and are discussed below.

Incubation Time. In situ incubation time should cover the retention time of the studied feed in the rumen. Poncet et al. (1995) reported that $\mathrm{kp}$ of labeled concentrate particles are usually in the range of 0.04 to $0.06 \mathrm{~h}^{-1}$ in dairy cows, which corresponds to 17 to $25 \mathrm{~h}$ mean retention time. Minimizing the number of time points included in an in situ analysis can reduce bag numbers to a more manageable level. Some researchers use a single incubation time point near an estimated mean retention time of the feedstuff studied. Inaccuracies of this approach have been discussed previously (Orskov and McDonald, 1979; Broderick, 1994). Wilkerson et al. (1995) used only a 16 -h ruminal incubation time to estimate ruminal $\mathrm{CP}$ degradability in roughages by assuming that the 16-h sample directly estimated undegraded CP, whereas Broderick (1994) and Calsamiglia et al. (1994) calculated ED by estimating the ruminal degradation rate from 2 incubation time points. However, questions remain as to whether it is possible to develop a simplified in situ method for feeds that can be used to estimate ED directly without losing accuracy. Calculation of the "optimal" incubation time to mimic time-series analysis requires a priori knowledge of both $\mathrm{kd}$ and $\mathrm{kp}$. Because these factors are unknown at the beginning of a study, the use of a single-time point estimate can yield unreliable estimates of the extent of degradation and should not be used to estimate kd. Olaisen et al. (2003) assessed the in situ CP degradation data from different concentrate feeds to test the accuracy of ED measures when using a reduced number of ruminal incubation time points compared with models based on 7 or 8 time points. Bilinear regression models based on 2 and 3 ruminal incubation times gave similar estimates to a standard in situ method over a wide range of $\mathrm{kp}$ both for the data set used to parameterize the models and the independent data set used to validate the models. The number of nylon bags used by these models was reduced by 58 to $78 \%$ compared with the standard in situ method, and the total incubation time needed was substantially shortened. Therefore, there is a potential to reduce the number of incubated bags needed for concentrate feeds, although feasibility of such an approach has to be demonstrated beforehand and it has not yet been fully assessed for forages.

Particles Losses and Rinsing Step. After ruminal incubation, a rinsing step is carried out to remove rumen contamination, such as external feed particles and microbial matter, from the bags. Microbial N contamination of bag residues underestimates ED in low $\mathrm{N} /$ high fiber feeds (by 26 to 34 percentage units), although this is less important in less mature forages, high in CP (underestimation by 5 to 10 percentage units; Kamoun et al., 2014). Incomplete removal of microbial $\mathrm{N}$ from the bag residues causes erroneous lag and rate estimates for CP degradation. Several approaches are assessed in the literature to correct for microbial contamination of the bag residues (Guevara-Gonzáles et al., 2013; Kamoun et al., 2014), including removing the microorganisms (through thorough washing/dipping in ice, or physical removal by sonication or stomaching), using microbial markers such as D-AA, glucosamine, 2,6-diaminopimelic acid (DAPA), or nucleic acids, or using correction equations.

Rinsing the nonincubated bags removes a fraction of the feed (i.e., washout), containing both soluble components and small particles. The kd of components of the fraction of feed remaining after washout (i.e., nonwashout) can be determined by the in situ method. Most feed evaluation systems, such as the French PDI (Vérité et al., 1979; INRA, 2018), the Dutch DVE (Van Duinkerken et al., 2011), the British FiM (Thomas, 2004), NRC (NRC, 2001), and the Nordic Norfor (Volden, 2011), use various assumptions for $\mathrm{kd}$ of the washout and nonwashout fractions. For several feed evaluation systems, rinsing nylon bags by using a washing machine 
separates the feed in different fractions. The washout fraction is determined by additional analysis based on solubility and filtration or centrifugation, after which the insoluble washout fraction is calculated by difference (e.g., Van Duinkerken et al., 2011; Volden, 2011). This presents several drawbacks (De Jonge et al., 2013) and is particularly critical for forages with a large soluble protein fraction (e.g., alfalfa). The large differences observed in many studies call for the need for an easily standardized end-point determination procedure. For concentrate feeds, Madsen and Hvelplund (1994) suggested the use of a $1 \mathrm{~h}$ incubation of a $1-\mathrm{g}$ sample in water, followed by filtration to determine solubility and rinsing in situ bags in a washing machine for 10 to $15 \mathrm{~min}$. However, these authors reported large standard deviations for this approach among laboratories. Coblentz et al. (2002) subsequently demonstrated that 4 machine rinse cycles were required to minimize $\mathrm{N}$ concentration in machine rinse water, when in situ bags containing alfalfa were washed. Broderick (1994) suggested the use of buffer extraction followed by trichloroacetic acid precipitation to minimize errors caused by the assumption that all solubilized $\mathrm{N}$ will be degraded rapidly. More recently, De Jonge et al. (2015) assessed a modified rinsing method, which enables direct quantification and characterization of all fractions, and applied this method to wheat yeast concentrates that are characterized by a high washout fraction of $\mathrm{N}$ (either soluble $\mathrm{N}$ or $\mathrm{N}$ in small particles that disappear in the rumen or during rinsing). These modifications involve a closed system and standardized conditions enabling the separation and estimation of all fractions using one rinsing method and the replacement of water by a buffer solution that better mimics rumen conditions (De Jonge et al., 2009). Despite the efforts made to standardize the rinsing step, several studies have shown that the in situ method fails to accurately determine the kd of the soluble protein fraction, which is known to be variable (120 to $400 \% / \mathrm{h}$; Sniffen et al., 1992; White et al., 2017).

Overall, the in situ technique is a valid method for comparing the extent and kinetics of protein degradation of different feeds in the rumen; however, it is unsuitable for determination of absolute degradability and, therefore, limitations of the technique must be considered when estimated values are used in feed evaluation systems. Limitations include (1) difficulty to standardize, (2) being labor-intensive, (3) low reproducibility, (4) inaccuracy for soluble or small particulate feeds, (5) need of fistulated animals, and (6) microbial contamination of the feed residues, which is particularly a problem with low-N, high-fiber forages. Although these limitations are well recognized, predictions of duodenal undegraded feed protein have been satisfactory, and the technique is used in many protein evaluation systems.

\section{In Vitro}

A variety of in vitro methods have been developed to analyze feed protein degradability. A common issue with all in vitro techniques is scarcity or complete lack of comparison with in vivo data (Yáñez-Ruiz et al., 2016). When such comparisons are made, discrepancies between in vitro and in vivo results are usually large (Devant et al., 2001; Sniffen et al., 2006; Hatew et al., 2015). Reasons for these discrepancies have been discussed elsewhere (Hristov et al., 2012; Yáñez-Ruiz et al., 2016); here, it is important to point out that in vitro techniques may provide satisfactory accuracy for comparative purposes, but rarely absolute values that are comparable to in vivo data.

One approach is to estimate ruminal CP degradation by determining ammonia- $\mathrm{N}$ production, rather than the loss of feed N (Broderick, 1982). However, measuring $\mathrm{CP}$ degradation through ammonia release is complex because feed CP degradation and ammonia uptake in de novo synthesized microbial proteins occur simultaneously (Leng and Nolan, 1984). To overcome this problem, Broderick (1987) devised an in vitro inhibitor method, in which hydrazine sulfate and chloramphenicol are used to inhibit microbial $\mathrm{N}$ uptake. Alternatively, enzymatic techniques can be used to measure protein degradation (Stern et al., 1997), or newly formed microbial protein can be distinguished from RUP using microbial markers such as ${ }^{15} \mathrm{~N}$ (Hristov and Broderick, 1994). The enzymatic approach, based on single or "cocktails" of proteases, is attractive because the procedure can be easily standardized, there is good repeatability, and a large number of samples can be simultaneously analyzed. Various proteases have been tested (see review by Stern et al., 1997) and some have found application in commercial feed analyses laboratories (e.g., protease enzyme from Streptomyces griseus; Krishnamoorthy et al., 1983). The main criticism of the enzymatic approach is that it cannot represent the spectrum of proteolytic activities found in the rumen. Nevertheless, the method may be sufficiently accurate for comparative purposes and to evaluate treatment effects on rumen degradability of common proteinous feeds, such as soybean meal (Giallongo et al., 2015b), or more generally concentrate feeds (Aufrère and Cartailler, 1988 used by INRA, 2007, 2018), but it cannot provide accurate absolute values for protein degradability.

The in vitro gas production (IVGP) technique is another approach that purportedly eliminates the confounding effects of de novo MPS during fermentation. 
Widespread use of IVGP technique to evaluate ruminant feeds has largely been due to high analytical capacity and low cost (Bueno et al., 2005; Yáñez-Ruiz et al., 2016). Karlsson et al. (2009), based on Raab et al. (1983), developed a modified IVGP technique for estimation of ruminal protein degradability that solves the problems associated with the original Raab et al. (1983) technique. In the modified technique, in vitro ruminal protein degradability is estimated via linear regression between gas production (as independent variable) and ammonia $\mathrm{N}$ production (as a dependent variable). It is assumed that the intercept of the regression shows the time that gas production was zero and no MPS has taken place, thus it represents absolute ammonia $\mathrm{N}$ produced due to feed degradation. The modified IVGP technique uses a mathematical approach to eliminate the confounding effects of de novo MPS during fermentation. In comparison to the Raab et al. (1983) method, the modified IVGP technique uses fermentation vessels (rather than glass syringes) that facilitate measurement of gas production and sampling of liquid phase from a single incubated feed sample at several time points during incubation. This improvement reduces the number of incubations required and eliminates the need for multiple rumen inocula. Other modifications (applicable to all in vitro systems) include drawing rumen fluid before morning feeding and conditioning it by pre-incubation (or dialysis) procedures to reduce background ammonia levels (Broderick et al., 2004; Cone et al., 2009). In addition, estimation of kinetic parameters of protein degradability and protein ED is possible by increasing sampling frequency (Karlsson et al., 2009). However, the method is still sensitive to variation in rumen fluid and ammonia background as well as complications due to microbial turnover in blanks and experimental samples (Karlsson et al., 2009). Although the in vitro methods offer the possibility to calculate the kinetic parameters of CP degradability and they are relatively simple, rapid, and inexpensive, their use in research and feed evaluation is still very limited.

It is also possible to estimate RUP, in combination with MPS, by using a modified Hohenheim gas test method (Steingaß et al., 2001; Edmunds et al., 2012; Steingaß and Südekum, 2013). The modified method builds on the standard protocol except for providing additional $\mathrm{N}$ for microbial fermentation throughout the incubation by partial substitution of $\mathrm{NaHCO}_{3}$ with $\mathrm{NH}_{4} \mathrm{HCO}_{3}$ in the buffer solution to ensure that there is no limitation of the model by insufficient RDP. Gidlund et al. (2018) evaluated this system using samples from omasal flow studies (34 diets) where RUP and microbial protein were quantified together. There was a good relationship $\left(\mathrm{R}^{2}=0.87\right)$ between predicted utilizable protein in vitro and omasal NAN flow.

\section{In Vivo}

Invasive or Direct Methods for Assessing Feed Protein Degradability and Microbial Protein Synthesis. Direct in vivo measurement would be the most logical and desirable way to evaluate the rate and extent of ruminal degradation of feed proteins (Broderick, 1994; Hvelplund et al., 1995; Mohamed and Chaudhry, 2008) and MPS (Clark et al., 1992; Broderick and Merchen, 1992; Dewhurst et al., 2000). Most in vivo methods entail feeding experiments to measure voluntary feed intake and the flow of dietary, microbial, and endogenous protein to the small intestine. Microbial $\mathrm{N}$ represents approximately $60 \%$ of the NAN reaching the duodenum (Clark et al., 1992), but in theory microbial protein can contribute $\geq 80 \%$ to the protein requirements of lactating dairy cows (Stern et al., 1994) or other ruminants. Given the fact that dietary rumen escape protein is an effective way to increase duodenal protein flow, the relative contribution of microbial protein to the total MP supply is lower with high MP diets, as illustrated in Figure 2.

The basic techniques for estimating protein flow to the intestine include an estimation of digesta outflow from the rumen and the proportion of microbial, and by the difference, nonmicrobial, protein in digesta. Digesta markers and the calculations involved in the measurement of digesta flow or $\mathrm{kp}$ have been reviewed in detail (e.g., Faichney, 1975; Armentano and Russell, 1985; France and Siddons, 1986). Ideal markers should be indigestible substances that are not affected by the digestive tract or the microbial population, must be equally associated with the different digesta phases (liquid and particulate; if sample is unrepresentative of the digesta), and must flow through the digestive tract at an identical rate and not separate from the respective labeled fractions (Marais, 2000). Digesta markers can be classified as "internal" and "external." Internal markers form an integral part of the feed consumed by the animal [e.g., indigestible ADF, indigestible NDF (iNDF), and acid insoluble ash], whereas external markers are added or bonded to the feed or digesta (e.g., rare earth elements such as $\mathrm{Yb}$, oxides and salts of transition metals such as $\mathrm{Cr}$ and $\mathrm{Co}$, and polyethylene glycol). Markers can also be broadly categorized according to their association with the fluid/liquid/ solute-phase (e.g., Co- and Cr-EDTA, and polyethylene glycol) or the particulate phase (e.g., alkanes, rare earths, and Cr-mordanted NDF) of digesta. An ideal marker does not exist, with some markers migrating, whereas others are partly digestible, or passing out of the rumen faster than their respective phase due to their small size and high density (Marais, 2000). Consequently, primary problems associated with markers in- 


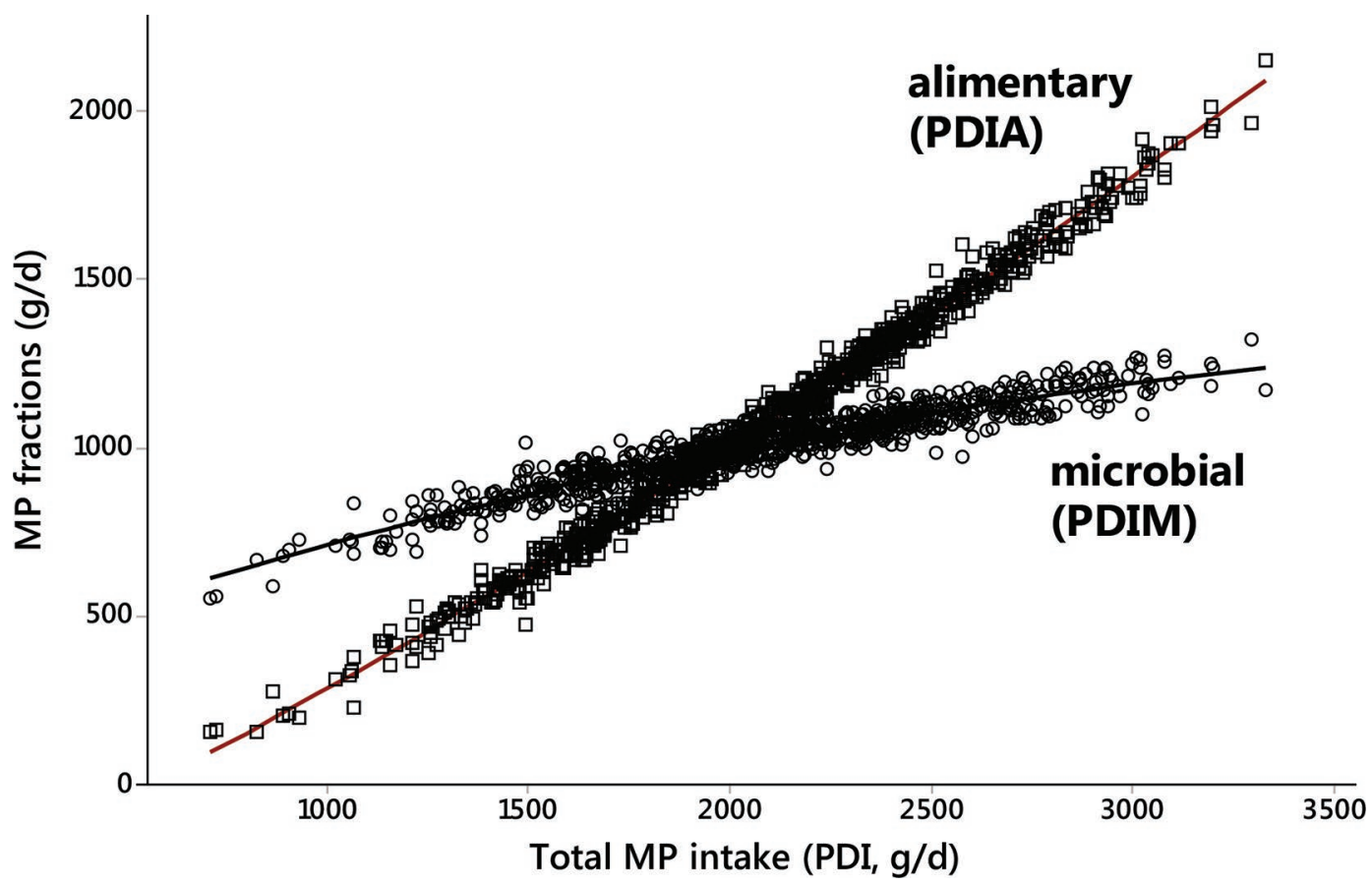

Figure 2. Calculated respective contribution of microbial (PDIM) and feed (PDIA) AA to total MP (proteins digestible in the intestine, PDI) supply in dairy cows. Calculations are according to INRA (2018), from the MoSARCO database (J. B. Daniel and D. Sauvant, AgroParisTechINRA, Paris, France, unpublished).

clude: (1) incomplete recovery, (2) variation in outflow from the rumen, and (3) unrepresentative sampling (Titgemeyer, 1997). Care is needed to ensure that the effects of all assumptions regarding marker behavior are accounted for when interpreting results obtained by their use (Faichney, 2005). Studies continue to evaluate the suitability of digesta markers or combinations of markers such as, LiCo-EDTA, Yb-acetate, Cr-mordanted straw, and iNDF (Ahvenjärvi et al., 2003), acid detergent-insoluble ${ }^{15} \mathrm{~N}$ (Huhtanen and Hristov, 2001; Lee and Hristov, 2014), ${ }^{13} \mathrm{C}$-labeled n-alkanes or labeled roughages (Warner et al., 2013a,b), n-alkanes, ADF, and ADL (Kozloski et al., 2014).

Reliable estimation of digesta flow is probably the most important factor in measuring protein degradability using in vivo techniques. The most commonly used method for measuring digesta flow involves the administration of markers at a constant rate, either in the diet or by continuous infusion (usually following a priming dose to reduce the time to reach equilibrium) at a point proximal to the point at which flow is to be measured, followed by sampling at that (those) points once equilibrium (steady-state) conditions have been achieved (Faichney, 2005). Intestinal flow is then calculated by dividing the marker dose rate by the mean marker concentration in the digesta (Tamminga and Chen, 2000). This calculation assumes that the concentrations in the sample of all the constituents of digesta, including the marker, are the same as the digesta flowing past the sampling point (Faichney, 1975; 2005). However, digesta consists of several phases with different flow characteristics (France and Siddons, 1986). Depending on the marker system employed, digesta can be viewed as comprising 2 phases: a fluid phase (solute and small particles) and a particulate phase (medium and large particles); 3 phases: liquid, small, and large particles; or greater (France and Siddons, 1986; Ahvenjärvi et al., 2003). A sample of whole digesta (or of a phase) is said to be representative when it has the same chemical composition as that of the total digesta (or phase), which flowed past the cannula during the steady-state period (France and Siddons, 1986). However, obtaining a representative sample from a heterogeneous mixture of liquid and particulate matter flowing past a cannula or sampling point is challenging (France and Siddons, 1986; Tamminga and Chen, 2000; Faichney, 2005). If the digesta samples obtained were representative, only a single marker is required to estimate flow rate; otherwise, 2 different approaches can be used to help overcome the problem (France and Siddons, 1986). Both approaches assume digesta flow to be in independent phases and that sampling is representative of each phase, but not total digesta, due to preferential selection. The first approach is based on estimating the individual phase flows, the sum of which is digesta flow, with the assumption that each marker 
is exclusively associated with its phase. The second approach is based on reconstitution of digesta using the double-marker method (e.g., fluid and particulate phase) or triple-marker (or more) method (e.g., liquid, small, and large particle phase), to obtain the composition of the representative digesta, in which case the markers do not have to be associated exclusively with 1 phase (France and Siddons, 1986; Faichney, 2005). Consequently, double- or triple-marker methods are recommended in digesta flow studies (Ahvenjärvi et al., 2003; Faichney, 2005). Markers can also be used to estimate the ruminal outflow of fluid or particles following cessation of a continuous infusion, or by giving a pulse dose of the marker, into the rumen; $\mathrm{kp}$ is calculated from its dilution in rumen samples or from its fecal excretion pattern with time, using appropriate mathematical models (Ellis et al., 1994; Tamminga and Chen, 2000; Faichney, 2005). In addition, this approach can also be used to calculate reticulorumen fluid volume (Faichney, 2005).

Fractionation and outflow rates of digesta fractions have implications in estimating MPS and contribution of metabolic fecal $\mathrm{N}$ (mostly of microbial origin) to total fecal $\mathrm{N}$ excretion. As shown in Figure 3, there appear to be relationships between output of bacteria and flow-rate (A) as well as between nondietary fecal $\mathrm{N}$ (metabolic fecal $\mathrm{N}$ ) and the retention time of solutes (B), particles (C), and the ratio of particle-to-solute retention times (D) in the rumen. With the restriction that the data are clustered according to the 2 data sets used, and the relationship within one experiment is far less pronounced, the ratio of particle-to-solute retention time might be indicative of the extent of microbial outflow from the rumen. At long particle- and short solute-retention time, microbial harvest from the rumen appears to increase (Figure 3B,C). Accordingly, the microbial harvest is greater with a larger ratio of particle-to-solute-retention time (Figure 3D). This enhanced "digesta washing" (Müller et al., 2011; Clauss and Hummel, 2017) appears to increase microbial yield from the rumen. In support of this, Hristov and Broderick (1996) estimated that the liquid and solid phase of ruminal contents had similar contribution to the total microbial $\mathrm{N}$ outflow from the rumen.

Digesta CP comprises ammonia N, RUP, microbial N, and endogenous N (Titgemeyer, 1997). Usually ammonia is subtracted from the total $\mathrm{N}$ flow, as ammonia is of little value to the animal, and the data are presented as NAN (Titgemeyer, 1997). Therefore, RUP flow is calculated as the difference of total NAN flow minus microbial $\mathrm{N}$ flow minus endogenous $\mathrm{N}$ flow (when flow is measured at the duodenum). Endogenous $\mathrm{N}$ flow can be directly measured but is more commonly estimated (Tamminga, 1979; Van Straalen and Tam- minga, 1990; Huhtanen, 2005). Measurement of the endogenous $\mathrm{N}$ contribution is technically challenging and furthermore, most available estimates have been derived under artificial conditions with highly invasive techniques or unusual semi-synthetic diets (Lapierre et al., 2006; Marini et al., 2008). Consequently, RUP has been routinely calculated in the duodenum simply as the difference between NAN and microbial N flow (nonammonia nonmicrobial N, NANMN), with endogenous protein being ignored (Poncet et al., 1995; Lapierre et al., 2006). While NANMN represents RUP, it also includes endogenous CP and experimental error (Robinson et al., 1992). Although microbial protein usually accounts for a substantial proportion of the total $\mathrm{N}$ entering the duodenum, endogenous secretions can represent a sizeable portion of duodenal $\mathrm{N}$ flow, between 15 and $20 \%$ in dairy cows (Lapierre et al., 2006). Using a meta-analytical approach to estimate endogenous $\mathrm{N}$ secretions in dairy and beef cattle, Marini et al. (2008) calculated that endogenous $\mathrm{N}$ represented a minimum of $13 \%$ of duodenal N flow. Data derived from Nozière et al. (2014) showed that, if not corrected for endogenous $\mathrm{N}$, true ruminal $\mathrm{N}$ digestibility was underestimated by 9 percentage units (Table 1). Estimates for duodenal endogenous $\mathrm{N}$ retained by protein-feeding systems varies as $5.3 \mathrm{~g}$ of $\mathrm{N} / \mathrm{kg}$ of nondigestible OM (INRA, 1989), revised to $2.3 \mathrm{~g}$ of $\mathrm{N} / \mathrm{kg}$ of DMI (Sauvant and Nozière, 2016; INRA, 2018), $4.8 \mathrm{~g}$ of N/kg duodenal OM in NorFor (Volden, 2011), and $1.9 \mathrm{~g}$ of N/DMI (NRC, 2001).

In vivo techniques for quantification of duodenal or abomasal flow only calculate the degradability of the overall (mixed) diet, not degradability of the individual feeds (Hvelplund et al., 1995; Firkins et al., 1998). Estimates of protein degradability for an individual feed can be determined by feeding increments of this feed to a basal diet (iso-fermentable OM), which in itself provides adequate $\mathrm{N}$ for MPS and eliminates the need for determining microbial N. The increase in duodenal flow of protein is attributed then to the test feed and slope of the flow versus intake indicates the "escape potential" of the test feed (Nocek, 1988; Titgemeyer et al., 1989; Flachowsky and Lebzien, 2006). However, this approach ignores the possible effect of increased supply of preformed AA on MPS.

Measurement of digesta flow requires some degree of surgical modification of the animal, and most studies involve either simple cannula close to the pylorus (in the antrum of the abomasum or the ascending duodenum) or re-entrant cannula in the duodenum (Tamminga and Chen, 2000; Faichney, 2005). The advantages and disadvantages of various gastrointestinal cannulas types and placement locations used for ruminants were reviewed by Harmon and Richards (1997). Cannulas for partitioning ruminal and postruminal digestion are 
best placed in the duodenum, which offers fewer problems than omasal or abomasal cannulas (Harmon and Richards, 1997). The use of postruminally cannulated animals is disadvantageous because such animals are prepared using invasive surgical modification, incur high labor and considerable cost associated with the care and maintenance of such animals, and are controversial from an animal welfare perspective (Tamminga and Chen, 2000). Consequently, there is increased, and renewed, interest in evaluating less invasive alternative techniques (i.e., using animals fitted with rumen cannula only).

The rumen evacuation method, which is based on assumptions of a steady-state rumen pool size and no disturbance of normal rumen function (Robinson et al., 1987), is one such alternative. When rumen evacuation is carefully performed at different times after feeding and combined with measuring $\mathrm{kp}$ out of the rumen using markers, it can give useful information on the dynamics of rumen degradation and synthesis of pro-

B

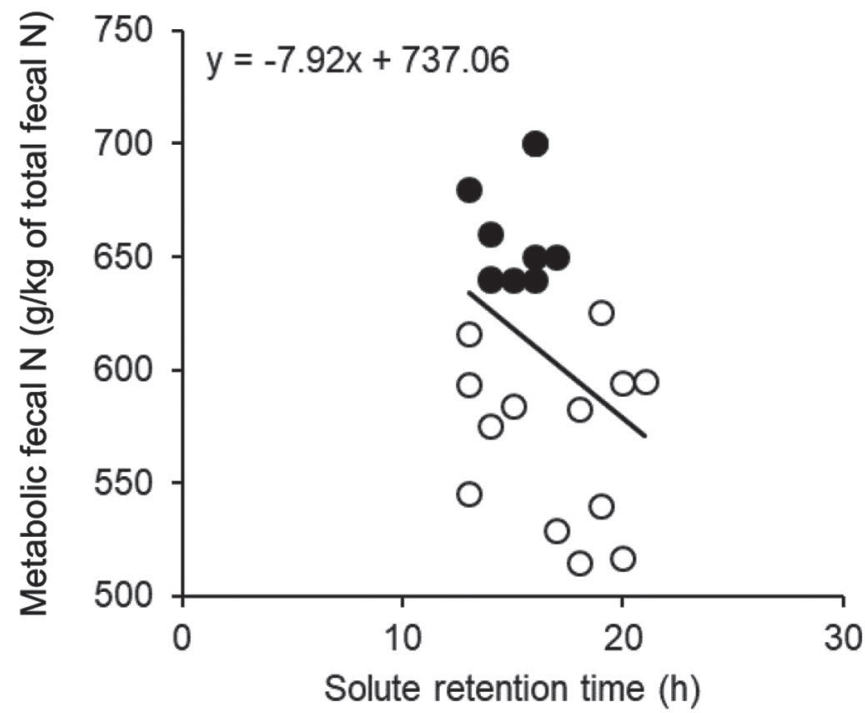

D

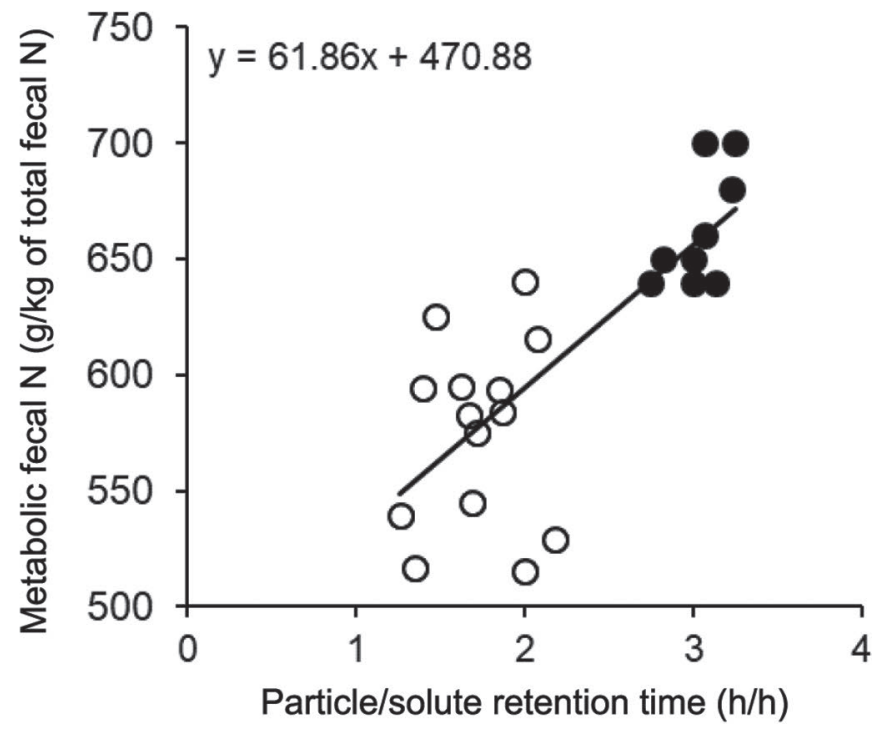

Figure 3. Relationship between (A) bacterial output and culture medium flow rate (source: Herbert et al., 1956), and between fecal metabolic $\mathrm{N}$ and (B) solute retention time, (C) particle retention time, and (D) the ratio of particle to solute retention time in the reticulorumen, that is, the degree of ruminal digesta washing in cattle (particle marker: Cr-mordanted NDF; solute marker: Co-EDTA). Data from $\bullet$ Schwarm et al., 2008, 2009a; O Schwarm et al., 2015. 
Table 1. Effects of reference microbial sample and correcting versus not correcting for endogenous $\mathrm{N}$ flow on determination of true ruminal $\mathrm{N}$ digestibility ${ }^{1}$

\begin{tabular}{|c|c|c|c|c|}
\hline \multirow[b]{2}{*}{ Item } & \multicolumn{4}{|c|}{ Treatment } \\
\hline & 1 & 2 & 3 & 4 \\
\hline DMI $(\mathrm{kg} / \mathrm{d})$ & 18.4 & 18.9 & 19.2 & 19.1 \\
\hline $\mathrm{N}$ intake $(\mathrm{g} / \mathrm{d})$ & 467 & 477 & 494 & 489 \\
\hline \multicolumn{5}{|l|}{ Duodenal N flow (g/d) } \\
\hline Non- $\mathrm{NH}_{3}(\mathrm{NAN})$ & 494 & 497 & 527 & 488 \\
\hline Endogenous $(2.27 \mathrm{~g}$ of $\mathrm{N} / \mathrm{kg}$ of DMI) & 42 & 43 & 44 & 43 \\
\hline \multicolumn{5}{|l|}{ Using LAB $^{2}$} \\
\hline Microbial & 251 & 283 & 266 & 270 \\
\hline NAN-nonmicrobial & 243 & 214 & 261 & 218 \\
\hline Alimentary (corrected with endogenous) & 201 & 171 & 217 & 175 \\
\hline \multicolumn{5}{|l|}{ Using $\mathrm{MB}^{3}$} \\
\hline Microbial & 361 & 378 & 365 & 375 \\
\hline NAN-nonmicrobial & 133 & 119 & 162 & 113 \\
\hline Alimentary (corrected with endogenous) & 91 & 76 & 118 & 70 \\
\hline \multicolumn{5}{|l|}{ True ruminal N digestibility (\%) } \\
\hline \multicolumn{5}{|l|}{ Using LAB } \\
\hline Corrected with endogenous $\mathrm{N}$ & 57 & 64 & 56 & 64 \\
\hline Not corrected & 48 & 55 & 47 & 55 \\
\hline \multicolumn{5}{|l|}{ Using MB } \\
\hline Corrected with endogenous N & 80 & 84 & 76 & 86 \\
\hline Not corrected & 72 & 75 & 67 & 77 \\
\hline
\end{tabular}

${ }^{1}$ Data derived from Nozière et al. (2014) with treatments differing according to starch level (1 and 2: $300 \mathrm{~g} /$ $\mathrm{kg}$ of DM; 3 and 4: $200 \mathrm{~g} / \mathrm{kg}$ of DM) and amylase addition (1 and 3: control; 2 and 4: amylase addition) and using purine and pyrimidine bases as a marker.

${ }^{2} \mathrm{LAB}=$ liquid-associated bacteria as reference microbial sample.

${ }^{3} \mathrm{MB}=$ mixed bacteria as reference microbial sample.

tein (Tamminga and Chen, 2000), particularly for fiber digestion and passage kinetics. Ruminal flux techniques can estimate $\mathrm{kp}$ of iNDF without using duodenal cannulas and without the inherent problems of measuring duodenal flows by assuming steady state (Robinson et al., 1987; Ellis et al., 1994; Firkins et al., 1998). In a steady state, the flux (flow) into or out of the rumen can be described by the pool size and fractional rates of intake, passage, and digestion; by rearrangement, rates of digestion and passage can be estimated as flow divided by rumen pool size available for these processes (Firkins et al., 1998; Huhtanen et al., 2006). Usually iNDF is used as the internal marker in rumen evacuation studies (Krizsan et al., 2010a). In the "compartmental flux method" employed by Huhtanen et al. (2014), the $\mathrm{kp}$ of ruminal particle fractions of different size was estimated by dividing the flux of fecal output of iNDF in these particle fraction by the ruminal pool of the corresponding iNDF fraction. By determining the corresponding $\mathrm{N}$ pool in these particle fractions, the duodenal outflow of this $\mathrm{N}$ was calculated as the $\mathrm{N}$ pool size times the iNDF $\mathrm{kp}$ of the corresponding particle fractions. However, Huhtanen et al. (2014) found that feed $\mathrm{N}$ flow estimates based on compartmental flux data were generally lower than, but also poorly correlated (treatment interactions) with, the feed $\mathrm{N}$ flow estimates determined by using the omasal sampling technique, indicating different proportions of feed $\mathrm{N}$ flowing as soluble or fine particles $(<38 \mu \mathrm{m})$.

Rumen outflow of $\mathrm{N}$ fractions, including microbial $\mathrm{N}$, can be estimated in animals fitted with rumen cannula only by (1) using rumen evacuation to determine DM and NAN pools in liquid and solid phases of ruminal digesta, (2) using liquid and particulate markers to determine rates of outflow from the rumen of liquid and solid digesta, and (3) using microbial markers to separate microbial from digesta N (e.g., Hristov and Broderick, 1996; De Ondarza and Sniffen, 2002; Hristov, 2007). However, in the study of Hristov (2007) when rumen sampling was compared with duodenal sampling, flows of NAN were found to be significantly higher for the rumen sampling technique, whereas flows of NANMN or microbial NAN did not differ significantly between the 2 sampling sites. This overestimation of NAN flow can be attributed to the fact that the single particulate marker used does not account for the different kinetics patterns associated with the multi-compartmental nature of solid digesta in the rumen (Faichney, 2005; Hristov, 2007). Some studies have focused on soluble NAN flow (i.e., in rumen fluid only) using rumen evacuation plus a liquid digesta marker (e.g., Aufrère et al., 2003). Alternatively, in other studies, rather than using rumen evacuation, markers were used to calculate both reticulorumen fluid volume and fractional flow rate 
to estimate flow of soluble $\mathrm{N}$ fractions (e.g., Chen et al., 1987; Volden et al., 2002). The rumen evacuation technique is laborious and time-consuming making it expensive and achieving steady-state conditions difficult; however, the latter can be partially overcome by frequent evacuations and careful selection of evacuation times to represent mean rumen pool sizes (Huhtanen et al., 2006).

Another approach for estimating microbial and feed protein flow is by sampling omasal digesta. The current methodology is based on the omasal sampling technique developed by Huhtanen et al. (1997). This technique permits sampling of omasal digesta using a tube that is inserted, via the ruminal cannula, through the reticuloomasal orifice and connected to a sampling device that resides in the omasum, and an alternating pressure-vacuum pump that withdraws the digesta samples. This technique was modified by Ahvenjärvi et al. (2000) and is now used widely (Huhtanen et al., 2010). Most omasal sampling protocols use a triple-marker system (France and Siddons, 1986) to mathematically correct for unrepresentative digesta sampling (Ahvenjärvi et al., 2003; Broderick et al., 2010; Roman-Garcia et al., 2016 ), with ${ }^{15} \mathrm{~N}$, and to a lesser extent purine bases, employed as microbial markers (Broderick et al., 2010). Compared with sampling from the duodenum, the omasal canal provides some advantages as a sampling site: it is less invasive, a rumen cannula suffices, secretion of endogenous $\mathrm{N}$ into the reticulorumen is lower than that into the duodenum, and sampling takes place before acid-pepsin hydrolysis in the abomasum (Huhtanen et al., 1997; Ahvenjärvi, 2006). The technique has most of the other disadvantages of duodenal sampling (Huhtanen, 2005). However, unlike sampling digesta from the duodenum, the omasal sampling technique permits the various $\mathrm{N}$ fractions to be distinguished (i.e., before gastric digestion). Consequently, the contribution of soluble $\mathrm{N}$ components (protein, peptides, and free AA), microbial populations (liquid and particle associated bacteria, protozoa, and fungi), and insoluble dietary $\mathrm{N}$ components to $\mathrm{N}$ flow from the reticulorumen can be determined (Ahvenjärvi, 2006). Studies that have directly compared $\mathrm{N}$ flows using omasal and duodenal sampling indicate that they are comparable (Ahvenjärvi et al., 2000; Rotta et al., 2014), although in the study of Ahvenjärvi et al. (2000) where microbial NAN was also determined, it tended to be higher in the omasal canal than in the duodenum. Roman-Garcia et al. (2016) in a meta-analysis reported a greater microbial $\mathrm{N}$ and smaller NANMN flows for omasal sampling than for duodenal sampling. An indirect validation based on the relationships between omasal NAN flow and milk protein yield derived using meta-analysis also showed that omasal measurements were accurate (Huhtanen et al., 2010). Similarly, Broderick et al. (2010) conducted a meta-analysis to evaluate the precision and accuracy of the omasal sampling technique for quantifying ruminal$\mathrm{N}$ metabolism and concluded that the technique yields useful estimates of ruminal MPS and RUP supply to high-producing cattle.

Hristov (2007) introduced a reticular sampling technique to estimate the outflow of nutrients from the rumen; this was based on the premise that digesta located in the reticulum appears to closely represent digesta leaving the reticulorumen. Studies comparing reticular and duodenal sampling (Hristov, 2007), and reticular and omasal sampling (Krizsan et al., 2010b), using triple-marker techniques at both sites, showed similar flows of NAN, NANMN, and microbial NAN, and ruminal digestibility of NAN for both methods. In contrast, Rotta et al. (2014) comparing reticular, abomasal, and omasal sampling reported that the flow of $\mathrm{CP}$ was lower for reticular than omasal sampling with abomasal being intermediate. Ruminal digestibility of $\mathrm{CP}$ was higher based on reticular sampling compared with the other 2 sites, which did not differ. Fatehi et al. (2015) also compared reticular and omasal sampling and, additionally, rumen sampling (collected in the same manner as the reticular samples) and reported significantly higher flows of NAN and microbial NAN for rumen compared with reticular sampling, which, in turn, were higher than omasal sampling; no difference was found between methods for NANMN flow, and ruminal digestibility of NAN. Discrepancies across studies may be partly attributed to the method of digesta processing whereby it was sieved through a $1-\mathrm{mm}$ screen to discard large particles in some studies, but not others (Fatehi et al., 2015). As with omasal sampling, reticular sampling avoids the necessity for overly invasive cannulation and interference from abomasal degradation and endogenous $\mathrm{N}$ secretions, but it has less interference with the animal's DMI and does not need elaboration of sampling equipment or the insertion of a sampling device through the reticulo-omasal orifice (Krizsan et al., 2010b). One disadvantage of reticular sampling may be selective retention of protozoa in the reticulum (Michalowski et al., 1986). Relatively few studies have employed the reticular sampling technique and more research is needed to verify it.

Several internal and external markers have been proposed and used to identify microbial protein in digesta including DAPA, D-alanine, 2-aminoethylphosphonic acid, ribonucleic acid, individual or total purine and pyrimidine bases, AA profiles, and radioactive ${ }^{35} \mathrm{~S}$ or ${ }^{32} \mathrm{P}$ (or ${ }^{33} \mathrm{P}$; Bucholtz and Bergen, 1973), and stable ${ }^{15} \mathrm{~N}$ isotopes [reviewed in detail by Broderick and Merchen (1992) and Dewhurst et al. (2000)]. These markers, in combination with the digesta flow markers discussed 
above, allow estimation of MPS. An ideal microbial marker must account for both the bacterial and protozoal pools associated with the fluid and particulate phases of digesta (Broderick and Merchen, 1992). A representative sample of rumen microorganisms is also required to determine marker-to-bacterial plus protozoal $\mathrm{N}$ ratio (Marais, 2000).

Markers of MPS such as DAPA, purines, and ${ }^{15} \mathrm{~N}$ have been used most widely. The existence of substantial amounts of DAPA in feeds and other issues have rendered this marker unreliable (Broderick and Merchen, 1992). Principal concerns with purines relate to unequal purine-to-total $\mathrm{N}$ ratios in protozoal and bacterial pools coupled with the need to assume that dietary purines are completely degraded in the rumen (Broderick and Merchen, 1992; see related discussion in the following section: Noninvasive or Indirect Methods for Measuring Microbial Protein Synthesis). Nitrogen-15 has a long history of use as a microbial marker (Pilgrim et al., 1970; Mathison and Milligan, 1971; Brandt et al., 1980) and in experiments utilizing duodenal, ruminal, omasal, or reticular sampling approaches (Siddons et al., 1982; Ahvenjärvi et al., 2000; Hristov, 2007). Several studies have demonstrated that ${ }^{15} \mathrm{~N}$ is the most accurate and precise microbial marker for ruminant nutrition research (e.g., Reynal et al., 2005).

Due to differences in marker-to- $\mathrm{N}$ ratio, the nature of the reference microbial sample (duodenal or ruminal bacteria, liquid-associated vs. solid-associated vs. mixed bacteria) can have an effect on the quantification of microbial N flow. For example, Fanchone et al. (2013) and Nozière et al. (2014; Table 1) reported that the proportion of microbial $\mathrm{N}$ in NAN duodenal flow was on average $74 \%$ when estimated with mixed bacteria (assuming 25\% of liquid-associated and 75\% of solid-associated bacteria) as a reference sample, compared with $54 \%$ when estimated with liquid-associated bacteria as a reference, using purine and pyrimidine bases as a marker. For obvious technical reasons (i.e., easier to isolate), liquid-associated bacteria (enriched to a various degree with loosely associated with feed particles bacteria) are the more widely used standard.

Feed N metabolism can be studied by labeling plants with ${ }^{15} \mathrm{~N}$ during growth and consequent isolation and analysis of various $\mathrm{N}$ fractions. Following this approach, Hristov et al. (2001) labeled alfalfa with ${ }^{15} \mathrm{~N}$ during growth in a greenhouse and harvested and preserved the forage as silage or as sun-cured hay. The labeled silage and hay were pulse dosed to lactating Holstein cows and samples of ruminal contents were collected over a 72 -h period and partitioned into $\mathrm{N}$ fractions. This allowed estimation of pool sizes and kinetics of rumen $\mathrm{N}$ compartments. In another experiment, in vitro rates of bacterial incorporation of $\mathrm{N}$ fractions from
${ }^{15} \mathrm{~N}$-labeled whole-crop barley were studied (Hristov and McAllister, 2001). Rates of microbial incorporation of $\mathrm{N}$ from soluble protein, easily-degraded protein, and slowly-degraded protein $\mathrm{N}$ pools were investigated. Plant $\mathrm{N}$ can be further fractionated and studied using ${ }^{15} \mathrm{~N}$-labeled plants (e.g., Melgar and Hristov, 2004; who reported rates of microbial breakdown of alfalfa insoluble N, soluble protein N, NPN, neutral-detergent insoluble $\mathrm{N}$, and neutral-detergent soluble N). Using ${ }^{15} \mathrm{~N}$-labeled grass silage and rumen modeling, Ahvenjärvi et al. (2018) showed that a considerable proportion of silage soluble NAN $(0.125 \mathrm{~g} / \mathrm{g})$ escapes ruminal degradation and contributes to postruminal feed NAN supply.

Nitrogen-15 can also be used to study the effect of dietary treatments on the efficiency of ammonia $\mathrm{N}$ utilization for milk protein synthesis. In this approach, rumen ammonia- $\mathrm{N}$ is labeled with ${ }^{15} \mathrm{~N}$, which labels the rumen microbial-N pool, and consequently milk protein N (Hristov and Ropp, 2003; Hristov et al., 2004a,b, 2005b). The technique involves continuous infusion or a pulse dose of ${ }^{15} \mathrm{~N}$-ammonium salt into the rumen followed by a continuous sampling and analysis of ${ }^{15} \mathrm{~N}$ enrichment of ruminal ammonia, bacterial, and milk protein $\mathrm{N}$ pools. The contribution of the primary $\mathrm{N}$ pool (ammonia in these studies, but also feed $\mathrm{N}$ fractions could be used) to the milk protein $\mathrm{N}$ pool is estimated from plateau enrichment or areas under the ${ }^{15} \mathrm{~N}$ enrichment curves and gravimetrically.

Noninvasive or Indirect Methods for Measuring Microbial Protein Synthesis. Perhaps the most prominent approach for estimating MPS in this category is the urinary purine derivatives method. Based on the early work by Elliott and Topps (1963) and Topps and Elliott (1965) and later developed and verified by Vercoe (1976), Antoniewicz et al. (1979, 1980), Zinn and Owens (1986), Chen et al. (1990), and Vagnoni et al. (1997), the method consists of quantitative analysis of animal urine for derivatives of purine metabolism (usually, allantoin, and uric acid in cattle). These derivatives are assumed to be originating from microbial nucleic acid outflowing from the rumen or from endogenous sources. The approach is based on the premise that feed nucleic acids are completely degraded in the rumen and all purines leaving the rumen are of microbial origin. Indeed, Smith and McAllan (1970) and McAllan and Smith (1973) reported that feed nucleic acids and purines were rapidly and extensively degraded by the rumen microorganisms. However, Perez et al. (1997) showed that dietary purines accounted for 13 to $27 \%$, depending on diet, of the total purine flow at the duodenum of sheep. Vicente et al. (2004) found an even greater flow (accounting for 33\% of the total) of feed purines to the duodenum of cattle fed high-con- 
centrate diets. Similarly, Hristov et al. (2005a) reported a significant contribution (up to 20\%) of nonmicrobial purines to duodenal purine flow, particularly from the solid digesta phase, in cattle fed barley- or corn-based diets. Apart from a dietary contribution of nucleic acids to duodenal purine flow, other sources of variation in the relationship between MPS and urinary excretion of purine derivatives include a varying purine-to-total $\mathrm{N}$ ratio in rumen microbes, differences in intestinal digestibility of nucleic acids, and an endogenous contribution of purine derivatives to urinary excretion (Tas and Susenbeth, 2007). The need to repeatedly measure total urine output to determine daily excretion rates of purine derivatives limits the use of the method in practice (although urine output can be calculated using creatinine as a marker; Chen et al., 1995). Firkins et al. (2005) proposed improved equations for predicting duodenal flow of purine bases or urinary allantoin excretion derived from multiple studies with different animals and dietary conditions. Overall, calculating absolute changes in MPS based on the urinary purine derivatives is not advisable. However, for a controlled experimental setting, differences in excretion of total purine derivatives in urine could indicate differences in MPS (provided that purine-to-total $\mathrm{N}$ ratio in rumen microbes is not influenced by treatment).

Another body fluid, in which microbial purine derivatives are secreted, is milk. Giesecke et al. (1994) found a good correlation between milk allantoin secretion and dietary net energy intake in dairy cows, which is in line with the expected relationship of MPS and dietary energy and used by most nutritional models to predict MPS (e.g., NRC, 2001; see following discussion). However, secretion of allantoin with milk is only a small fraction, 1.6\% (Giesecke et al., 1994), of the urinary allantoin excretion. Indeed, Shingfield and Offer (1998) reported poor correlation between individual cow milk allantoin concentration or secretion, and urinary purine derivative excretion or calculated MPS. These authors clearly showed that auto-correlation of milk allantoin concentration and secretion with milk yield was the reason for the high correlation of milk allantoin and urinary excretion of purine derivatives. Another issue brought up by these authors was the lack of specificity of the colorimetric assay for allantoin, which resulted in low variability in milk allantoin concentration reported in earlier studies. Shingfield and Offer (1998) concluded that milk allantoin is not a reliable indicator of MPS in individual cows. Later work of Timmermans et al. (2000) and Schager et al. (2003) also did not establish milk purine derivatives secretion as a reliable tool for predicting MPS in dairy cows.

Specific milk fatty acids have also been suggested as proxies for MPS. Milk odd- and branched-chain fatty, which include C15:0, C17:0, and iso and anteiso fatty acids (iso-14:0, anteiso-15:0, iso-17:0, iso-16:0, iso15:0, and anteiso-17:0), are found in microbial lipids (Keeney et al., 1962) and are also synthesized from propionate in the adipose and mammary tissues (Vlaeminck et al., 2006). Considered predominantly from microbial origin, these fatty acids have been proposed as biomarkers of MPS (Vlaeminck et al., 2006; Fievez et al., 2012). The concept, however, has been questioned, based on significant endogenous contributions (de Souza et al., 2018), and needs verification under differing dietary regimens (Dewhurst et al., 2007; Mohammed et al., 2011; French et al., 2012).

Microbial protein synthesis can be estimated indirectly through empiric equations based primarily on available energy in the rumen. This approach is widely used in current nutritional models. Among feed evaluation systems, the estimation of MPS is invariably based on estimation of fermentable energy available in the rumen and its net rumen efficiency of utilization for microbial biosynthesis. Concerning the estimation of energy available in the rumen, 2 different approaches can be distinguished: the first approach is based on estimation of energy (or OM, or nutrients) apparently digested in the total tract (NRC, 2001; Galyean and Tedeschi, 2014; NRC, 2016) followed by subtraction of nonfermented digestible fractions (Vérité and Peyraud, 1989; AFRC, 1992; INRA-PDI, as described by Sauvant and Nozière, 2016). The other approach is based on the addition of rumen digested substrates estimated by in situ data: NorFor (Volden, 2011), Cornell Net Carbohydrate and Protein System (Sniffen et al., 1992), Feed into Milk (Thomas, 2004), and Dutch DVE/OEB 2011 (Van Duinkerken et al., 2011). The second approach, which is a priori more mechanistic, requires more information and assumptions on the contribution of the various fractions to MPS and their fractional rumen degradation and passage rates. Concerning the estimation of efficiency of microbial growth, differences also exist between the 2 approaches. The simpler approach considers that microbial flow is proportional (or directly linked) to the $\mathrm{OM}$ fermented in the rumen as INRA-PDI or DVE/OEB ${ }_{1994}$ (Tamminga et al., 1994), or to the total nutrients digested in the digestive tract (NRC, 2001), whereas the other approach considers a differential efficiency of microbial growth according to fermented substrates (DVE/OEB ${ }_{2011}$, NorFor, Feed into Milk). The second approach has not proven to be more accurate but allows flexibility and taking account of various rumen fermentation details. Although theoretically correct, more complicated models taking into account different ATP supply from different components (e.g., fat and fermentation acids) have failed to improve predictions of milk protein yield from MP supply 
(Schwab et al., 2005). A more recent meta-analysis by White et al. (2016) compared empirical and mechanistic (i.e., microbial $\mathrm{N}$ as a function of ruminal carbohydrate digestibility) approaches to predict MPS and concluded that predicting MPS empirically had the lowest prediction error. In a review by Bannink et al. (2016), it was delineated what added value mechanistic approaches may have above empirical approaches by representing the interactions between various rumen pools (substrate, microbial, and metabolites) to explain the more dynamic aspects of rumen fermentation, which an empirical approach cannot give. The latter approaches normally adopt the concept of additivity of predicted MPS values for the individual dietary components and are, in essence, linear models not accounting for nonlinear effects. Conclusions about the usefulness of various models, empirical and mechanistic, for practical diet formulation, however, have to be carefully considered. Owens et al. (2014) compared MP predictions by the beef NRC (2000) model vs. duodenal flow measurements in cattle fed 118 different diets and concluded that the NRC model failed to accurately predict in vivo measurements. As these authors suggested, lack of data to support model values for various feeds and "inclusion of numerous theoretical but unverified equations within current MP models severely limits their precision and usefulness for field application." Uncertainties can also arise from inaccurate and variable microbial flow data (most often due to variable accuracy of marker and sampling techniques) used to derive prediction equations in nutritional models.

Yet another approach to indirectly estimate ruminal MPS is through fecal metabolic $\mathrm{N}$ by calculating the difference between total and dietary fecal N. Dietary fecal $\mathrm{N}$ is easily measured by a routine analysis of $\mathrm{N}$ in NDF residue (Mason, 1969), assuming that all undigested plant $\mathrm{N}$ would be captured in the NDF fraction. Microbial N (both from rumen and hindgut origin) accounts for a major part of fecal metabolic $\mathrm{N}$ in mature ruminants, with endogenous matter such as epithelial cells and secretions constituting only a minor part (Blaxter and Mitchell, 1948; Mason, 1969, 1979; Figure 3B, C, and D). In feces of herbivores, attempts using easy-to-apply detergent extraction procedures with modifications to separate fecal metabolic $\mathrm{N}$ further into microbial $\mathrm{N}$ and endogenous $\mathrm{N}$ were not successful (Schwarm et al., 2009b). However, this distinction might be of minor relevance assuming that endogenous $\mathrm{N}$ is fermented in the ruminant hindgut (Van Soest, 1994; Richard et al., 2017). No attempts have been made to separate fecal microbial $\mathrm{N}$ into rumen and hindgut derived microbial $\mathrm{N}$, but it is assumed that the undigested cell-wall residues from ruminal microorganisms contribute the larger fraction to fecal microbial $\mathrm{N}$ than intact microbial cells originating from the cecum and the large intestine (Mason, 1969; Van Soest, 1994). In dairy cattle fed a wide variety of diets, van Vliet et al. (2007) measured microbial carbon excretion in feces based on numbers of intact fecal bacteria and showed that this excretion was much smaller than total microbial carbon excretion including damaged microbial cells arising from undigested rumen microbial material. When the amount of substrate fermented in the hindgut increases (e.g., NaOH-treated grain, high levels of feed and starch intake), this approach can lead to substantial errors in MPS estimates (Hetta et al., 2013).

\section{Nitrogen/Urea Recycling}

Ruminants are capable of recycling $\mathrm{N}$ from blood to the gastrointestinal tract (GIT). The gastrointestinal tract entry rate (GER) through blood and saliva contributes substantially to $\mathrm{N}$ availability in the GIT and may amount to as much as half of the daily dietary uptake (Lapierre and Lobley, 2001). Recycling of urea-N through the rumen wall does not occur against a concentration gradient; it appears to be strongly regulated by expression of urea transporter proteins in kidney and GIT tissues (Røjen et al., 2011; Spek et al., 2013a). High urea GER is not immediately apparent from fecal $\mathrm{N}$ digestibility because of extensive recycling as absorbed AA, ammonia, or other nitrogenous compounds. Regulation of urea N recycling is an important mechanism for ruminants to conserve $\mathrm{N}$ to maintain microbial synthesis processes in the rumen and catabolic processes in the animal (Lapierre and Lobley, 2001). Various techniques have been used to study N recycling to GIT, including indirect and direct methods of measurement.

Current protein evaluation systems estimate rumen $\mathrm{N}$ balance, which is indicative of $\mathrm{N}$ surplus or shortage, to sustain MPS in the rumen (reviewed by Dijkstra et al., 1998, and Tedeschi et al., 2014). As discussed earlier, estimates of rumen availability and degradability of dietary $\mathrm{N}$ and $\mathrm{OM}$ are obtained by external washing procedures and in situ incubations of feeds in the rumen. These degradation characteristics allow estimation of MPS from the available and degraded feed and the amount of $\mathrm{N}$ required and available from the feed. The difference between available and required $\mathrm{N}$ indicates rumen $\mathrm{N}$ balance. A negative value indicates $\mathrm{N}$ shortage that needs to be compensated by a net movement of $\mathrm{N}$ into the rumen to maintain fermentation (i.e., the difference of urea- $\mathrm{N}$ recycled from blood to the rumen minus ammonia- $\mathrm{N}$ absorbed or washed out from the rumen). Current protein evaluation systems, and (due to their static nature) many mechanistic rumen models as well, typically treat rumen $\mathrm{N}$ balance values as feed 
characteristics that are additive and independent of the diet type or composition and of conditions in the rumen and systemic blood (Bannink et al., 2016). In this regard, estimates of urea recycling based on rumen in situ degradation characteristics should not be considered precise. Rumen in situ techniques are used to measure rumen degradation from which MPS and rumen $\mathrm{N}$ balance may be estimated. The duodenal or omasal sampling techniques are used to measure duodenal flow using markers. Both techniques, discussed in more detail earlier in this review, give only a rough indication of the net amounts of $\mathrm{N}$ entry to the rumen and do not indicate cause and effect of urea $\mathrm{N}$ recycling (Dijkstra et al., 1998), or how rumen fermentation depends on urea-N recycling (Bannink et al., 2016). Direct methods are needed to measure and quantify urea recycling.

A more direct method is the use of indwelling catheters around portral-drained viscera (PDV) to measure urea removal by PDV, which excludes, however, the urea removal through salivation and includes arginase activity in the GIT. Direct measurement of urea GER through the use of labeled urea tracers (to be discussed later in this section) and, hence, must be expected to differ from urea net PDV flux. Furthermore, measurement of urea net PDV fluxes typically involves rather small arterial-venous concentration differences multiplied with large numbers for blood flow. This makes urea net PDV flux observations highly variable and treatment differences often statistically insignificant. El-Kadi et al. (2006) performed regressions on urea net PDV flux in steers fed 4 incremental levels of ME ranging from 0.028 to $0.056 \mathrm{MJ} / \mathrm{kg}$ of $\mathrm{BW}^{0.75}$ per d. They reported a linear increase in urea concentrations in arterial and portal blood, but relative to the average value of $12.8 \mathrm{~g}$ urea-N/d, almost no change in PDV urea removal. Also in steers, Reynolds and Huntington (1988) observed that change in diet (chopped alfalfa hay vs. pelleted concentrates) did not affect net urea removal by PDV tissues. However, there was variation in GER within different GIT compartments. With twice daily feeding of a concentrate diet providing more $\mathrm{ME}$ and less $\mathrm{N}$, less urea was recycled to the mesenteric drained viscera (intestines) and more (numerically) to the stomach compartments (i.e., the reticulo-rumen, omasum, and abomasum), and more AA were absorbed from the intestine (indirectly indicating more microbial origin) compared with an alfalfa diet containing $58 \%$ more $\mathrm{N}(26.5 \mathrm{~g}$ of $\mathrm{N} / \mathrm{kg}$ of $\mathrm{DM})$. Mesenteric drained tissues were responsible for $32 \%$ (concentrate diet) to more than $100 \%$ (alfalfa diet) of urea net PDV flux (i.e., stomach compartments responsible for $68 \%$ to less than $0 \%$, respectively), whereas urea net PDV flux did not differ. A study with steers by Huntington et al. (1989) showed blood urea removal shifted from the stomach toward the intestine when changing from an alfalfa diet to a high concentrate diet. This was accompanied with a reduction of portal appearance of ammonia reflecting reduced $\mathrm{N}$ intake, and with a reduction in urea removal through saliva reflecting reduced blood urea concentration. However, distinctions between portal drained and mesenteric drained tissues are rarely made, probably because of the technical difficulties encountered with extra catheterization in the mesenteric vein. These measurements are important, however, to determine the fate of urea removal by GIT and its contribution to rumen fermentation. Although the results exclude urea transfer to the reticulorumen via saliva, they indicate that urea fluxes depend on the urea supply by arterial blood and regulatory mechanisms do play a role (Spek et al., 2012). Portal net flux measurement by Røjen et al. (2011) demonstrated the existence of long-term upregulation by kidneys and GIT of urea recycling when reducing urea infusion rate on an $\mathrm{N}$-depleted diet.

The regulatory mechanisms of urea recycling can also be studied by other techniques. Direct measurement of mRNA abundance of urea transporter proteins in rumen epithelial tissue is possible. However, Røjen et al. (2011) and Røjen and Kristensen (2012) did not establish an apparent relationship between mRNA abundance for these transporter proteins and the $\mathrm{N}$ supply or urea GER. It must be acknowledged, however, that such measurements basically determine the concentration of mRNA coding for these transporter proteins instead of the actual presence of these proteins. Moreover, such measurements are incapable of determining total tissue mass and transporter protein capacity actually present (Bannink et al., 2016). One might safely assume that tissue mass remains unaltered across urea infusion treatments. However, this assumption becomes less likely as soon as changes occur in DMI, in the type of carbohydrates ingested, or perhaps even in the daily pattern of presence of nutrients and metabolites in digesta at the mucosal side and in blood at the serosal side of rumen tissue. As an alternative to measurements, modeling approaches can also be undertaken to evaluate measurements in the rumen and blood, as adopted by Dijkstra et al. (1992). Their concept of urea recycling being limited with high rumen ammonia concentrations and becoming saturated at high arterial urea concentration due to increased $\mathrm{N}$ supply, seems to be supported by the observations of Røjen et al. (2011) on long- and short-term (postprandial) regulation of urea recycling to the rumen. Røjen and Kristensen (2012) did not establish an effect of time-period of urea infusion on urea GER due to a confounding effect of DMI and amounts of urea infused relative to DMI. Without any effect on DMI, urea infusion treatment resulted in an increased arterial 
urea concentration of $9.6 \mathrm{~m} M$ (vs. $3.0 \mathrm{~m} M$ for negative control) and a $61 \%$ greater urea GER. These findings do not seem to conflict with earlier observations by Kennedy (1980) with the use of ${ }^{14} \mathrm{C}$ isotope (discussed below). From these observations, Dijkstra et al. (1992) deduced a relationship with a saturating stimulatory effect of blood urea and an inhibitory effect of rumen ammonia on urea recycling to the rumen. In agreement with this, Reynolds and Huntington (1988) and Huntington et al. (1989) observed a reduced stomach net removal of urea from blood to be associated with higher stomach ammonia absorption.

An alternative technique for the direct measurement of flow rates of a nutrient, or a metabolite such as urea, is the measurement of dilution of known tracer amounts of isotope-labeled compound infused into the bloodstream. The protocol may involve a long-term infusion (days) or involve infusion of a bolus to determine the kinetics of dilution (hours). Continuous infusion protocols have been used in cows with multiple indwelling catheters across the PDV. Lobley et al. (2000) applied a tracer of dual-labeled ${ }^{15} \mathrm{~N}^{15} \mathrm{~N}$ urea to measure the entry of urea to the GIT, with analysis of the 3 different isotopomers ${ }^{15} \mathrm{~N}^{15} \mathrm{~N},{ }^{14} \mathrm{~N}^{15} \mathrm{~N}$ and ${ }^{14} \mathrm{~N}^{14} \mathrm{~N}$ urea eliminated in urine. A full evaluation of flows of ${ }^{15} \mathrm{~N}^{15} \mathrm{~N},{ }^{15} \mathrm{~N}^{14} \mathrm{~N}$ and ${ }^{14} \mathrm{~N}^{14} \mathrm{~N}$ urea, ${ }^{15} \mathrm{~N}$ and ${ }^{14} \mathrm{~N}$ ammonia, and ${ }^{15} \mathrm{~N}$ AA in blood allows to distinguish the different catabolic fates of recycled urea (ammonia absorption, MPS, and fecal excretion) and to determine the effect of nutritional treatment (Lapierre and Lobley, 2001). Lapierre et al. (2004) used this technique to test the effect of infused urea with a diet containing $15.6 \% \mathrm{CP}$, but could not establish an effect of urea addition to the diet on urea GER.

Also, infusion of a single dose of labeled ${ }^{13} \mathrm{C}$ urea can be used to estimate total urea- $\mathrm{N}$ entry rate in blood from the kinetics of total or urea ${ }^{13} \mathrm{C}$ dilution in time. The ${ }^{13} \mathrm{C}$ urea recycled to the GIT that re-enters the blood stream as ammonia will not affect the measurement of ${ }^{13} \mathrm{C}$ urea kinetics as it has lost the ${ }^{13} \mathrm{C}$ as ${ }^{13} \mathrm{CO}_{2}$ due to microbial hydrolysis of the ${ }^{13} \mathrm{C}$ urea. Although some ${ }^{13} \mathrm{CO}_{2}$ will be formed from the tracer, the amount is negligible compared with total $\mathrm{CO}_{2}$ production rate and, hence, will be diluted and have negligible effects on observed total ${ }^{13} \mathrm{C}$ kinetics in blood, which can be considered as ${ }^{13} \mathrm{C}$ urea kinetics. The urea GER can then be calculated by difference of urea entry rate in blood and amount of urea excreted with milk and urine. Spek et al. (2013b) used this method and found that with high compared with low dietary $\mathrm{NaCl}$ levels, plasma urea $\mathrm{N}$ concentration decreased, whereas the fraction of total urea entry rate that returned to the GIT was unaffected. The decline in plasma (and milk) urea $\mathrm{N}$ concentration due to the increased urine production must be expected to occur with any $\mathrm{Na}$ or $\mathrm{K}$ salt (Bannink et al., 1999; Eriksson and Rustas, 2014). In line with Reynolds and Huntington (1988), Spek et al. (2013b) observed that the fraction of total urea entry rate that returned to the GIT was negatively related to dietary protein content. Reports on this type of measurements allowed Reynolds and Kristensen (2008), and more recently Batista et al. (2017), to demonstrate that GER accounts for almost the entire urea entry rate in systemic blood when dietary DM contains $8 \%$ or less CP.

Irrespective of the type of infusion protocol adopted and the type of labeled tracer used, animals have to be in steady state during the course of the trial (and across experimental periods) to prevent bias and obtain consistent results. If during a measurement period there is a transient development in (the pattern of) blood concentrations of nutrients and metabolites, treatment results may be affected. There are labile $\mathrm{N}$ pools in the ruminant animal, which can be exchanged with systemic blood within hours or days and include urea and protein in visceral organs. Urea space volume is estimated to be around $50 \%$ of a cow's BW, which means more than $300 \mathrm{~L}$, and 7 times the volume of systemic blood (Agnew et al., 2005). These labile N pools can easily be exchanged with systemic blood, if the studied animals are not in a steady state across time. Also, labile protein reserves may affect experimental outcomes and the size of these reserves may change with animal treatment. Based on a literature survey of this kind of studies, Reynolds and Kristensen (2008) concluded that oscillating dietary CP supply has surprisingly small effects on beef cattle or sheep performance, if an oscillation does not extend beyond 3 d. Similarly, Brown and Weiss (2014) concluded that oscillating $\mathrm{CP}$ content of the diet had no effect on milk and milk protein production in dairy cows. Nevertheless, Ludden et al. (2002) reported increased weight of the reticulorumen, small intestine, and liver by 6,17 , and $5 \%$ in growing lambs for oscillation between a low and high CP diet every $2 \mathrm{~d}$. For dairy cows entering lactation, even larger changes, about $27 \%$ increase in GIT and liver mass (from 5.5 to $7.0 \%$ of BW; Baldwin, 1995), are described, which may also affect urea net PDV flux or urea GER.

\section{TECHNIQUES FOR STUDYING POSTRUMINAL DIGESTION AND ABSORPTION OF NITROGENOUS COMPOUNDS}

In ruminants, as in other mammalian species, dietary $\mathrm{N}$ is absorbed from the lumen of the GIT into portal vein blood almost entirely as either ammonia, AA, or nucleic acids. There is undoubtedly uptake of small peptides across the brush border membrane 
of absorptive enterocytes in the small intestine; as in other species, however, it does not appear that peptides are transferred to venous blood intact (Reynolds et al., 1994; Seal and Reynolds, 1993; Smith and Morton, 2010). Instead, the absorbed peptides are hydrolyzed by enterocyte peptidases and their constitutive AA transferred into venous blood across the basolateral membrane.

By comparing measurements of postruminal flow and fecal output of nitrogenous compounds, apparent (or net) digestion, and apparent absorption of compounds across the total postruminal digestive tract can be calculated. However, measurements of total postruminal digestion of nitrogenous compounds include protein digestion and microbial fermentation in the hindgut (large intestine and cecum). While further digestion of proteins not digested in the small intestine occurs in the hindgut, MPS and excretion in feces partially reduce the total apparent digestion of feed and microbial protein leaving the rumen, making interpretation of results (e.g., for specific AA) difficult. For example, decreases in total-tract digestion of protein in lactating dairy cows due to abomasal starch infusion were attributed to increased starch fermentation in the hindgut and subsequent microbial protein excretion in the feces, rather than any effect on digestion of protein in the small intestine (Reynolds et al., 2001a). Microbial protein excreted in feces includes $\mathrm{N}$ from ammonia (and likely AA and peptides) arising from protein digestion, or $\mathrm{N}$ in urea transferred to the lumen of the hindgut from blood. In this regard, abomasal starch infusion was shown to reduce ammonia absorption into the portal vein of multi-catheterized lactating dairy cows, presumably due to increased MPS in the hindgut (Reynolds et al., 1998).

Because of the effects of the hindgut on fecal composition, better measurements of true protein digestion and $\mathrm{AA}$ absorption are obtained with the addition of a fistula and cannula in the ileum allowing comparison of postruminal and ileal flow. By comparing daily rates of duodenal and ileal flow of specific AA, their net disappearance from the lumen of the small intestine provides an estimate of apparent absorption into intestinal enterocytes. Establishment and maintenance of ileal cannula is typically more problematic than for duodenal cannula, especially in lactating dairy cows, and for this reason measurements of small intestinal digestion in lactating dairy cows are relatively scarce in the literature (Reynolds et al., 1994, 2015; Hindle et al., 2005). Postoperative recovery of animals with ileal cannula can be especially difficult due to gut stasis and the potential for torsion and blockage, especially if fistulas are established using recumbent rather than standing surgery. Ileal flow is much more sporadic than duode- nal flow, making sampling at specific time points even more problematic than for duodenal cannula, but ileal digesta is typically more homogeneous than duodenal digesta, thus representative ileal subsamples are easier to obtain than duodenal samples. Chyme in the ileum includes endogenous proteins from sloughed cells and secretions, thus true absorption of AA is greater than the net difference between duodenal and ileal flow (apparent absorption). There is a high rate of turnover of the cells in the intestinal villi, and substantial secretion of enzymes and mucin into the lumen of the small intestine. A portion of these endogenous proteins and AA is digested and re-absorbed anterior to the ileum, and thus would have no net effect on the supply of "novel" nitrogenous compounds to the animal, but endogenous protein may represent as much as $15 \%$ of total protein flow in the ileum of dairy cows (Reynolds et al., 2001b; Ouellet et al., 2002).

\section{Intestinal Digestibility of Microbial Protein and RUP}

Estimation of intestinal digestibility of microbial protein and feed RUP is a prerequisite of predicting MP supply required by nutritional models (NRC, 2001; Dutch DVE/OEB, Van Duinkerken et al., 2011). The proportions of bacterial versus protozoal protein in the total microbial protein leaving the rumen is one of the factors influencing its digestibility; therefore, isolation and quantification of microbial fractions is an important step in determining intestinal digestibility of microbial protein. Recently, alternatives to the old methods have been introduced for isolation of microbial fractions from digesta. For instance, a procedure has been developed for isolation of culturable mixed ruminal protozoa (Sylvester et al., 2004, 2005; Denton et al., 2015) that does not have the major disadvantages of the differential centrifugation method [i.e., contamination with bacteria and feed particles, or use of formalin by some methods for isolation and storage of samples, which can adversely affect AA hydrolysis (Fessenden et al., 2017)].

Different methods have been used to estimate intestinal digestibility of microbial protein (and individual AA) including regression approaches (Storm et al., 1983a; Hvelplund and Hesselholt, 1987), in vitro procedures (Gargallo et al., 2006), and in vivo assays using cecectomized roosters (Stern et al., 1997; Fonseca et al., 2014), or mobile bags (Hvelplund et al., 1992). Single time point hydrolysis of feed or microbial protein as a routine procedure has been criticized for underestimation of AA release and minimizing the loss of acid-sensitive AA (Rutherfurd, 2009; Fessenden et al., 2017). Alternatively, multiple time point determination of protein digestion followed by nonlinear re- 
gression procedures to provide more accurate estimates of availability of AA has been proposed (Darragh and Moughan, 2005). Applying this technique to ruminal bacterial and protozoal protein using different time points of up to $168 \mathrm{~h}$, led to estimations of 87.8 and $81.6 \%$ average AA digestibility of ruminal bacteria and protozoa, respectively (Fessenden et al., 2017). However, protozoal protein constitutes a small proportion of microbial protein arriving in the duodenum (10 to $30 \%$, Sylvester et al., 2005; 23\% Hristov and Jouany, 2005; 17\%, Sok et al., 2017). Quantity of protozoa flowing to the duodenum may be less than its outflow from the rumen due to considerable sequestration or selective retention of protozoa in the omasum as indicated in a modeling attempt by Hook et al. (2017), confirming the earlier observations of Michalowski et al. (1986). Therefore, the influence of the proportion of bacterial to protozoal protein on microbial protein digestibility in the small intestine is expected to be small. Changes in the composition of bacteria under different rumen environments (Clark et al., 1992; Rodríguez et al., 2000) might also contribute to the variability of intestinal digestibility of microbial protein. Hoogenraad and Hird (1970), using labeled bacteria, showed a wide range of microbial protein digestibility (79 to $95 \%$ ). However, using continuous intra-abomasal infusion of microbial protein in sheep, Schwarting and Kaufmann (1978) reported that digestibility of microbial protein was 90 to $95 \%$. In another study, true digestibility of total microbial $\mathrm{N}$ compounds in the small intestine, estimated by infusing pre-digested ${ }^{15} \mathrm{~N}$ labeled rumen bacteria into the proximal duodenum and determining recovery of ${ }^{15} \mathrm{~N}$ at the distal ileum, ranged from 75 to 85\% (Salter and Smith, 1977). Storm et al. (1983a,b) infused isolated microbial protein into the abomasum of sheep and reported true digestibility of microbial $\mathrm{N}$ to be 81 to $82 \%$. Multiple regression analyses (Tas et al., 1981) indicated that $87 \%$ of microbial protein is digested in the small intestine (between proximal duodenum and terminal ileum) with considerable variability among individual AA. Currently, most nutritional models use values between $80 \%$ (NRC, 2001) and $85 \%$ (Dutch DVE/OEB; Van Duinkerken et al., 2011) for intestinal digestibility of microbial protein.

Similar to microbial protein, determination of in vivo digestibility of RUP is challenging. In ileal sampling studies, digesta flow is typically determined by a single marker method due to rather homogeneous nature of digesta and the general assumption of laminar digesta flow in the small intestine. However, in slaughter studies using goats (Walz et al., 2004; Leite et al., 2015 ), the ratio between iNDF and NDF was markedly lower in the small intestine (segments were not specified) than in the abomasum or hindgut. Similar differences were found in a slaughter study using dairy cows (unpublished data from Ahvenjärvi et al., 2010). These observations question the general assumption of laminar digesta flow in the small intestine (e.g., Ellis et al., 1994). Multiple marker systems can improve the accuracy of the estimation of ileal digesta flow, but to our knowledge double-marker systems have not been applied for ileal sampling (Reynolds et al., 2001a).

The Lucas test (Van Soest, 1994) could be used to estimate undigested $\mathrm{CP}$ from protein supplements by plotting digested $\mathrm{CP}$ concentration $(\mathrm{g} / \mathrm{kg}$ of $\mathrm{DM})$ against dietary $\mathrm{CP}$ concentration in studies where graded levels of protein supplements are fed. The slope of the regression represents the true $\mathrm{CP}$ digestibility and negative intercept represents fecal metabolic and endogenous CP output. The method is too laborious to be used only to determine digestibility of RUP, but it might serve as a reference method for developing laboratory methods. One criticism is that the Lucas test also includes digestion in the hindgut.

A method based on the use of a single dose of an indigestible marker can be a useful application in determining digestibility of a labeled compound in the small intestine because the flow itself need not be determined (Faichney, 2005). Digestibility is calculated as $1-\left(\mathrm{AUC}_{\mathrm{A}} / \mathrm{AUC}_{\mathrm{M}}\right)$, where $\mathrm{AUC}=$ area under the concentration curve (A, labeled compound; M, indigestible marker) versus time curve as a fraction of marker dose. Ashes et al. (1984) applied this method using Cr-EDTA as a marker to determine digestibility of labeled casein AA. Hvelplund et al. (1994), using the technique, determined intestinal digestibility of RUP and intact feed protein in sheep completely nourished by intragastric nutrient infusions. In that study, there was a good agreement between mobile bags technique data and true digestibility in the intestines.

Estimating the digestibility of RUP (or microbial protein and AA) using cecectomized roosters (Fonseca et al., 2014) suffers from differences in enzymatic and physiochemical ( $\mathrm{pH}$, for instance) conditions of the GIT of avian species versus ruminants, leading to difficulties in direct comparison of results (Fessenden et al., 2017). Stern et al. (1997) reviewed studies using different bioassays (cecectomized roosters, rat growth studies) to determine intestinal digestibility of RUP. Some promising results were obtained, but the authors concluded that it was more realistic to obtain relative, rather than absolute, measurements of ruminal and intestinal nutrient digestion of feedstuffs and diets; however, ration formulation models require absolute rather than relative feeding values. One possibility to estimate the intestinal digestibility of RUP is to derive it from tabulated apparent digestibility coefficients of $\mathrm{CP}$ by estimating true CP digestibility (TCPD; fraction of 
1) using a default value for metabolic and endogenous fecal CP. Truly undigested CP (UDCP; $\mathrm{g} / \mathrm{kg}$ of DM) is then calculated as $(1-\mathrm{TCPD}) \times \mathrm{CP}(\mathrm{g} / \mathrm{kg}$ of $\mathrm{DM})$ and then RUP digestibility as 1 - UDCP $(\mathrm{g} / \mathrm{kg}$ of DM) $\div$ RUP $(\mathrm{g} / \mathrm{kg}$ of DM)

Postruminal and small intestinal digestion of feed (or microbial) proteins can also be measured using the mobile nylon bag technique, where bags containing representative samples of feed ingredients are pretreated to simulate degradation and residence in the rumen and abomasum, and then placed into the duodenum and subsequently retrieved from the ileum or feces (Hvelplund et al., 1992). The difference in protein present in the bags introduced into the duodenum and those retrieved represents the postruminal digestion of protein in the bags. The technique can be influenced by microbial colonization and digestion in the hindgut, and thus retrieval of bags in the ileum (e.g., using magnets) is a preferred approach for estimating the digestibility of proteins in the small intestine (Stern et al., 1997). The mobile bag technique has disadvantages similar to the rumen in situ procedure, including disappearance of both indigestible and digestible protein from fine feed particles, as discussed previously.

In vitro procedures have also been used to estimate intestinal digestion of feed (or microbial) protein. A 3 -step in vitro procedure was developed by Calsamiglia and Stern (1995), including $16 \mathrm{~h}$ rumen pre-incubation followed by an acid/pepsin step to simulate abomasal digestion, and incubation in pancreatin and phosphate buffer solution to simulate intestinal digestion. The technique was sensitive to heat damage of soybean protein and anti-trypsin factors in soybeans. A more recent modification of common in vitro approaches uses ruminal fluid for the fermentation part of the procedure and a cocktail of enzymes (trypsin, chymotrypsin, lipase, and amylase) to estimate intestinal digestibility of proteins (Ross et al., 2013). This assay was developed to reduce sample loss and variation among samples when instead of bags, Erlenmeyer flasks, and small pore size filter paper were used to improve recoveries of undegraded feed $\mathrm{N}$.

\section{Appearance of Nutrients in Blood as Estimates of Absorption}

Measurements of venous-arterial concentration differences and blood flow across the PDV is another method that has been used to estimate the absorption of AA and ammonia from the GIT (Reynolds et al., 1994; Seal and Reynolds, 1993; Reynolds, 2002). The tissues of the PDV include the GIT, pancreas, spleen, and mesenteric and omental adipose tissue, and their metabolism is included in the measurements of net PDV flux (venous- arterial concentration differences times blood flow) of nutrients (Huntington et al., 1989). The true portal vein in cattle is relatively short, or nonexistent (Seal and Reynolds, 1993), therefore it is essential that portal vein samples be obtained downstream from the porta hepatis, usually from a branch well within the liver parenchyma, to reduce errors associated with laminar flow of mesenteric, gastrosplenic, and gastroduodenal blood at the porta hepatis (Seal and Reynolds, 1993). Measurements of blood flow have been obtained in some studies using electronic flow probes, which have a limited functional life-span, but in most studies, blood flow is estimated based on downstream dilution rate of a marker, such as $\rho$-amino hippuric acid $(\mathbf{P A H})$, that is infused into a distal mesenteric vein at a constant rate. It is helpful if the distance between mesenteric infusion site and portal vein sampling is maximized to promote mixing of $\mathrm{PAH}$ with the increasing volumes of venous blood from the other PDV tissues (Huntington et al., 1989).

Measurements of ammonia $\mathrm{N}$ absorption into the portal vein include absorption of ammonia throughout the GIT, but primarily the reticulo-rumen and hindgut, as well as release of ammonia arising from the metabolism of PDV tissues. In some studies, anterior mesenteric vein sampling catheters have been used to quantify the portion of PDV nutrient flux attributable to tissues of the mesenteric-drained viscera (MDV), which depending on catheter placement includes varying portions of the small intestine, mesenteric fat, large intestine, and cecum. Reynolds and Huntington (1988) reported that $52 \%$ of net PDV release of ammonia was attributable to the MDV in steers fed a high concentrate (corn and soybean meal) diet, but the MDV accounted for $28 \%$ of net PDV release of ammonia when chopped alfalfa hay was fed. Net MDV absorption was not affected by diet. Thus, the difference in the fraction of ammonia absorption attributable to the MDV was due to greater N intake and net "stomach" (reticulorumen and omasum) release of ammonia when alfalfa hay was fed.

Measurements of net PDV release of AA represent their net availability after metabolism by all tissues drained by the portal vein is accounted for. This metabolism includes metabolism of AA during their initial absorption (sometimes called first-pass metabolism), but also the uptake and metabolism of AA from arterial blood. Tissues of the PDV collectively have a high rate of protein turnover and oxidative metabolism, but only a small portion of the PDV tissues is responsible for absorbing and assimilating AA from digesta (i.e., absorptive enterocytes in the duodenum and jejunum); therefore, the vast majority of the AA metabolized by the PDV tissues are derived from arterial blood (Reynolds, 2002). This "unidirectional" uptake of AA from 
arterial blood masks the true rate of absorption and unidirectional release of AA from the small intestine into the portal vein blood, although a portion of the AA taken up from arterial blood is used for the synthesis of endogenous proteins appearing in the small intestine chyme that may be digested and reabsorbed. The effect of the uptake of AA from arterial blood by the reticulorumen and other stomach tissues is illustrated by comparisons of net MDV and PDV release of EAA, which was on average $38 \%$ greater for net MDV release of individual EAA than for net PDV release (MacRae et al., 1997b). In this regard, net MDV release of EAA is a much better estimate of their absorption by the small intestine than measurements of their net PDV release. Assessment of net PDV or MDV flux of NEAA is complicated by their synthesis within PDV tissues (Seal and Reynolds, 1993; Reynolds et al., 1994). Net PDV release of alanine in particular is high relative to other AA, which reflects its role as a carrier of $\mathrm{N}$ arising from PDV tissue metabolism of other AA that transport metabolic $\mathrm{N}$ to the liver for ureagenesis. In contrast, the high rate of glutamine metabolism as energy yielding substrates for GIT tissues substantially reduces their net PDV release (e.g., Stoll et al., 1999).

\section{Isotopic Labeling of Nutrients to Measure Unidirectional Flux and Absorptive Use}

As discussed previously (Reynolds, 2002), measurements of unidirectional flux rates (removal from arterial blood and release into venous blood) of AA and other nutrients can be obtained using isotopic labeling techniques developed for use in sheep and described in detail by Bergman (1975). The blood pool is labeled using intravenous infusion, and the extraction of labeled nutrient by the tissue (e.g., the PDV) is measured and used to calculate the unidirectional removal of the AA. Unidirectional release of the AA is then calculated as the difference between net flux and unidirectional removal. However, these measurements do not account for any first-pass metabolism, or "absorptive use," of AA that occurs during their absorption by the small intestine enterocytes. Metabolism of EAA during their absorption was estimated using a dual-isotope technique developed for use in sheep (MacRae et al., 1997a; Yu et al., 2000) where one isotope of an AA is used to label the arterial blood pool and a separate isotope of the same AA is infused into the duodenum to measure the recovery of the isotope in the portal vein, after correction for the extraction of isotope absorbed from the lumen that appears in arterial blood (based on extraction of the isotope used to label the blood pool). While an elegant and sophisticated model for measuring rates of AA metabolism by the PDV, the method has only been used in a limited number of studies and it remains to be determined to what extent sequestration and turnover of the label in tissue proteins affect the measurements obtained. Infusion of labeled AA at known rates also allows calculation of whole body turnover and irreversible loss (IRL). Differences in whole body IRL of an EAA (Leu) determined using peripheral blood infusion of a labeled marker compared with label infusion into the small intestine lumen has been used as an indication of "first-pass" use (El-Kadi et al., 2006). Differences in this case include metabolism by the liver, and differences in IRL attributable to the site of label infusion may be due to more than "first-pass" metabolism by specific tissues per se (Pell et al., 1983). In addition, the splanchnic tissue utilization of labeled AA infused into the gut lumen and subsequently recycled to PDV tissues in arterial blood must be accounted for. Absorptive use of AA has also been estimated by comparing net disappearance of AA from the small intestine obtained using ileal cannula with their net MDV or PDV release (MacRae et al., 1997b; Berthiaume et al., 2001), but as discussed above, these comparisons are compromised by the heterogeneity and multiple routes of metabolism (e.g., uptake of AA from arterial blood, reabsorption of endogenous AA, and so on) that occur in tissues of the MDV or PDV and make interpretation of net flux rates difficult. More recently, an alternative approach based on modeling changes in the enrichment of EAA in jugular blood during short-term infusions has been used to estimate true appearance of individual EAA during abomasal infusions of AA or casein (Estes et al., 2018). Using this approach, the peripheral plasma pool entry of abomasally infused Ile, Leu, or Met was 93 to $94 \%$, whereas the entry of EAA in abomasally infused casein ranged from 73 to $93 \%$ (Estes et al., 2018).

\section{MAMMARY METABOLISM OF NITROGENOUS COMPOUNDS}

Direct measurement of the net anabolism of the mammary gland as secreted milk proteins, fat, and lactose provides an opportunity that is not available with studies of other tissues and organs. The net uptake/release of nutrients from the blood supply can be compared or, rather, balanced with milk outputs. Balance studies can provide meaningful information if the arterio-venous (A-V) difference in blood (plasma) metabolites, mammary gland blood flow rate, and milk outputs are accurately measured. Mepham (1982) highlighted many of the important considerations and problems that he and Linzell (1974) identified when applying the $\mathrm{A}-\mathrm{V}$ difference technique to the bovine and caprine mammary gland. Accurate measurements of mammary blood flow form an integral part of $\mathrm{A}-\mathrm{V}$ difference stud- 
ies and mammary blood flow has been estimated using a wide variety of methods including thermodilution, electromagnetic flow meters, ultrasound flow meters, dye dilution procedures, and several methods based on the Fick principle (see Linzell, 1974). Electromagnetic and ultrasonic probes have been used to determine mammary blood flow and its variation on a minute-tominute basis (Peeters et al., 1979; Gorewit et al., 1989), but the cost and the surgical and technical preparation associated with their implantation and calibration have limited their use. Nonetheless, several research groups have used ultrasonic flow meters to measure mammary blood flow (Prosser and Davis, 1992; Guinard et al., 1994; Thivierge et al., 2000). However, when Metcalf et al. (1992) compared the ultrasonic flow meters with the dye dilution method, the ultrasound estimates were 51 to $54 \%$ of the estimates from dye dilution. Comparing ultrasonic flow meters with the Fick principle (using Phe+Tyr), Wonsil (1993) found ultrasound underestimated mammary blood flow by 46 to $56 \%$ and Thivierge et al. (2000) reported flow probes underestimated mammary blood flow by $30 \%$. However, Davis et al. (1988) found no difference between methods. The discrepancy between electromagnetic and ultrasonic probes and other methods is presumed to be due to turbulence in the blood flow through the probe and possibly constriction of the blood vessel as the probe head becomes encapsulated in connective tissue. In addition, the mammary gland also receives some blood via the cranial epigastric and perineal arteries, which unless ligated or occluded would provide mammary blood flow not included in measurements obtained by flow probes on the external pudic artery (Linzell, 1974).

Indicator or dye dilution methods have been used extensively in metabolic and circulatory studies for the measurement of blood flow rate (see Zierler, 2000). Methods based on the injection of an indicator into the external pudic artery and measuring its dilution in a vein draining the gland have been used to estimate blood flow in different species of lactating animals (Reynolds et al., 1968; Metcalf et al., 1996; Bequette et al., 1998; Crompton et al., 2014). Several indicators have been suggested including Evans blue, indocyanine green, and PAH; the latter has become the indicator of choice due to cost and ease of measurement in blood. The accuracy of the indicator dilution method is dependent upon thorough mixing of the dye between the sites of infusion and sampling and can be significantly affected by laminar flow.

Several methods for measuring mammary blood flow are based on the Fick principle. Diffusible tracers that distribute intracellularly have also been widely used to estimate organ blood flow in animals and humans including $\mathrm{N}_{2} \mathrm{O}$ (Reynolds, 1964), tritiated water (Pappenheimer and Setchell, 1972), urea, ethanol, and aminoantipyrine (Linzell, 1974). Only tritiated water has been used to measure mammary blood flow in dairy cows (McDowell et al., 1987; Pacheco-Rios et al., 2001) and the technique tends to underestimate blood flow relative to other methods due in part to losses of tritiated water through the skin and lungs. In the case of a substance that is wholly transferred from blood to milk, blood flow can be calculated if the quantities appearing in milk in a given time and the mean $\mathrm{A}-\mathrm{V}$ differences are known. Linzell (1974) suggested that certain AA may fulfill the criteria for the method. Methionine (Davis and Bickerstaffe, 1978), Trp (Davis and Collier, 1985), and Gln (Meijer et al., 1993) have been suggested as suitable AA, but are rarely used. However, the sum of Phe+Tyr, as recommended by Spires et al. (1975), has been extensively used by many investigators (Davis et al., 1988; Cant et al., 1993; Thivierge et al., 2002; Doepel and Lapierre, 2010). Assumption of the stoichiometric transfer of Phe+Tyr from plasma into milk protein is the basis of the method. It is known that Phe can be converted to Tyr within the mammary gland of ruminant species (Jorgensen and Larson, 1968; Verbeke et al., 1972) and this is why Phe+Tyr is used; however, the extent of this conversion is not well established, neither is any further catabolism of Tyr in the mammary gland. Crompton et al. (2014) reported that Phe conversion to Tyr across the mammary gland of dairy cows was on average only $1.3 \%$ of net Phe uptake and no Tyr oxidation was detected. Similarly, Lemosquet et al. (2010), reported only 1.5 to $3.6 \%$ of the Tyr secreted into milk had been synthesized from intracellular Phe within the mammary gland, even under conditions of excess Phe supply and oxidation of Phe (and Tyr) across the gland was less than $0.7 \%$ of the AA inflow. The technique benefits from the simultaneous measurement of $\mathrm{A}-\mathrm{V}$ difference and the approach has been substantiated by its equivalence to direct measurements of mammary blood flow using dye dilution techniques (Bequette et al., 1996) and electromagnetic flow meters (Davis et al., 1988). Use of the Fick principle in many studies does represent a compromise, but it should be treated with caution in the longer term for the simple reason that blood flow is crucial for the nutrient/isotope transfer measurements obtained, particularly in experiments investigating responses in mammary metabolism to changes in nutrient availability.

Posture and the regularity of feed consumption appear to have a major influence on mammary gland blood flow and possibly nutrient uptake (Metcalf et al., 1992; Rajczyk et al., 1995). Researchers now endeavor 
to minimize blood flow variability by ensuring that animals are only sampled when standing or remain standing for the sampling periods and are fed frequently (12 to 24 times daily; see Bequette et al., 1998). In addition, A-V blood samples can be withdrawn continuously over an hour to provide integrated samples directly comparable with milk output during the sampling period.

When applying the $\mathrm{A}-\mathrm{V}$ difference technique to the mammary gland, probably the most important criterion is that blood leaving the gland via the subcutaneous abdominal veins is not contaminated by blood originating outside the mammary gland. Thivierge et al. (2000) demonstrated that in second lactation cows, blood flow in the external pudic vein flows away from the mammary gland, whereas in third and fourth lactation cows there was regurgitant flow of blood down the external pudic vein toward the milk vein. Therefore, in studies measuring the metabolic utilization of nutrients across the mammary gland, cows in first and second lactations should preferably be used (Thivierge et al., 2000).

Collection of arterial and venous blood samples is essential for estimating nutrient uptake and release by the mammary gland. Venous blood can be easily sampled from the subcutaneous abdominal veins in dairy cows and arterial blood is often obtained from indwelling catheters in the carotid, external pudic, or external iliac arteries. To avoid the need of surgical preparation, numerous $\mathrm{A}-\mathrm{V}$ difference studies of the mammary gland have sampled blood from the milk vein and one of the coccygeal vessels in the tail, on the basis that $\mathrm{A}-\mathrm{V}$ differences across the tail are negligible and therefore the composition of either arterial or venous blood from the tail represents that of the mammary arterial supply (Cant et al., 1993; based on the work of Emery et al., 1965). Emery et al. (1965) found no difference in the concentrations of glucose and acetate in arterial and venous coccygeal blood. This premise has been accepted in studies on mammary gland metabolism of AA (Lykos and Varga, 1997; Doepel and Lapierre, 2010) and fatty acids (Yang et al., 2012). Moorby et al. (2002) reported that although concentrations of some AA were slightly different between coccygeal arterial and coccygeal venous blood, the differences were not significant. However, Moorby et al. (2002) did report differences between coccygeal arterial and venous samples for glucose concentration and others have reported differences for blood gases (Tvedten et al., 2000) and ethanol metabolism (Levitt et al., 1994). A recent study by Zhang et al. (2016) reported significant difference in AA concentrations between the coccygeal arterial, coccygeal venous blood and external pudic artery for Asp, Thr, and Pro. Caution should be exercised when using coccygeal venous samples to represent the external pudic artery.

\section{WHOLE-ANIMAL NITROGEN BALANCE STUDIES}

Body $\mathrm{N}$ balance has long been measured and reported for ruminants and provides an indicator of $\mathrm{N}$ and indirectly protein retention or loss by all body tissues. When measured using slaughter balance methods, the retention of $\mathrm{N}$ within the body tissues is measured directly, if an appropriate representative sample of body tissues can be obtained and analyzed, or the amount of body protein present can be estimated, typically using indirect measurements and assumptions based on the species-specific composition of body fat-free mass (NRC, 1968; Johnson, 1986). However, slaughter balance measurements are cost-prohibitive and rarely reported for large ruminants (e.g., Gibb et al., 1992). The dynamics of body water (including the rumen) pools in ruminants, and in particular lactating dairy cows, make estimation of fat-free mass subject to variability (Andrew et al., 1995). The measurements also depend on how representative the control group slaughtered at the beginning of the experiment is for the experimental animals slaughtered at the end. Therefore, measurements of body $\mathrm{N}$ balance in ruminants reported in the literature are largely based on indirect estimates using digestion trials coupled with urine (and milk in lactating animals) collection to determine digestion and excretion/secretion of $\mathrm{N}$, with the difference between digested $\mathrm{N}$ and $\mathrm{N}$ excretion/secretion in urine and milk assumed to be equal to body tissue loss or gain (Johnson, 1986). These estimates of $\mathrm{N}$ balance based on digestion trials will be the focus of the present discussion.

Accurate measurements of fecal $\mathrm{N}$ excretion (and thus, apparent $\mathrm{N}$ digestion) are paramount for estimating body $\mathrm{N}$ balance. Digestion trials have historically been central to the study of ruminant nutrition, with reports in the literature dating back to the 1860s in Europe and experiments on protein digestion of forages conducted in Maine in the United States reported in the 1880s (Schneider and Flatt, 1975). Numerous previous publications have described methods and recommended procedures for conducting digestion trials (e.g., Maynard and Loosli, 1975; Rymer, 2000) and the book by Schneider and Flatt (1975), The Evaluation of Feeds Through Digestibility Experiments, is highly recommended. Considering the long-term historical use and prevalence of digestion trials in the literature, there is a danger that the techniques used are viewed as being so commonplace and routine that in practice standards have slipped and recommendations for best practice are no longer followed. For example, as pointed out by Firkins and Reynolds (2005), the number of days of fecal collection required to account for daily variation in fecal output vary with diet composition and other factors, but historically at least 7 to $8 \mathrm{~d}$ of collection 
was considered a minimal requirement (Maynard and Loosli, 1975; Schneider and Flatt, 1975). Depending on the composition of the diet fed and frequency of feeding, the length of time required for diet adaptation before digestion trials, and the number of days required to minimize daily variation in fecal excretion, varies from 4 to $12 \mathrm{~d}$ (Rymer, 2000), but a period of at least 2 wk was recommended for production trials in the preceding section (Experimental Design). Regardless, variation in measurement of diet digestion reduces, and accuracy increases, as the number of days of collection increases (Blaxter, 1967; Schneider and Flatt, 1975). More recently, concerns over health, safety, and costs of weekend labor have meant that many researchers conducting digestion trial collect fecal samples for only 4 d (i.e., from Monday to Friday), and there are reports of $\mathrm{N}$ digestion measurements in the literature based on as short as $2 \mathrm{~d}$ of collection, which is clearly inadequate (Firkins and Reynolds, 2005). Such complacency regarding the rigor of methods and protocols used needs to be considered in light of long-held concerns over the accuracy of body $\mathrm{N}$ balance measurements in ruminants (e.g., Owen, 1967; Spanghero and Kowalski, 1997).

Measurements of $\mathrm{N}$ digestion begin with accurate measurements of dietary $\mathrm{N}$ intake, which include measurements of feed intake over the course of the trial and a representative sample of the feed consumed for measurement of $\mathrm{N}$ concentration. Diet sampling and measurements of intake begin 48 to $24 \mathrm{~h}$ before collection of feces, to allow for the time taken to allow passage of consumed undigested feed components to be excreted in feces (Schneider and Flatt, 1975; Rymer, 2000). For animals fed mixed diets at ad libitum intakes, selection of feed components during feeding can result in differences in the composition of the diet fed and refusals, which requires chemical analysis of both the feed offered and the refusals. Another concern for mixed diets is the extent to which a small sample saved for analysis, often as little as a few hundred grams, is representative of the composition of the diet fed, which over the course of $7 \mathrm{~d}$ could be more than $350 \mathrm{~kg}$ (fresh weight) for a lactating dairy cow. Recent research on sources of variation in measurements of diet composition have highlighted sampling error as a major source of variation (St-Pierre and Weiss, 2015) and emphasized the need to rigorously follow appropriate methods of diet handling and sub-sampling, for example through quartering and other sample size reduction methods. Similarly, care should be taken that samples are stored and processed in a way that minimizes any potential $\mathrm{N}$ losses before analysis (see below).

Body balance of $\mathrm{N}$ is calculated as the difference between $\mathrm{N}$ intake and the sum of $\mathrm{N}$ losses from the body, which include feces, milk, urine, hair and scurf, and any volatile $\mathrm{N}$ losses. Of these, feces, urine and milk, in lactating ruminants, are by far the most routinely measured, while the other losses are normally considered to be minor and rarely measured or reported. Determination of milk $\mathrm{N}$ secretion in lactating animals relies on accurate measurement of daily milk production and milk $\mathrm{N}$ concentration, with milk $\mathrm{N}$ output the sum of milk $\mathrm{N}$ output measured for each milking, not the average milk $\mathrm{N}$ concentration multiplied by total daily milk yield. Potential sources of error include the calibration of meters used to estimate milk yield, if milk is not collected and manually weighed. In addition, milk N concentration is often estimated based on protein concentration determined using infrared spectral analysis. In this case it is important that the estimate of milk protein used is based on total $\mathrm{N}$ and does not exclude NPN (Spanghero and Kowalski, 1997) and, therefore, researchers should confirm if the spectral analysis used provides a prediction of true or crude milk protein. In a previous study, milk $\mathrm{N}$ secretion was slightly lower for estimates of $\mathrm{N}$ based on Kjeldahl analysis versus milk protein concentration estimates from mid-infrared analysis (Reynolds et al., 2001a). In addition to milk $\mathrm{N}$ secretion, measurement of $\mathrm{N}$ balance also requires measurement of fecal and urine excretion and their $\mathrm{N}$ concentrations. This can be achieved using total collection methods, or indirectly using "spot sampling" and internal or external markers to estimate total volume of the excreta. Examples of markers that are often used include Cr, n-alkanes, and iNDF or ADF. For a review of marker techniques that enable estimate of fecal output without total collection of feces, see Rymer (2000) and previous sections of this article. In most cases, total collection is achieved using techniques that enable separate collection of feces and urine to determine apparent digestion of $\mathrm{N}$ and urine $\mathrm{N}$ excretion, but $\mathrm{N}$ balance can also be estimated based on measurement of feces and urine combined. In this case, the loss of volatile $\mathrm{N}$ (primarily ammonia) due to the hydrolysis of urinary urea by fecal microbial urease needs to be accounted for (e.g., van Gastelen et al., 2017), whereas in the case of separate collection, urine is typically acidified (see below). Another approach to estimate urinary $\mathrm{N}$ excretion in respiration chambers is to measure total manure (feces + urine) $\mathrm{N}$ excretion as well as fecal $\mathrm{N}$ excretion separately and calculate urinary $\mathrm{N}$ loss by the difference (e.g., Nichols et al., 2019).

Methods for total and separate collection of feces and urine have been used and refined since the first reports of diet digestion in the 1860s (for review see Schneider and Flatt, 1975), but there is still a need for improvement in the techniques and methods used, especially when considering concerns for animal and staff health, safety and welfare. In addition, there is a 
practical need for automated approaches that reduce the labor required for balance measurements. The approaches used vary with species, breed, sex, size, and physiological state of the experimental animal used. In addition, the type of diet fed can influence fecal composition and physical characteristics, which can also affect the suitability of the methods used. In this regard, a particular challenge is the high-yielding dairy cow producing large volumes of urine and feces that have a low DM concentration. Methods used vary widely across research facilities, but normally include some sort of fecal collection pan or receptacle that the feces drop into and in some cases a chute attached to the cow that directs the feces into the collection receptacle and minimizes splashing. This approach requires the animal to be restrained in a stall that minimizes movement, but a variety of fecal (and urine) collection devices that enable freedom of movement for collection of excreta from grazing animals have been developed. Frequent scraping of collection equipment to minimize retention of feces on equipment is often required (see methods described by Tyrrell et al., 1979). Feces is normally collected for successive 24-h periods (or 8-h sub-periods), mixed, and proportionally sub-sampled to form a representative composite sub-sample for analysis. As for diet samples, care must be taken to ensure that fecal subsamples are representative of the average composition of each 24-h collection period and are handled in a way that minimizes any losses of sample $\mathrm{N}$ during sampling, storage, and analysis. Samples are typically either frozen as soon as possible or treated with preservative and refrigerated to minimize microbial activity until analysis for $\mathrm{N}$ concentration as soon as possible after collection (e.g., Tyrrell et al., 1979). In some cases, feces collected may be removed at intervals over the course of a 24-h collection and stored refrigerated in covered containers to minimize volatile $\mathrm{N}$ losses until the excreta collected are combined, mixed, and subsampled. Spanghero and Kowalski (1997) found only a small, nonsignificant decrease in fecal $\mathrm{N}$ concentration over a 24-h simulated collection period but observed a $15 \%$ decrease in measured fecal $\mathrm{N}$ concentration following either air or freeze drying compared with the same sample analyzed without drying, which is why fecal $\mathrm{N}$ analysis is recommended to be performed on a nondried sample. Martin (1966) also found that volatile loss of $\mathrm{N}$ from feces of mature wether sheep fed dried grass hay was negligible over $24 \mathrm{~h}$ at varying ambient temperatures.

Urine samples need to be collected with minimal contamination by feces. In sheep, samples of feces and urine can be collected in metabolic crates independent of the sex (e.g., Wang et al., 2018). In cattle, sampling of total urine varies depending on the sex of the experi- mental animal. For males a raised stall is often used to facilitate gravity collection of urine via a funnel or sloping tray built into the stall floor (e.g., Smith, 1979). Alternatively, funnels may be attached to the animal that in some cases are evacuated following urination using a vacuum system (Wainman and Paterson, 1963; Martin, 1966). In female cattle, collection of urine is typically performed by funnel devices ("urinals") attached to the skin surrounding the vulva using commercial "branding" cement for temporarily attaching identification numbers to the hair of livestock (Hobbs et al., 1950), which can be removed using solvents such as acetone. Often hook-and-loop fastener bases are fastened onto the skin glue, and the urinals are attached with their counterparts. Regardless of the approach, the use of strong glues often causes hair loss and skin irritations that need time to heal before subsequent measurements can be made. Alternatives include urinals that are held in place by elasticated bands and straps (Fellner et al., 1988; Lascano et al., 2010), but the success of external vulva collection devices is in part dependent on the anatomy and body condition of the animal (the presence of subcutaneous fat helps create a smoother surface for contact with the urinal cup). Another alternative is the use of sloped, motorized fecal collection belts that drain into a urine collection receptacle (Flatt et al., 1958), or urine collection receptacles with large openings covered with screens that retain feces but allow urine to pass through to the collection vessel (Reynolds et al., 2014). In both cases, contamination of feces with urine, and vice versa, is unavoidable, even with frequent automated or manual removal of feces from the belts or screens, respectively. Urine contamination can be avoided by using temporary bladder catheters, but care must be taken to maintain sterility over time and minimize the potential discomfort for the animal, including accidental expulsion (Fellner et al., 1988; Lascano et al., 2010). Catheters may also affect urine volume and subsequently $\mathrm{N}$ excretion in some animals (Patience et al., 1987).

The urine collected should have sufficient acid added to prevent volatile losses of ammonia, but in a review of published $\mathrm{N}$ balance measurements for dairy cows, Spanghero and Kowalski (1997) reported that the amount of acid added during urine collection varied widely, and in many cases, acid was not added or added in amounts insufficient to prevent ammonia loss. As a rule of thumb, urine $\mathrm{pH}$ should be kept below 2 during collection and, owing to the differences in specific gravity between acid and urine, urine and acid should be frequently and thoroughly mixed. In addition, covering collection vessels to minimize surface air flow is advisable, as well as intermittent removal and refrigeration of urine during the course of each $24 \mathrm{~h}$ collection 
period. Again, sample handling to minimize volatile $\mathrm{N}$ losses during collection, subsampling, storage, processing, and analysis is critical. Spanghero and Kowalski (1997) estimated volatile losses of $\mathrm{N}$ from unacidified urine to be $5 \%$ during a 24 -h collection period for lactating dairy cows, whereas Martin (1966) reported that the measured loss of $\mathrm{N}$ from sheep urine was dependent on temperature and $\mathrm{pH}$ of the urine. At neutral $\mathrm{pH}$, up to $10 \%$ of urine $\mathrm{N}$ was lost as ammonia $\mathrm{N}$ over $24 \mathrm{~h}$, but urine $\mathrm{N}$ loss was only $1 \%$ at temperatures as high as $28^{\circ} \mathrm{C}$, if the urine $\mathrm{pH}$ was less than 2 . These urine $\mathrm{N}$ losses were also exacerbated if the urine was collected using evacuated funnels and tubing for aspiration. It is important to note that these losses were measured in the absence of fecal contamination, which would increase volatile $\mathrm{N}$ losses due to hydrolysis of urea. Losses of ammonia during excreta collection can be accounted for if balance trials are conducted in respiration chambers equipped with traps for quantifying ammonia in exhaust air and if air conditioner condensate is collected in acidified containers and analyzed for ammonia concentration (Reynolds et al., 2010; van Gastelen et al., 2017). Similarly, any losses of $\mathrm{N}$ as $\mathrm{N}_{2} \mathrm{O}$ can also be accounted for if representative samples of incoming and exhaust air can be obtained and analyzed (Reynolds et al., 2010). Other potential volatile losses of $\mathrm{N}$ include expiration, eructation, or dermal losses. Martin (1966) was unable to detect any losses of ammonia via expiration or eructation of sheep, even following rumen dosing of urea, and reported that dermal losses were also minimal unless there was urine contamination during collection.

Both Martin (1966) and Spanghero and Kowalski (1997) identified ammonia losses from urine as the largest potential source of error in measurements of $\mathrm{N}$ balance in both dairy cows and sheep. Other $\mathrm{N}$ losses undoubtedly occur, including those losses that occur during sample processing and analyses. Relatively small losses of $\mathrm{N}$ also occur as hair and scurf shed by the animal during collection, which are direct dermal losses that can be measured, along with fecal material retained on collection equipment that can be collected and subsampled at the end of a balance trial (e.g., Tyrrell et al., 1979). Any unmeasured $\mathrm{N}$ losses are included in the difference between $\mathrm{N}$ intake and $\mathrm{N}$ excretion, potentially giving rise to estimates of body $\mathrm{N}$ balance that are excessively high, especially if it is assumed that the $\mathrm{N}$ is retained within animal tissues as protein (Owen, 1967; Spanghero and Kowalski, 1997). Martin (1966) noted that urine and dermal $\mathrm{N}$ losses during measurements of $\mathrm{N}$ balance in sheep were positively related to $\mathrm{N}$ intake, presumably due to the positive relationship between $\mathrm{N}$ intake and urinary excretion of $\mathrm{N}$ as urea (Dijkstra et al., 2013). As discussed previ- ously (Reynolds and Kristensen, 2008), excessively high (or low) $\mathrm{N}$ balance is often reported in nonruminants (e.g., Hegsted, 1976) and ruminants (e.g., Owen, 1967) and has been the subject of much debate regarding potential "unexplained" losses of $\mathrm{N}$ that are not measured or occur during sample processing and analysis. Intriguingly, excessively high or low $\mathrm{N}$ balance is often measured during adaptation to a change in diet protein intake. This has led to the hypothesis that "labile pools" of body $\mathrm{N}$ are involved in $\mathrm{N}$ exchanges during dietary protein adaptation in humans (Hegsted, 1976; Waterlow, 1999) as well as ruminants (Paquay et al., 1972; Biddle et al., 1975). The exact nature of these "labile pools" of body $\mathrm{N}$, discussed earlier in relation to urea recycling to the GIT, has never been confirmed and it may be that measurements of excessively high $\mathrm{N}$ balance are at least in part a consequence of the loss of $\mathrm{N}$ during balance trials that occurs via routes that are not measured. Regardless, there is no doubt that after more than 150 yr of collective experience, accurate measurements of $\mathrm{N}$ balance in ruminants, and other species, continue to be exceedingly difficult to achieve, require rigorous attention to detail, and would benefit from further development and innovation. When reporting measurements of tissue $\mathrm{N}$ balance, researchers are encouraged to consider if their results are biologically plausible in terms of daily protein accretion or loss and the physiological state of the experimental animals.

\section{METHODS TO MEASURE N EMISSIONS FROM MANURE AND PLANT UTILIZATION OF MANURE N OBTAINED FROM ANIMAL NUTRITION STUDIES}

As discussed in the previous section, $\mathrm{N}$ balance studies testing nutritional interventions in ruminants include separate data on fecal and urinary $\mathrm{N}$ losses obtained by separation techniques. In most studies, however, composition of manure and its $\mathrm{N}$ emission potential and $\mathrm{N}$ fertilizer value are not determined or reported. It is often assumed that the information given by the $\mathrm{N}$ losses with excreta in total and the urinary$\mathrm{N}$-to-total excreted-N ratio provides sufficient information for predicting the $\mathrm{N}$ emission potential of manure. For this reason, measuring $\mathrm{N}$ emissions from manure is the domain of environmental, plant nutrition, and soil scientists. In their studies, often only one type of manure with one feces-to-urine ratio is used (e.g., Laubach et al., 2013; Verloop et al., 2014), which carries no information about the nutrition of the animals from which the manure originates and ignores the effects of nutrition on manure composition. In this section, reasons are presented as to why additional information regarding animal nutrition is helpful and in fact needed. Several methods available to obtain such information 
from individual ruminant animals subjected to $\mathrm{N}$ balance studies are described together with presenting the limited number of studies actually applying these techniques (Table 2). A compilation of some of these techniques can also be found in Bougouin et al. (2016).

\section{Specific Information Gathered by Measuring N Emission and Fertilizer Value}

Although there is a close relationship between urine $\mathrm{N}$, manure total ammoniacal-N [consisting of ammonia $\left(\mathrm{NH}_{3}\right)$ and its dissolved, ionized form, ammonium $\left(\mathrm{NH}_{4}^{+}\right)$], and eventually, the ammonia emitting potential of manure (AEP), there are several reasons why the information provided by the urinary-N-to-total manureN ratio is limited. For instance, Dijkstra et al. (2013) reported that at low $\mathrm{N}$ intake, the proportion of urea $\mathrm{N}$ in total urine $\mathrm{N}$ is much lower compared with higher $\mathrm{N}$ intake. They pointed out that the remainder consists of compounds such as purine derivatives, hippuric acid, creatine, and creatinine, which are less susceptible to volatilization than urea. Low-protein diets can result in urinary $\mathrm{N}$ excretion as proportion of $\mathrm{N}$ intake as low as $17 \%$ in lactating dairy cows (Lee et al., 2012c). Studies with labeled urine or fecal $\mathrm{N}$ have clearly shown that urea in (cattle) manure is rapidly hydrolyzed, within 24 $\mathrm{h}$, to ammonia and urinary $\mathrm{N}$ is the main contributor to ammonia emission from manure (Figure 4).

The simplified prediction of $\mathrm{N}$ emissions from $\mathrm{N}$ balance data also ignores the importance of other constituents present in manure. Gaseous $\mathrm{N}$ emission depends on the $\mathrm{N}$ exchange between manure and air on top of the manure. In cases where manure is rich in volatile $\mathrm{N}$, ambient temperature is high, and there is intensive air removal from the top of the manure, the $\mathrm{N}$ concentrations in manure and air differ substantially. The inclination to equilibrate concentrations is then particularly strong thus promoting $\mathrm{N}$ emission from the manure. Ruminants having different water consumption due to factors such as dietary salt content can produce urine with different $\mathrm{N}$ concentration irrespective of $\mathrm{N}$ intake relative to requirements (Spek et al., 2012, 2013b), and the digestibility of OM also influences manure composition and subsequent losses during storage and application (Dijkstra et al., 2018). Moreover, some constituents added to the diet to reduce urinary $\mathrm{N}$ excretion may still be active in manure. One such example is phenols, especially condensed tannins, which may firmly bind to proteins. Manure from diets rich in such compounds was sometimes (Powell et al., 2011; Abbeddou et al., 2013), but not always (Tiemann et al., 2009), shown to have a lower plant $\mathrm{N}$ fertilizer value, a phenomenon

Table 2. Overview of techniques applied for research on the properties of manure derived from $\mathrm{N}$ balance studies with ruminants

\begin{tabular}{|c|c|c|}
\hline Target variable & Technique & Animal nutrition studies investigating manure properties \\
\hline $\mathrm{NH}_{3}$ emissions & Model manure storage with acid traps & $\begin{array}{l}\text { Paul et al., 1998; Misselbrook et al., 2005; van der Stelt et al., } \\
\text { 2008; Hristov et al., 2009a; Agle et al., 2010; Lee et al., 2011, } \\
\text { 2012b, } 2014\end{array}$ \\
\hline $\mathrm{NH}_{3} / \mathrm{NO}_{\mathrm{x}}$ emissions & Covered buckets (chambers) & $\begin{array}{l}\text { Külling et al., 2001, 2002, 2003; Hao et al., 2011; Lee et al., } \\
\text { 2012a, } 2016\end{array}$ \\
\hline $\mathrm{NH}_{3} / \mathrm{NO}_{\mathrm{x}}$ emissions & $\begin{array}{l}\text { Respiration chambers or climatic } \\
\text { controlled rooms }\end{array}$ & $\begin{array}{l}\text { Śliwiński et al., 2002; Machmüller et al., 2006; Chiavegato et } \\
\text { al., } 2015\end{array}$ \\
\hline $\mathrm{NH}_{3} / \mathrm{NO}_{\mathrm{x}}$ emissions & $\begin{array}{l}\text { Barrels; using gas emission equipment } \\
\text { (e.g., from respiration chambers) }\end{array}$ & $\begin{array}{l}\text { Hindrichsen et al., 2005, 2006; Klevenhusen et al., 2011; } \\
\text { Aguerre et al., 2012a,b; Mathot et al., } 2012\end{array}$ \\
\hline $\mathrm{NH}_{3}$ emissions & Chambers in barn with roll-up curtains & Aguerre et al., 2011 \\
\hline $\mathrm{NH}_{3} / \mathrm{NO}_{\mathrm{x}}$ emissions & Towers with Eddy covariance technique & \\
\hline $\mathrm{NH}_{3} / \mathrm{NO}_{\mathrm{x}}$ emissions & Compartmented animal houses & Mathot et al., 2012 \\
\hline Nitrate leaching & Pot or field lysimeter & Lee et al., 2012a, 2014 \\
\hline Nitrification $\left(\mathrm{NO}_{3}\right.$ formation $)$ & Manure storage and compositing & Hao et al., 2011 \\
\hline $\mathrm{N}$ mineralization in soil & Pot experiment with soil & Powell et al., 2006; Abbeddou et al., 2013 \\
\hline Plant N use efficiency & Pot experiment with plants & $\begin{array}{l}\text { Paul et al., 1998; Sangaré et al., 2002; Powell et al., 2006; } \\
\text { Tiemann et al., 2009; Abbeddou et al., } 2013\end{array}$ \\
\hline Plant $\mathrm{N}$ use efficiency & Field experiment & Reijs et al., 2007 \\
\hline
\end{tabular}


pointing toward a lower $\mathrm{N}$ availability and AEP as well. Emission studies normally focus on complete slurry (mixtures of feces and urine) and rarely on other forms of manure collected, such as farmyard manure (FYM) and urine-rich slurry, or the usually much drier deep litter manure from freestall barns. Külling et al. (2001, 2002, 2003) demonstrated that the proportion of ammonia and $\mathrm{N}_{2} \mathrm{O}$ differed between dairy cow slurry and FYM plus urine rich slurry, and that this difference was dependent, to some extent, on the diet. Hristov et al. (2015) showed that barn floor ammonia emissions were lower for flush than for gutter-scrape and gravityflow manure management systems. Another general misconception is that a low urine $\mathrm{N}$ concentration is always favorable in terms of low $\mathrm{N}$ emissions. However, such manure has a low fertilizer value. The majority of the fecal $\mathrm{N}$ becomes or remains organically fixed in the soil and may become mineralized at times when the plants do not need it and thus gets emitted or lost. Comprehensive analyses have to consider total farm system $\mathrm{N}$ efficiency. Although urine $\mathrm{N}$ is likely best used by the plants, $\mathrm{N}$ use efficiency cannot be fully and reliably predicted from this information, because the fertilizer value is a complex matter including $\mathrm{C}: \mathrm{N}$ ratio, phosphorus content, and anti-nutritional compounds possibly hampering plant growth and thus $\mathrm{N}$ utilization (Abbeddou et al., 2013).

\section{Sampling and Sample Preparation of Manure from N Balance Studies}

The best way of sampling and storing manure designed for further experiments may differ depending on the experimental conditions and the research question. The ideal case is that feces and urine are separately and completely collected, and the urine is not acidified (which will inhibit consequent microbial activities in manure and also ammonia volatilization). However, sometimes compromises have to be made. These include the following: (1) Combining manure from several animals of the same dietary treatment group in cases where not enough material is available. This does not allow the biological variation between animals to be measured; (2) There are situations where the construction of the individual barn stalls does not allow urine and feces separation or only animal groups can be sampled. In such cases, it has to be considered that there are large $\mathrm{N}$ losses from unacidified urine, triggered by contact of urine with fecal microorganisms; (3) Using spot sampling of feces and urine results in the lack of information about the individual feces and urine proportions in excreta and requires the application of assumed ratios or estimates for each form of excreta (Estermann et al., 2002); and (4) The question about how to best deal with stepwise collection of excreta in balance studies (performing measurements directly or all at once) extended over more than one collection period is difficult to answer. Starting measurements immediately after excretion by the animals may, apart from being very laborious, create a time-dependent bias due to changes in micro-climatic conditions (unless done under a controlled environment). Frozen storage, on the other hand, may affect the microbial activity in the manure, but seems to yield overall emission data similar to unfrozen samples (Van Kessel et al., 1999). However, freezing manure at $-20^{\circ} \mathrm{C}$ for $40 \mathrm{~d}$ resulted
A

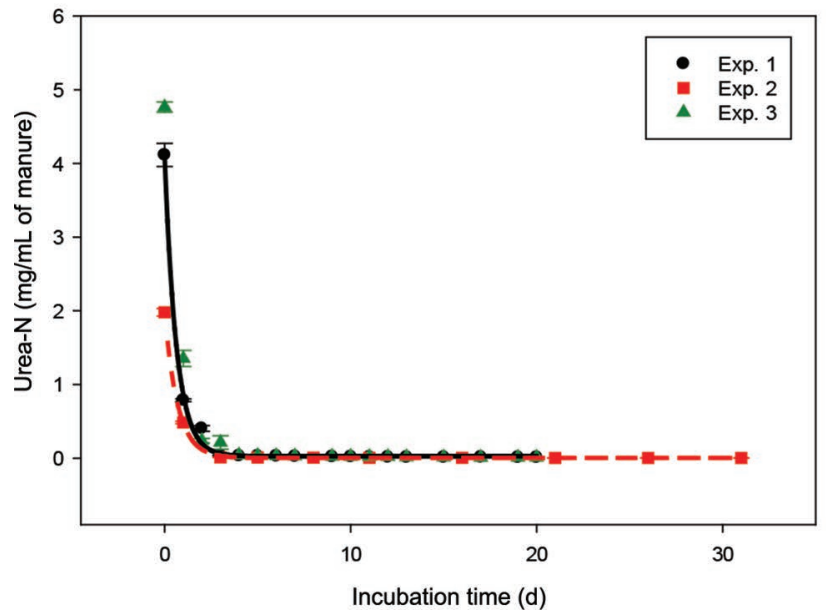

B

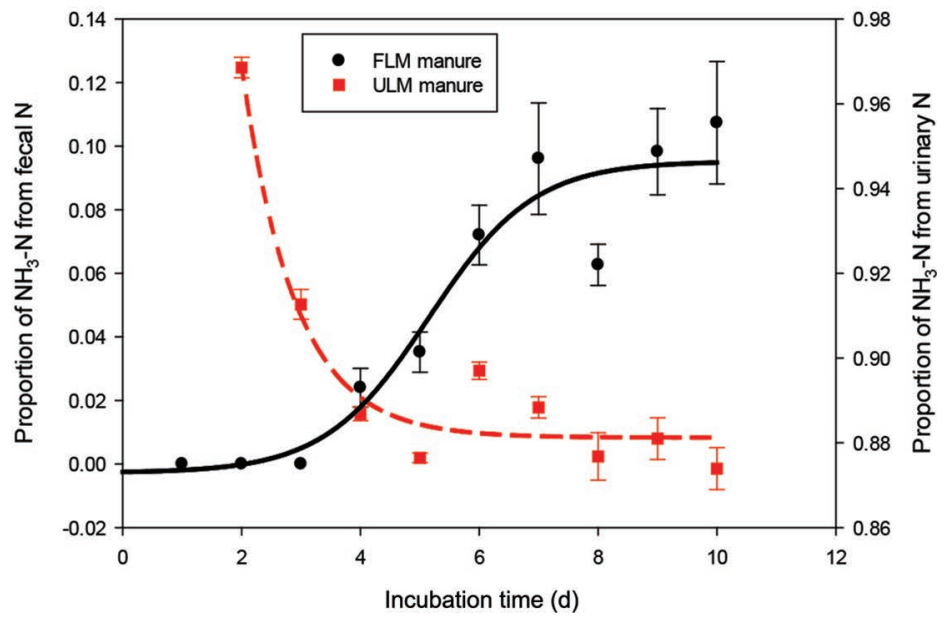

Figure 4. Urea-N concentration (A) in dairy cattle manure incubated for $30 \mathrm{~d}$ and proportion of ammonia-N emitted from manure over the course of $10 \mathrm{~d}$ originating from fecal- or urinary-N using ${ }^{15} \mathrm{~N}$-labeled feces (FLM) or ${ }^{15} \mathrm{~N}$-labeled urine (ULM; data from Lee et al., 2011). Data are means $\pm \mathrm{SE}(\mathrm{n}=8)$. Exp. = experiment. 
in a $47 \%$ higher AEP compared with fresh manure (unpublished data from Hristov et al., 2015), which suggests that AEP of frozen manure may not be fully representative of that of fresh manure.

Preparing manure for the experiments also needs specific considerations. Typically, manure is deliberately or involuntarily diluted with water in farm practice. One way to make results comparable in research is to apply standardized additions of water (cf. Külling et al., 2001); to make results more widely applicable, more than 1 water proportion has to be tested. Testing the system based on FYM and urine-rich slurry requires several specific arrangements. First, standardized proportions of urine and feces for the FYM fraction and proportions of feces for the urine-rich slurry have to be defined. The FYM will undergo self-heating, which substantially increases the level of $\mathrm{N}$ emission. Külling et al. (2001) developed model parameters for experiments on FYM and urine-rich slurry with excreta from individual cows including a temperature program for FYM developed from actual measurements.

Storage conditions, especially storage temperature, are other key factors in determining the level of emissions and studying dietary treatment differences. A high storage temperature may, however, impair a typical manure aging (drying up, crust formation) in small samples. In case enough manure is available, larger containers (Hindrichsen et al., 2005) should be used for emission studies.

\section{Methods to Measure N Emissions from Manure}

Several different methods have been developed for determining $\mathrm{N}$ emissions from manure (Table 2). The first step to allow a more comprehensive prediction of AEP and $\mathrm{N}$ fertilizer value is a more extensive manure analysis. The most important variable is ammonium $\mathrm{N}$ or, better, the total ammoniacal $\mathrm{N}$, and its development during manure storage. In addition, information about the C:N ratio, various minerals, especially the often plant growth-limiting phosphorus, and the content of undigested plant secondary compounds is helpful in this respect. Direct information about the resulting manure properties can, however, only be obtained by specific experiments described below.

The easiest way to obtain direct information about $\mathrm{N}$ emissions is to measure losses through the mass balance method [Pollet et al. (1998); first applied for $\mathrm{N}$ balance studies by Estermann et al. (2002) for individual animal manure storage experiments]. The manure is filled into uncovered flasks, pots, or barrels, and is stored under controlled environmental conditions. After predefined periods, the containers are weighed again, and homogeneous samples are prepared and analyzed for their N content. This method requires separate containers for each sampling date, because stirring destroys important structures such as crust layer formation.

Several different methods are available for determining ammonia emissions and AEP of manure from individual animals. All methods have to account for the property of ammonia to slowly adsorb onto and desorb from surfaces. This requires sufficiently long equilibrium periods before starting the measurements. Storage of manure in model containers as described above can be further developed to measure ammonia emissions. Külling et al. (2001) first applied the dynamic chamber technique described by Mosier (1989) for manure from animal nutritional studies. In this method, 2 plastic buckets are placed on top of each other, and a continuous airflow through the buckets' headspace is established by household ventilators. Misselbrook et al. (2005) prepared a set-up with a combination of acid traps (i.e., air is ducted through solutions of sulfuric acid where ammonia is transformed to ammonium sulfate, a compound easily analyzed). Also, chambers in which animals are kept can be used (Chiavegato et al., 2015). As respiration chambers are equipped to register exact gas volumes and are automated to collect gas samples, research institutes having chambers could complement their equipment with automatic ammonia analyzers. This approach was first applied by Śliwiński et al. (2002) by leaving the manure of sheep in the chambers after the animals were removed. However, a serious limitation of this method is that the chambers are unavailable for months and therefore experiments with sufficient replicates would go on for extended periods. For this reason, Hindrichsen et al. (2005) used the respiration chamber technique by attaching the tubes for gas sampling to the lids of the manure storage containers and regularly moved these lids between containers. This procedure restricts chamber use for a much shorter period. Such covered barrels can also be attached to other gas analytical equipment (Aguerre et al., 2012a,b). In entire (tiestall) barns, a method using chambers for several animals with roll-up curtains was developed by Powell et al. (2007) and was modified by Aguerre et al. (2011). This method, however, may lack accuracy. For example, in a study by Arndt et al. (2015) manure ammonia emissions from dairy cows fed increasing amounts of alfalfa forage did not increase when measured with this system while urinary $\mathrm{N}$ excretion increased linearly by up to $26 \%$. Another approach for simulating ammonia emissions at the site of origin is to make standardized deposits to barn floor achieving a thin manure layer and measuring emissions from this surface (Misselbrook et al., 2005).

Instead of the individual animal approaches, ammonia emissions could be measured directly in animal houses 
with different compartments containing animals receiving different diets. Measurements can either be done in the barn air or in exhaust air chimneys (Ndegwa et al., 2009). The latter is difficult to achieve in ruminants as forced exhaust air systems are not common. Some research institutes have built identical animal compartments where a comprehensive assessment of gaseous $\mathrm{N}$ emissions across the individual compartments is possible (Pollet et al., 1998; Mathot et al., 2012; Mohn et al., 2018). As the number of test compartments is limited to few, this type of equipment is more suitable to generate information about developments with time and to confirm whether effects from balance experiments can be recovered in entire herds.

Once the manure is distributed in the field, other setups are required to measure gaseous emissions. Methods to measure ammonia emissions on top of manure fertilized areas include (1) chambers filled with soil and manure (Misselbrook et al., 2005; Lee et al., 2012a, 2014; Figure 5); (2) wind tunnels where the area is covered with transparent material and standardized air speed is generated by an attached ventilator (developed by Lockyer, 1984); and (3) simple measurement towers completed with gas sampling devices containing acid traps at different altitude above ground (Genermont et al., 1998), or towers equipped to model turbulence via the Eddy covariance technique (Felber et al., 2015;

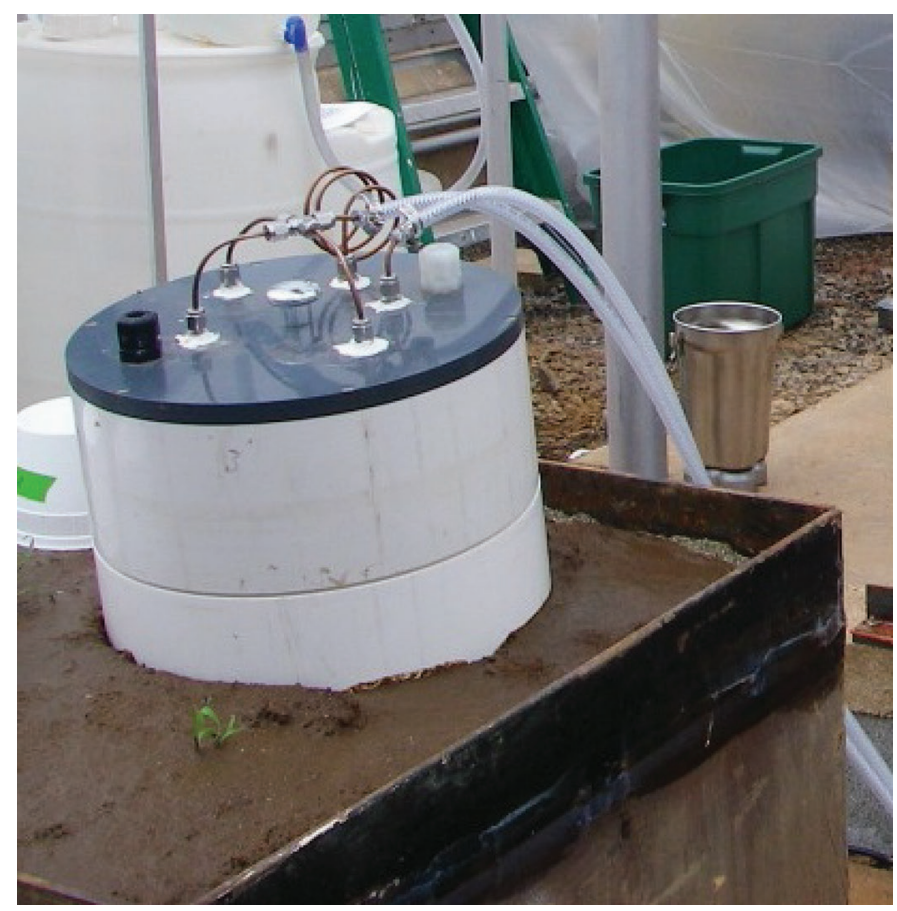

Figure 5. Measurement of ammonia emissions from the surface of manure-amended soil using a vented chamber (Lee et al., 2014; photo provided by A. N. Hristov, The Pennsylvania State University).
Figure 6). For the latter group of methods, the test manure amounts available have to be large.

An indirect approach for estimating ammonia losses from manure is based on $\mathrm{N}$ isotope fractionation as proposed by Hristov et al. (2009b). These authors clearly demonstrated that $\mathrm{N}$ isotope fractionation (discrimination against the heavier $\mathrm{N}$ isotope) takes place during ammonia volatilization from manure, leaving the remaining substrate enriched in ${ }^{15} \mathrm{~N}$. As a result, the ${ }^{15} \mathrm{~N} /{ }^{14} \mathrm{~N}$ ratio in fresh and aged manure can be used to quantitatively estimate ammonia- $\mathrm{N}$ losses during storage.

Arrangements used to determine ammonia emissions can often also be used to measure $\mathrm{N}_{2} \mathrm{O}$ emissions once the appropriate analyzers are installed. It has to be kept in mind that the air concentrations of $\mathrm{N}_{2} \mathrm{O}$ are much lower than those of ammonia. Unlike ammonia, $\mathrm{N}_{2} \mathrm{O}$ does not adsorb to surfaces and therefore can be measured without previous equilibration. Accordingly, the simple and cheap device developed for measuring ammonia emissions from manure by Külling et al. (2001) was modified in a way that $\mathrm{N}_{2} \mathrm{O}$ accumulated

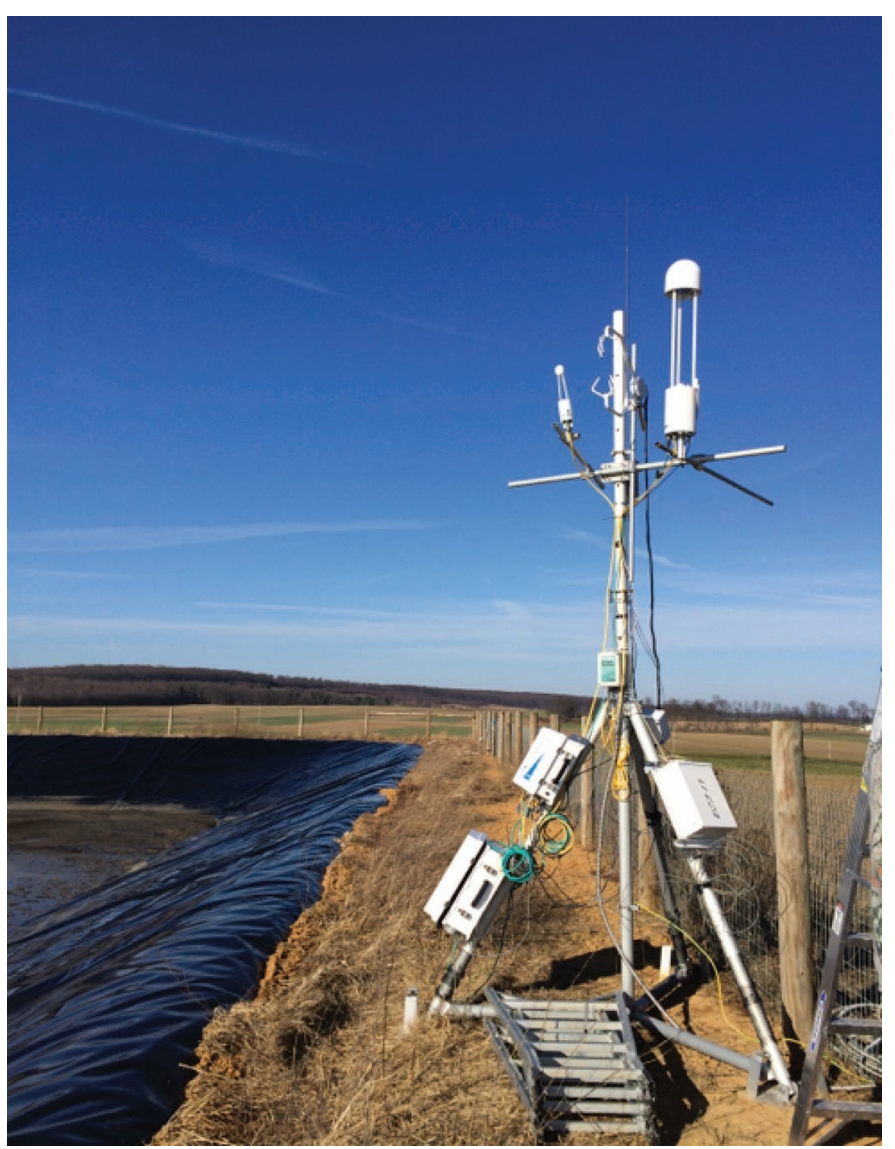

Figure 6. Manure emission measurement at a commercial dairy farm using the Eddy covariance technique (provided by A. N. Hristov, The Pennsylvania State University). 
in the covered bucket is led into a sampling bag by pressing down the top bucket. Sophisticated arrangements are necessary to measure $\mathrm{N}_{2} \mathrm{O}$ emissions from soil fertilized with manure (Fléchard et al., 2005). In the lysimeter experiment by Lee et al. (2014), $\mathrm{N}_{2} \mathrm{O}$ emissions of manure-amended soil were measured using vented chambers and a photoacoustic gas monitor. Usually, longer measurement periods are needed to document effects of manure composition on $\mathrm{N}_{2} \mathrm{O}$ emissions. Formation and release of $\mathrm{N}_{2} \mathrm{O}$ can occur immediately after manure is applied to soil due to denitrification of soil nitrate in the presence of easily degradable manure OM. However, much more additional $\mathrm{N}_{2} \mathrm{O}$ can be produced by denitrification of mineralized and nitrified manure $\mathrm{N}$ with time after manure application (Velthof et al., 2003).

Nitrate leaching from fertilization with manure from individual animals, and its comparative difference between feeding treatments, can be quantified by its recovery in the water pouring from plant pots (in plant pot experiments this run-off water is often put on top to avoid $\mathrm{N}$ losses). For this purpose, standardized soils and watering schemes are required; the pots can be filled with soil only or grown with model plants. For larger-scale experiments, field areas or entire fields can be equipped with drainage pipes. Such lysimeters have been used in relation to animal nutrition, for instance, by Lee et al. (2014). Rough indications of the nitrate leaching potential may be obtained by manure storage experiments aiming at determination of nitrification (Hao et al., 2011).

\section{CONCLUSIONS}

Both continuous and changeover design experiments are suitable for studying protein metabolism in ruminant animals, except when changes in BW or carryover effects due to treatment are expected. In the latter case, changeover designs are not recommended unless experimental periods are sufficiently long and, if needed, include washout periods. The length of adaptation to dietary treatments (at least 2, and preferably 3 , wk) should be considered carefully and may be affected by the contribution of labile body pools that can contribute to rumen $\mathrm{N}$ recycling but are poorly understood. Rumen protein degradability and intestinal digestibility can be estimated using in situ, in vitro, or in vivo techniques, and the pros and cons of each technique are discussed in this review. Techniques for direct determination of rumen MPS are laborious, expensive, and variability in the data can be large; current indirect approaches do not have the accuracy required for widespread adoption. Techniques for studying postruminal digestion and absorption, urea recycling, and mammary
AA metabolism are relatively accurate but laborious, expensive (usually involve isotopes), and results can also be variable. Recycling of urea from blood to the rumen is an important mechanism to increase $\mathrm{N}$ supply to rumen microorganisms. Net flux measurements in blood as well as labeled marker techniques have been used to measure removal of urea from blood to the GIT. Techniques greatly differ in the results obtained and their variability and accuracy, as well as in the various sites of urea removal included. A major source of error is often the determination of digesta or blood flow rate, which is then applied to differences in concentrations at specific sites. Measurements of total-tract $\mathrm{N}$ digestion and body $\mathrm{N}$ balance are labor intensive and prone to substantial measurement error, especially in terms of volatile $\mathrm{N}$ losses during collection, processing, and analysis of samples. Considering concerns over animal welfare, labor requirements, and accuracy of body $\mathrm{N}$ balance measurements based on total collection of excreta, technological innovation and refinement of techniques are needed to identify and minimize sources of experimental error. In studying ruminant $\mathrm{N}$ metabolism, nutritionists should consider the fate of manure $\mathrm{N}$ as well. Practical methods for analyzing manure $\mathrm{N}$ emissions directly or determining the effect of animal nutrition on the ammonia or $\mathrm{N}_{2} \mathrm{O}$ emitting potential of manure, are available allowing such measurements to be done for various types and amounts of manure available from nutrition experiments.

\section{ACKNOWLEDGMENTS}

The authors acknowledge support for preparation of this manuscript by the USDA National Institute of Food and Agriculture, grant/award number: 2014-6700321979, NH00616-R, the Department of Animal Science and College of Agricultural Sciences, The Pennsylvania State University; the Swiss Federal Office of Agriculture, INIA (Spain, project MIT01-GLOBALNETEEZ); Natural Resources Institute Finland (Luke); and Ministry of Agriculture, Nature and Food Quality (the Netherlands), GRA project BO-43-003.02.004.

\section{REFERENCES}

Abbeddou, S., J. Diekmann, B. Rischkowsky, M. Kreuzer, and A Oberson. 2013. Unconventional feeds for small ruminants in dry areas have a minor effect on manure nitrogen flow in the soil-plant system. Nutr. Cycl. Agroecosyst. 95:87-101.

AFRC (Agricultural and Food Research Council). 1992. Nutritive requirements of ruminant animals: Protein. Technical Committee on Responses to Nutrients, Report No. 9. Nutrition Abstracts and Reviews, Series B 62:787-835.

Agle, M., A. N. Hristov, S. Zaman, C. Schneider, P. Ndegwa, and V. K. Vaddella. 2010. The effects of ruminally degraded protein on rumen fermentation and ammonia losses from manure in dairy cows. J. Dairy Sci. 93:1625-1637. 
Agnew, R. E., T. Yan, W. J. McCaughey, J. D. McEvoy, D. C. Patterson, M. G. Porter, and R. W. Steen. 2005. Relationships between urea dilution measurements and body weight and composition of lactating dairy cows. J. Dairy Sci. 88:2476-2486.

Aguerre, M. J., M. A. Wattiaux, T. Hunt, and N. E. Lobos. 2012b. Effect of nitrogen content and additional straw on changes in chemical composition, volatile losses, and ammonia emissions from dairy manure during long-term storage. J. Dairy Sci. 95:3454-3466.

Aguerre, M. J., M. A. Wattiaux, and J. M. Powell. 2012a. Emissions of ammonia, nitrous oxide, methane, and carbon dioxide during storage of dairy cow manure as affected by dietary forage-to-concentrate ratio and crust formation. J. Dairy Sci. 95:7409-7416.

Aguerre, M. J., M. A. Wattiaux, J. M. Powell, G. A. Broderick, and C. Arndt. 2011. Effect of forage-to-concentrate ratio in dairy cow diets on emission of methane, carbon dioxide, and ammonia, lactation performance, and manure excretion. J. Dairy Sci. 94:3081-3093.

Ahvenjärvi, S. 2006. Measurement of digesta flow entering the omasal canal. Pages 587-589 in Ruminant Physiology: Digestion, Metabolism and Impact of Nutrition on Gene Expression, Immunology and Stress. K. Sejrsen, T. Hvelplund, and M. O. Nielson, ed. Wageningen Acad. Publ., Wageningen, the Netherlands.

Ahvenjärvi, S., M. Vaga, A. Vanhatalo, and P. Huhtanen. 2018. Ruminal metabolism of grass silage soluble N fractions. J. Dairy Sci. 101:279-294.

Ahvenjärvi, S., A. Vanhatalo, P. Huhtanen, and T. Varvikko. 2000. Determination of reticulo-rumen and whole-stomach digestion in lactating cows by omasal canal or duodenal sampling. Br. J. Nutr. 83:67-77

Ahvenjärvi, S., A. Vanhatalo, K. J. Shingfield, and P. Huhtanen. 2003. Determination of digesta flow entering the omasal canal of dairy cows using different marker systems. Br. J. Nutr. 90:41-52.

Ahvenjärvi, S., A. Vanhatalo, T. Stefanski, and P. Huhtanen. 2010. Fibre digestion in different segments of the digestive tract of dairy cows fed grass silage based diets. Pages 199-201 in Proc. 1st Nordic Feed Science Conference, SLU Repro, Uppsala, Sweden.

Andrew, S. M., R. A. Erdman, and D. R. Waldo. 1995. Prediction of body composition of dairy cows at three physiological stages from deuterium oxide and urea dilution. J. Dairy Sci. 78:1083-1095.

Andrew, S. M., D. R. Waldo, and R. A. Erdman. 1994. Direct analysis of body composition of dairy cows at three physiological stages. J. Dairy Sci. 77:3022-3033.

Antoniewicz, A. M., W. W. Heinemann, and E. M. Hanks. 1979. Factors affecting allantoin excretion in sheep urine. Ann. Rech. Vet. 10:300-302.

Antoniewicz, A. M., W. W. Heinemann, and E. M. Hanks. 1980. The effect of changes in the intestinal flow of nucleic acids on allantoin excretion in the urine of sheep. J. Agric. Sci. 95:395-400.

Armentano, L. E., and R. W. Russell. 1985. Method for calculating digesta flow and apparent absorption of nutrients from nonrepresentative samples of digesta. J. Dairy Sci. 68:3067-3070.

Arndt, C., J. M. Powell, M. J. Aguerre, and M. A. Wattiaux. 2015. Performance, digestion, nitrogen balance, and emission of manure ammonia, enteric methane, and carbon dioxide in lactating cows fed diets with varying alfalfa silage-to-corn silage ratios. J. Dairy Sci. 98:418-430.

Arriaga, H., G. Salcedo, L. Martinez-Suller, S. Calsamiglia, and P. Merino. 2010. Effect of dietary crude protein modification on ammonia and nitrous oxide concentration on a tie-stall dairy barn floor. J. Dairy Sci. 93:3158-3165.

Ashes, J. R., J. L. Mangan, and G. S. Sidhu. 1984. Nutritional availability of amino acids from protein cross-linked to protect against degradation in the rumen. Br. J. Nutr. 52:239-247.

Aufrère, J., and D. Cartailler. 1988. Mise au point d'une méthode de laboratoire de prévision de la dégradabilité des protéines alimentaires des aliments concentrés dans le rumen. Ann. Zootech. $37: 255-270$.

Aufrère, J., D. Graviou, and C. Demarquilly. 2003. Ruminal degradation of protein of cocksfoot and perennial ryegrass as affected by various stages of growth and conservation methods. Anim. Res. $52: 245-261$.

Baldwin, R. L. 1995. Modeling Ruminant Digestion and Metabolism. Chapman \& Hall, London, UK.
Bannink, A., H. Valk, and A. M. van Vuuren. 1999. Intake and excretion of sodium, potassium, and nitrogen and the effects on urine production by lactating dairy cows. J. Dairy Sci. 82:1008-1018.

Bannink, A., H. J. van Lingen, J. L. Ellis, J. France, and J. Dijkstra. 2016. The contribution of mathematical modeling to understanding dynamic aspects of rumen metabolism. Front. Microbiol. $7: 1820$.

Batista, E. D., E. Detmann, S. C. Valadares Filho, E. C. Titgemeyer, and R. F. D. Valadares. 2017. The effect of CP concentration in the diet on urea kinetics and microbial usage of recycled urea in cattle: A meta-analysis. Animal 11:1303-1311.

Bello, N. M., M. Kramer, R. J. Tempelman, W. W. Stroup, N. R. St-Pierre, B. A. Craig, L. J. Young, and E. E. Grub. 2016. Short communication: On recognizing the proper experimental unit in animal studies in the dairy sciences. J. Dairy Sci. 99:8871-8879.

Bequette, B. J., F. R. Backwell, and L. A. Crompton. 1998. Current concepts of amino acid and protein metabolism in the mammary gland of the lactating ruminant. J. Dairy Sci. 81:2540-2559.

Bequette, B. J., J. A. Metcalf, D. Wray-Cahen, F. R. Backwell, J. D. Sutton, M. A. Lomax, J. C. Macrae, and G. E. Lobley. 1996. Leucine and protein metabolism in the lactating dairy cow mammary gland: responses to supplemental dietary crude protein intake. J. Dairy Res. 63:209-222.

Bergen, W. G. 2007. Contribution of research with farm animals to protein metabolism concepts: a historical perspective. J. Nutr. 137:706-710.

Bergman, E. N. 1975. Production and utilisation of metabolites by the alimentary tract as measured in portal and hepatic blood. Page 292 in Digestion and Metabolism in the Ruminant. I. W. McDonald and A. C. I. Warner, ed. The University of New England, Armidale, Australia.

Berthiaume, R., P. Dubreuil, M. Stevenson, B. W. McBride, and H. Lapierre. 2001. Intestinal disappearance and mesenteric and portal appearance of amino acids in dairy cows fed ruminally protected methionine. J. Dairy Sci. 84:194-203.

Biddle, G. N., J. L. Evans, and J. R. Trout. 1975. Labile nitrogen reserves and plasma nitrogen fractions in growing cattle. J. Nutr. 105:1584-1591.

Blaxter, K. L. 1967. Nutrition balance techniques and their limitations. Proc. Nutr. Soc. 26:86-96.

Blaxter, K. L., and H. H. Mitchell. 1948. The factorization of the protein requirements of ruminants and of the protein values of feeds, with particular reference to the significance of the metabolic fecal nitrogen. J. Anim. Sci. 7:351-372.

Botts, R. L., R. W. Hemken, and L. S. Bull. 1979. Protein reserves in the lactating dairy cow. J. Dairy Sci. 62:433-440.

Bougouin, A., A. Leytem, J. Dijkstra, R. S. Dungan, and E. Kebreab. 2016. Nutritional and environmental effects on ammonia emissions from dairy cattle housing: A meta-analysis. J. Environ. Qual. 45:1123-1132.

Brandt, M., K. Rohr, and P. Lebzien. 1980. Determination of microbial protein synthesized in the rumen by means of $15 \mathrm{~N}$. Pages 496-503 in Protein Metabolism and Nutrition. H. J. Oslage and K. Rohr, ed. EAAP Publication No. 23, Rome, Italy.

Broderick, G. A. 1982. Estimation of protein degradation using in situ and in vitro methods. Pages $72-80$ in Proceedings of an International Symposium on Protein Requirements for Cattle. F. N. Owens, ed. Oklahoma State University, Stillwater, OK.

Broderick, G. A. 1987. Determination of protein degradation rates using a rumen in vitro system containing inhibitors of microbial nitrogen metabolism. Br. J. Nutr. 58:463-475.

Broderick, G. A. 1994. Quantifying forage protein quality. Pages 200228 in Forage Quality, Evaluation and Utilization. G. C. Fahey Jr., M. Collins, D. R. Mertens, and L. E. Moser, ed. American Society of Agronomy, Madison, WI.

Broderick, G. A., and R. C. Cochran. 2000. In vitro and in situ methods for estimating digestibility with reference to protein degradability. Pages 53-85 in Feeding Systems and Feed Evaluation Models. M. K. Theodorou and J. France, ed. CAB International, Wallingford, UK.

Broderick, G. A., P. Huhtanen, S. Ahvenjärvi, S. M. Reynal, and K. J. Shingfield. 2010. Quantifying ruminal nitrogen metabolism using 
the omasal sampling technique in cattle-a meta-analysis. J. Dairy Sci. 93:3216-3230.

Broderick, G. A., and N. R. Merchen. 1992. Markers for quantifying microbial protein synthesis in the rumen. J. Dairy Sci. 75:26182632.

Broderick, G. A., P. Uden, M. L. Murphy, and A. Lapins. 2004. Sources of variation in rates of in vitro ruminal protein degradation. J. Dairy Sci. 87:1345-1359.

Brown, A. N., and W. P. Weiss. 2014. Effects of oscillating the crude protein content in dairy cow rations. J. Dairy Sci. 97(E-Suppl. 1):169. (Abstr.)

Bucholtz, H. F., and W. G. Bergen. 1973. Microbial phospholipid synthesis as a marker for microbial protein synthesis in the rumen. Appl. Microbiol. 25:504-513.

Bueno, I. C. S., S. L. S. C. Filho, S. P. Gobbo, H. Louvandini, D. M. S. S. Vitti, and A. L. Abdalla. 2005. Influence of inoculum source in a gas production method. Anim. Feed Sci. Technol. 123:95-105.

Calsamiglia, S., and M. D. Stern. 1995. A three-step in vitro procedure for estimating intestinal digestion of protein in ruminants. J. Anim. Sci. 73:1459-1465.

Calsamiglia, S., I. K. Yoon, and M. D. Stern. 1994. Effect of various incubation times on in situ estimation of ruminal crude protein degradation. J. Anim. Sci. 72(Suppl. 1):171.

Cameron, K. C., H. J. Di, and J. L. Moir. 2013. Nitrogen losses from the soil/plant system: A review. Ann. Appl. Biol. 162:145-173.

Cant, J. P., E. J. DePeters, and R. L. Baldwin. 1993. Mammary amino acid utilization in dairy cows fed fat and its relationship to milk protein depression. J. Dairy Sci. 76:762-774.

Chen, G., C. J. Sniffen, and J. B. Russell. 1987. Concentration and estimated flow of peptides from the rumen of dairy cattle: Effects of protein quantity, protein solubility, and feeding frequency. J. Dairy Sci. 70:983-992.

Chen, X. B., F. D. Hovell, E. R. Orskov, and D. S. Brown. 1990. Excretion of purine derivatives by ruminants: Effect of exogenous nucleic acid supply on purine derivative excretion by sheep. Br. J. Nutr. 63:131-142.

Chen, X. B., A. T. Mejia, D. J. Kyle, and E. R. Ørskov. 1995. Evaluation of the use of the purine derivative: creatinine ratio in spot urine and plasma samples as an index of microbial protein supply in ruminants: Studies in sheep. J. Agric. Sci. 125:137-143.

Chiavegato, M. B., W. Powers, and N. Palumbo. 2015. Ammonia and greenhouse gas emissions from housed Holstein steers fed different levels of diet crude protein. J. Anim. Sci. 93:395-404.

Clark, J. H., T. H. Klusmeyer, and M. R. Cameron. 1992. Microbial protein synthesis and flows of nitrogen fractions to the duodenum of dairy cows. J. Dairy Sci. 75:2304-2323.

Clauss, M., and J. Hummel. 2017. Physiological adaptations of ruminants and their potential relevance for production systems. Rev. Bras. Zootec. 46:606-613. https://doi.org/10.1590/s1806 $-92902017000700008$

Coblentz, W. K., K. P. Coffey, J. E. Turner, D. A. Scarbrough, J. V. Skinner, D. W. Kellogg, and J. B. Humphry. 2002. Comparisons of in situ dry matter disappearance kinetics of wheat forages harvested by various techniques and evaluated in confined and grazing steers. J. Dairy Sci. 85:854-865.

Cochran, W. G., and G. M. Cox. 1992. Experimental Designs. 2nd ed. John Wiley \& Sons Inc., Hoboken, NJ.

Cone, J. W., M. A. M. Rodrigues, C. M. Guedes, and M. C. Blok 2009. Comparison of protein fermentation characteristics in rumen fluid determined with the gas production technique and the nylon bag technique. Anim. Feed Sci. Technol. 153:28-38.

Crompton, L. A., J. France, C. K. Reynolds, J. A. Mills, M. D. Hanigan, J. L. Ellis, A. Bannink, B. J. Bequette, and J. Dijkstra. 2014 An isotope dilution model for partitioning phenylalanine and tyrosine uptake by the mammary gland of lactating dairy cows. J. Theor. Biol. 359:54-60.

Darragh, A. J., and P. J. Moughan. 2005. The effect of hydrolysis time on amino acid analysis. J. AOAC Int. 88:888-893.

Davis, S. R., and R. Bickerstaffe. 1978. Mammary glucose uptake in the lactating ewe and the use of methionine arterio-venous difference for the calculation of mammary blood flow. Aust. J. Biol. Sci. $31: 133-139$
Davis, S. R., and R. J. Collier. 1985. Mammary blood flow and regulation of substrate supply for milk synthesis. J. Dairy Sci. 68:10411058.

Davis, S. R., R. J. Collier, J. P. McNamara, H. H. Head, and W. Sussman. 1988. Effects of thyroxine and growth hormone treatment of dairy cows on milk yield, cardiac output and mammary blood flow. J. Anim. Sci. 66:70-79.

De Jonge, L. H., J. W. Spek, H. van Laar, and J. Dijkstra. 2009. Effects of $\mathrm{pH}$, temperature and osmolality on the level and composition of soluble $\mathrm{N}$ in feedstuffs for ruminants. Anim. Feed Sci. Technol. 153:249-262.

De Jonge, L. H., H. van Laar, W. H. Hendriks, and J. Dijkstra. 2013. A modified rinsing method for the determination of the S, W-S and $\mathrm{D}+\mathrm{U}$ fraction of protein and starch in feedstuff within the in situ technique. Animal 7:1289-1297.

De Jonge, L. H., H. van Laar, W. H. Hendriks, and J. Dijkstra. 2015. A new approach to estimate the in situ fractional degradation rate of organic matter and nitrogen in wheat yeast concentrates. Animal 9:437-444.

De Ondarza, M. B., and C. J. Sniffen. 2002. A new method to estimate microbial nitrogen escape from the rumen of the dairy cow. Anim. Feed Sci. Technol. 101:201-214.

Denton, B. L., L. E. Diese, J. L. Firkins, and T. J. Hackmann. 2015. Accumulation of reserve carbohydrate by rumen protozoa and bacteria in competition for glucose. Appl. Environ. Microbiol. $81: 1832-1838$

de Souza, J., H. Leskinen, K. J. Shingfield, A. L. Lock, and P. Huhtanen. 2018. Changes in the omasal flow of long-chain fatty acids alters the yield of de novo and preformed milk fatty acids. J. Dairy Sci. 101(Suppl. 2):160.

Devant, M., A. Ferret, S. Calsamiglia, R. Casals, and J. Gasa. 2001. Effect of nitrogen source in high-concentrate, low-protein beef cattle diets on microbial fermentation studied in vivo and in vitro. J. Anim. Sci. 79:1944-1953.

Dewhurst, R. J., D. R. Davies, and R. J. Merry. 2000. Microbial protein supply from the rumen. Anim. Feed Sci. Technol. 85:1-21.

Dewhurst, R. J., J. M. Moorby, B. Vlaeminck, and V. Fievez. 2007. Apparent recovery of duodenal odd- and branched-chain fatty acids in milk of dairy cows. J. Dairy Sci. 90:1775-1780.

Dieho, K., B. van den Bogert, G. Henderson, A. Bannink, J. RamiroGarcia, H. Smidt, and J. Dijkstra. 2017. Changes in rumen microbiota composition and in situ degradation kinetics during the dry period and early lactation as affected by rate of increase of concentrate allowance. J. Dairy Sci. 100:2695-2710.

Dijkstra, J., A. Bannink, P. M. Bosma, E. A. Lantinga, and J. W. Reijs. 2018. Modelling the effect of nutritional strategies for dairy cows on the composition of excreta nitrogen. Front. Sustain. Food Syst. 2:63

Dijkstra, J., J. France, and D. R. Davies. 1998. Different mathematical approaches to estimating microbial protein supply in ruminants. J. Dairy Sci. 81:3370-3384.

Dijkstra, J., H. D. Neal, D. E. Beever, and J. France. 1992. Simulation of nutrient digestion, absorption and outflow in the rumen: Model description. J. Nutr. 122:2239-2256.

Dijkstra, J., O. Oenema, J. W. van Groenigen, J. W. Spek, A. M. van Vuuren, and A. Bannink. 2013. Diet effects on urine composition of cattle and $\mathrm{N}_{2} \mathrm{O}$ emissions. Animal 7(Suppl. 2):292-302.

Doepel, L., and H. Lapierre. 2010. Changes in production and mammary metabolism of dairy cows in response to essential and nonessential amino acid infusions. J. Dairy Sci. 93:3264-3274.

Edmunds, B., K. H. Südekum, H. Spiekers, M. Schuster, and F. J. Schwarz. 2012. Estimating utilisable crude protein at the duodenum, a precursor to metabolisable protein for ruminants, from forages using a modified gas test. Anim. Feed Sci. Technol. 175:106113.

El-Kadi, S. W., R. L. Baldwin VI, N. E. Sunny, S. L. Owens, and B. J. Bequette. 2006. Intestinal protein supply alters amino acid but not glucose, metabolism by the sheep gastrointestinal tract. J. Nutr. 136:1261-1269.

Elliott, R. C., and J. H. Topps. 1963. Nitrogen metabolism of African cattle fed diets with an adequate energy, low-protein content. Nature 197:668-670. 
Ellis, W. C., J. H. Matis, T. M. Hill, and M. R. Murphy. 1994. Methodology for estimating digestion and passage kinetics of forages. Pages 682-756 in Forage Quality, Evaluation and Utilization. G. C. Fahey Jr., M. Collins, D. R. Mertens, and L. E. Moser, ed. American Society of Agronomy, Madison, WI.

Emery, R. S., L. D. Brown, and J. W. Bell. 1965. Correlation of milk fat with dietary and metabolic factors in cows fed restricted-roughage rations supplemented with magnesium oxide or sodium bicarbonate. J. Dairy Sci. 48:1647-1651.

Eriksson, T., and B.-O. Rustas. 2014. Effects on milk urea concentration, urine output, and drinking water intake from incremental doses of potassium bicarbonate fed to mid-lactation dairy cows. J. Dairy Sci. 97:4471-4484.

Estermann, B. L., F. Sutter, P. O. Schlegel, D. Erdin, H. R. Wettstein, and M. Kreuzer. 2002. Effect of calf age and dam breed on intake, energy expenditure, and excretion of nitrogen, phosphorus, and methane of beef cows with calves. J. Anim. Sci. 80:1124-1134.

Estes, K. A., R. R. White, P. S. Yoder, T. Pilonero, H. Schramm, H. Lapierre, and M. D. Hanigan. 2018. An in vivo stable isotopebased approach for assessment of absorbed amino acids from individual feed ingredients within complete diets. J. Dairy Sci. 101:7040-7060.

Faichney, G. J. 1975. The use of markers to partition digestion within the gastrointestinal tract of ruminants. Pages 277-291 in Digestion and Metabolism in the Ruminant. I. W. McDonald and A. C. I. Warner, ed. University of New England Publishing Unit, Armidale, New South Wales, Australia.

Faichney, G. J. 2005. Digesta flow. Pages 49-86 in Quantitative Aspects of Ruminant Digestion and Metabolism. J. Dijkstra, J. M. Forbes, and J. France, ed. CAB International, University Press, Cambridge, UK.

Fanchone, A., P. Nozière, J. Portelli, B. Duriot, V. Largeau, and M. Doreau. 2013. Effects of nitrogen underfeeding and energy source on nitrogen ruminal metabolism, digestion, and nitrogen partitioning in dairy cows. J. Anim. Sci. 91:895-906.

FAO (Food and Agriculture Organization of the United Nations). 2015. World fertilizer trends and outlook to 2018. FAO, Rome, Italy.

Farenzena, R., G. V. Kozloski, M. Gindri, and S. Stefanello. 2017. Minimum length of the adaptation and collection period in digestibility trials with sheep fed ad libitum only forage or forage plus concentrate. J. Anim. Physiol. Anim. Nutr. (Berl.) 101:1057-1066.

Fatehi, F., S. J. Krizsan, H. Gidlund, and P. Huhtanen. 2015. A comparison of ruminal or reticular digesta sampling as an alternative to sampling from the omasum of lactating dairy cows. J. Dairy Sci. 98:3274-3283.

Felber, R., A. Muenger, A. Neftel, and C. Ammann. 2015. Eddy covariance methane flux measurements over a grazed pasture: Effect of cows as moving point sources. Biogeosciences 12:3925-3940.

Fellner, V., M. F. Weiss, A. T. Belo, R. L. Belyea, F. A. Martz, and A. H. Orma. 1988. Urine cup for collection of urine from cows. J. Dairy Sci. 71:2250-2255.

Fernando, S. C., H. T. Purvis II, F. Z. Najar, L. O. Sukharnikov, C. R. Krehbiel, T. G. Nagaraja, B. A. Roe, and U. Desilva. 2010. Rumen microbial population dynamics during adaptation to a high-grain diet. Appl. Environ. Microbiol. 76:7482-7490.

Fessenden, S. W., T. J. Hackmann, D. A. Ross, A. Foskolos, and M. E. Van Amburgh. 2017. Ruminal bacteria and protozoa composition, digestibility, and amino acid profile determined by multiple hydrolysis times. J. Dairy Sci. 100:7211-7226.

Fievez, V., E. Colman, J. M. Castro-Montoya, I. Stefanov, and B. Vlaeminck. 2012. Milk odd- and branched-chain fatty acids as biomarkers of rumen function-An update. Anim. Feed Sci. Technol. $172: 51-65$

Firkins, J. L., M. S. Allen, B. S. Oldick, and N. R. St-Pierre. 1998. Modeling ruminal digestibility of carbohydrates and microbial protein flow to the duodenum. J. Dairy Sci. 81:3350-3369.

Firkins, J. L., A. N. Hristov, M. B. Hall, and G. A. Varga. 2005. Integration of ruminal metabolism in dairy cattle. J. Dairy Sci. 89(E-Suppl. 1):E31-E51.

Firkins, J. L., and C. K. Reynolds. 2005. Whole animal nitrogen balance in cattle. Pages 167-186 in Nitrogen and Phosphorus Nutri- tion of Cattle and the Environment. E. Pfeffer and A. N. Hristov, ed. CAB International, Wallingford, UK.

Flachowsky, G., and P. Lebzien. 2006. Possibilities for reduction of nitrogen $(\mathrm{N})$ excretion from ruminants and the need for further research - A review. Landbauforsch. Völk. 56:19-30.

Flatt, W. P., P. J. Van Soest, J. F. Sykes, and L. A. Moore. 1958. A description of the energy metabolism laboratory at the U.S. Department of Agriculture Research Center in Beltsville, Maryland. Pages 53-64 in Proc. Int. Symposium on Energy Metabolism: Principles, Methods and General Aspects. G. Torbeck and H. Aersoe, ed. Statens Husdyrbrugsudvalg. Copenhagen, Denmark.

Fléchard, C. R., A. Neftel, M. Jocher, C. Ammann, and J. Fuhrer. 2005. Bi-directional soil/atmosphere $\mathrm{N} 2 \mathrm{O}$ exchange over two mown grassland systems with contrasting management practices. Glob. Change Biol. 11:2114-2127.

Fonseca, A. C., S. M. Fredin, L. F. Ferraretto, C. M. Parsons, P. L. Utterback, and R. D. Shaver. 2014. Short communication: Intestinal digestibility of amino acids in fluid- and particle-associated rumen bacteria determined using a precision-fed cecectomized rooster bioassay. J. Dairy Sci. 97:3855-3859.

France, J., and R. C. Siddons. 1986. Determination of digesta flow by continuous market infusion. J. Theor. Biol. 121:105-119.

French, E. A., S. J. Bertics, and L. E. Armentano. 2012. Rumen and milk odd- and branched-chain fatty acid proportions are minimally influenced by ruminal volatile fatty acid infusions. J. Dairy Sci. 95:2015-2026.

Galyean, M. L., and L. O. Tedeschi. 2014. Predicting microbial protein synthesis in beef cattle: relationship to intakes of total digestible nutrients and crude protein. J. Anim. Sci. 92:5099-5111.

Gargallo, S., S. Calsamiglia, and A. Ferret. 2006. Technical note: A modified three-step in vitro procedure to determine intestinal digestion of proteins. J. Anim. Sci. 84:2163-2167.

Genermont, S., P. Cellier, D. Flura, T. Morvan, and P. Laville. 1998 Measuring ammonia fluxes after slurry spreading under actual field conditions. Atmos. Environ. 32:279-284.

Giallongo, F., A. N. Hristov, J. Oh, T. Frederick, H. Weeks, J. Werner, H. Lapierre, R. A. Patton, A. Gehman, and C. Parys. 2015a. Effects of slow-release urea and rumen-protected methionine and histidine on performance of dairy cows. J. Dairy Sci. 98:3292-3308.

Giallongo, F., J. Oh, T. Frederick, B. Isenberg, D. M. Kniffen, R. A. Fabin, and A. N. Hristov. 2015b. Extruded soybean meal increased feed intake and milk production in dairy cows. J. Dairy Sci. 98:6471-6485.

Gibb, M. J., W. E. Ivings, M. S. Dhanoa, and J. D. Sutton. 1992. Changes in body components of autumn-calving Holstein-Friesian cows over the first 29 weeks of lactation. Anim. Sci. 55:339-360.

Gidlund, H., M. Vaga, S. Ahvenjärvi, M. Rinne, M. Ramin, and P. Huhtanen. 2018. Predicting omasal flow of nonammonia N and milk protein yield from in vitro-determined utilizable crude protein at the duodenum. J. Dairy Sci. 101:1164-1176.

Giesecke, D., L. Ehrentreich, M. Stangassinger, and F. Ahrens. 1994. Mammary and renal excretion of purine metabolites in relation to energy intake and milk yield in dairy cows. J. Dairy Sci. 77:23762381.

Gorewit, R. C., M. C. Aromando, and D. G. Bristol. 1989. Measuring bovine mammary gland blood flow using a transit time ultrasonic flow probe. J. Dairy Sci. 72:1918-1928.

Grant, R. J., H. M. Dann, and M. E. Woolpert. 2015. Time required for adaptation of behavior, feed intake, and dietary digestibility in cattle. J. Dairy Sci. 98(Suppl. 2):312. (Abstr.)

Guevara-González, J. A., J. González, J. M. Arroyo, V. J. Moya, and O. Piquer. 2013. Effects of the correction of particle microbial contamination and particle transit model in the rumen on in situ protein evaluation of grass hays. Anim. Prod. Sci. 53:134-141.

Guinard, J., H. Rulquin, and R. Vérité. 1994. Effect of graded levels of duodenal infusions of casein on mammary uptake in lactating cows. 1. Major nutrients. J. Dairy Sci. 77:2221-2231.

Hao, X., M. B. Benke, C. Li, F. J. Larney, K. A. Beauchemin, and T. A. McAllister. 2011. Nitrogen transformations and greenhouse gas emissions during composting of manure from cattle fed diets containing corn dried distillers grains with solubles and condensed tannins. Anim. Feed Sci. Technol. 166-167:539-549. 
Harmon, D. L., and C. J. Richards. 1997. Considerations for gastrointestinal cannulations in ruminants. J. Anim. Sci. 75:2248-2255.

Hatew, B., J. W. Cone, W. F. Pellikaan, S. C. Podesta, A. Bannink, W. H. Hendrik, and J. Dijkstra. 2015. Relationship between in vitro and in vivo methane production measured simultaneously with different dietary starch sources and starch levels in dairy cattle. Anim. Feed Sci. Technol. 202:20-31.

Hegsted, D. M. 1976. Balance studies. J. Nutr. 106:307-311.

Henderson, G., F. Cox, S. Kittelmann, V. H. Miri, M. Zethof, S. J. Noel, G. C. Waghorn, and P. H. Janssen. 2013. Effect of DNA extraction methods and sampling techniques on the apparent structure of cow and sheep rumen microbial communities. PLoS One 8:e74787. https://doi.org/10.1371/journal.pone.0074787.

Herbert, D., R. Elsworth, and R. C. Telling. 1956. The continuous culture of bacteria; a theoretical and experimental study. J. Gen. Microbiol. 14:601-622.

Hetta, M., M. N. Tahir, S. J. Krizsan, A. Puranen, and P. Huhtanen. 2013. Effects of $\mathrm{NaOH}$-treated wheat and a mixture of barley and oats on the voluntary feed intake and milk production in dairy cows. Livest. Sci. 154:103-111.

Hindle, V. A., A. M. Van Vuuren, A. Klop, A. Mathijssen-Kamman, A. H. Van Gelder, and J. W. Cone. 2005. Site and extent of starch degradation in the dairy cow - A comparison between in vivo, in situ and in vitro measurements. J. Anim. Physiol. Anim. Nutr. (Berl.) 89:158-165.

Hindrichsen, I. K., H. R. Wettstein, A. Machmuller, B. Jorg, and M. Kreuzer. 2005. Effect of the carbohydrate composition of feed concentrates on methane emission from dairy cows and their slurry. Environ. Monit. Assess. 107:329-350.

Hindrichsen, I. K., H. R. Wettstein, A. Machmüller, and M. Kreuzer. 2006. Methane emission, nutrient degradation and nitrogen turnover in dairy cows and their slurry at different milk production scenarios with and without concentrate supplementation. Agric. Ecosyst. Environ. 113:150-161.

Hobbs, C. S., S. L. Hansard, and E. R. Barrick. 1950. Simplified methods and equipment used in separation of urine from feces eliminated by heifers and by steers. J. Anim. Sci. 9:565-570.

Hoogenraad, N. J., and F. J. Hird. 1970. The chemical composition of rumen bacteria and cell walls from rumen bacteria. Br. J. Nutr. 24:119-127.

Hook, S. E., J. France, and J. Dijkstra. 2017. Further assessment of the protozoal contribution to the nutrition of the ruminant animal. J. Theor. Biol. 416:8-15.

Hristov, A. N. 2007. Comparative characterization of reticular and duodenal digesta and possibilities of estimating microbial outflow from the rumen based on reticular sampling in dairy cows. J. Anim. Sci. 85:2606-2613.

Hristov, A. N. 2011. Contribution of ammonia emitted from livestock to atmospheric $\mathrm{PM}_{2.5}$ in the United States. J. Dairy Sci. 94:31303136 .

Hristov, A. N., and G. A. Broderick. 1994. In vitro determination of ruminal protein degradability using $15 \mathrm{~N}$ ammonia to correct for microbial nitrogen uptake. J. Anim. Sci. 72:1344-1354.

Hristov, A. N., and G. A. Broderick. 1996. Synthesis of microbial protein in ruminally cannulated cows fed alfalfa silage, alfalfa hay or corn silage. J. Dairy Sci. 79:1627-1637.

Hristov, A. N., R. P. Etter, J. K. Ropp, and K. L. Grandeen. 2004a. Effect of dietary crude protein level and degradability on ruminal fermentation and nitrogen utilization in lactating dairy cows. J. Anim. Sci. 82:3219-3229.

Hristov, A. N., K. L. Grandeen, J. K. Ropp, and M. A. McGuire. 2004b. Effect of sodium laurate on ruminal fermentation and utilization of ruminal ammonia nitrogen for milk protein synthesis in dairy cows. J. Dairy Sci. 87:1820-1831.

Hristov, A. N., M. Hanigan, A. Cole, R. Todd, T. A. McAllister, P. M. Ndegwa, and A. Rotz. 2011. Ammonia emissions from dairy farms and beef feedlots: A review. Can. J. Anim. Sci. 91:1-35.

Hristov, A. N., K. Heyler, E. Schurman, K. Griswold, P. Topper, M. Hile, V. Ishler, E. Fabian-Wheeler, and S. Dinh. 2015. Reducing dietary protein decreased the ammonia emitting potential of manure from commercial dairy farms. Prof. Anim. Sci. 31:68-79.
Hristov, A. N., P. Huhtanen, L. M. Rode, S. N. Acharya, and T. A. McAllister. 2001. Comparison of the ruminal metabolism of nitrogen from $15 \mathrm{~N}$-labeled alfalfa preserved as hay or as silage. J. Dairy Sci. 84:2738-2750.

Hristov, A. N., and J. P. Jouany. 2005. Factors affecting the efficiency of nitrogen utilization in the rumen. E. Pfeffer and A. N. Hristov, ed. Pages 117-166 in Nitrogen and Phosphorus Nutrition of Cattle: Reducing the Environmental Impact of Cattle Operations. CAB International, Wallingford, UK.

Hristov, A. N., C. Lee, R. A. Hristova, P. Huhtanen, and J. Firkins. 2012. A meta-analysis of the variability in continuous culture rumen fermentation and digestibility data. J. Dairy Sci. 95:52995307 .

Hristov, A. N., and T. A. McAllister. 2001. In vitro rates of bacterial incorporation of nitrogen fractions from ${ }^{15} \mathrm{~N}$-labeled whole-crop barley ensiled at two dry matter contents. J. Anim. Sci. 79(Suppl. 1):360.

Hristov, A. N., T. A. McAllister, D. R. Ouellet, and G. A. Broderick. 2005a. Comparison of purines and nitrogen-15 as microbial flow markers in beef heifers fed barley- or corn-based diets. Can. J. Anim. Sci. 85:211-222.

Hristov, A. N., and J. K. Ropp. 2003. Effect of dietary carbohydrate composition and availability on utilization of ruminal ammonia nitrogen for milk protein synthesis in dairy cows. J. Dairy Sci. $86: 2416-2427$.

Hristov, A. N., J. K. Ropp, K. L. Grandeen, S. Abedi, R. P. Etter, A. Melgar, and A. E. Foley. 2005b. Effect of carbohydrate source on ammonia utilization in lactating dairy cows. J. Anim. Sci. 83:408-421.

Hristov, A. N., M. Vander Pol, M. Agle, S. Zaman, C. Schneider, P. Ndegwa, V. K. Vaddella, K. Johnson, K. J. Shingfield, and S. K. R. Karnati. 2009a. Effect of lauric acid and coconut oil on ruminal fermentation, digestion, ammonia losses from manure, and milk fatty acid composition in lactating cows. J. Dairy Sci. 92:5561-5582.

Hristov, A. N., S. Zaman, M. Vander Pol, L. Campbell, P. Ndegwa, and S. Silva. 2009b. Nitrogen losses from dairy manure estimated through nitrogen mass balance or using markers. J. Environ. Qual. $38: 2438-2448$

Huhtanen, P. 2005. Critical aspects of feed protein evaluation systems for ruminants. J. Anim. Feed Sci. 14:145-170.

Huhtanen, P., S. Ahvenjärvi, G. A. Broderick, S. M. Reynal, and K. J. Shingfield. 2010. Quantifying ruminal digestion of organic matter and neutral detergent fiber using the omasal sampling technique in cattle-A meta-analysis. J. Dairy Sci. 93:3203-3215.

Huhtanen, P., S. Ahvenjärvi, M. R. Weisbjerg, and P. N. Ørgaard. 2006. Digestion and passage of fibre in ruminants. Pages $87-138$ in Ruminant Physiology: Digestion, Metabolism and Impact of Nutrition on Gene Expression, Immunology and Stress. K. Sejrsen, T. Hvelplund, and M. O. Nielson, ed. Wageningen Acad. Publ., Wageningen, the Netherlands.

Huhtanen, P., A. R. Bayat, S. J. Krizsan, and A. Vanhatalo. 2014 Compartmental flux and in situ methods underestimate total feed nitrogen as judged by the omasal sampling method due to ignoring soluble feed nitrogen flow. Br. J. Nutr. 111:535-546.

Huhtanen, P., P. G. Brotz, and L. D. Satter. 1997. Omasal sampling technique for assessing fermentative digestion in the forestomach of dairy cows. J. Anim. Sci. 75:1380-1392.

Huhtanen, P., and M. Hetta. 2012. Comparison of feed intake and milk production responses in continuous and change-over design dairy cow experiments. Livest. Sci. 143:184-194.

Huhtanen, P., and A. N. Hristov. 2001. Estimating passage kinetics using fibre-bound $15 \mathrm{~N}$ as an internal marker. Anim. Feed Sci. Technol. 94:29-41.

Huhtanen, P., and A. N. Hristov. 2009. A meta-analysis of the effects of dietary protein concentration and degradability on milk protein yield and milk N efficiency in dairy cows. J. Dairy Sci. 92:3222-3232

Huntington, G. B., C. K. Reynolds, and B. H. Stroud. 1989. Techniques for measuring blood flow in splanchnic tissues of cattle. J. Dairy Sci. 72:1583-1595. 
Hvelplund, T., J. Andrieu, M. R. Weisbjerg, and M. Vermorel. 1995. Prediction of the energy and protein value of forages for ruminants. Pages 205-227 in Recent developments in the nutrition of herbivores. M. Journet, E. Grenet, M-H. Farce, M. Theriez, and C. Demarquilly, ed. INRA Editions, Paris, France.

Hvelplund, T., F. D. De, B. Hovel, E. R. Ørskov, and D. J. Kyle. 1994. True intestinal digestibility of protein estimated with sheep on intragastric infusion and with the mobile bag technique. Proc. Soc. Nutr. Phys. 3:64.

Hvelplund, T., and M. Hesselholt. 1987. Digestibility of individual amino acids in rumen microbial protein and undegraded dietary protein in the small intestine of sheep. Acta Agric. Scand. 37:469477.

Hvelplund, T., and M. R. Weisbjerg. 1998. In vitro techniques to replace in vivo methods for estimating amino acid supply. Page 131 in In Vitro Techniques for Measuring Nutrient Supply to Ruminants. E. R. Deaville, E. Owen, A. T. Adesogan, C. Rymer, J. A. Huntington, and T. L. J. Lawrence, ed. Occasional Pub. No. 22, Br. Soc. of Anim. Sci. Proc., July 1997, Univ. of Reading, UK.

Hvelplund, T., M. R. Weisbjerg, and L. S. Andersen. 1992. Estimation of the true digestibility of rumen undegraded protein in the small intestine of ruminants by the mobile bag technique. Acta Agric. Scand. A. Anim. Sci. 42:34-39.

INRA. 1989. Ruminant nutrition: Recommended allowance and feed tables. John Libbey Eurotext, Montrouge, France.

INRA. 2007. Alimentation des Bovins Ovins Caprins: Besoins des Animaux et Tables des Aliments. Editions QUAE, Versailles, France.

INRA. 2018. INRA feeding system for ruminants. Wageningen Academic Publishers, Wageningen, the Netherlands.

Johnson, D. E. 1986. Fundamentals of whole animal calorimetry: Use in monitoring body tissue deposition. J. Anim. Sci. 63(Suppl. 2):111-114.

Jorgensen, G. N., and B. L. Larson. 1968. Conversion of phenylalanine to tyrosine in the bovine mammary secretory cell. Biochim. Biophys. Acta 165:121-126.

Kamoun, M., H. Ammar, A. Théwis, Y. Beckers, J. France, and S. López. 2014. Comparison of three $15 \mathrm{~N}$ methods to correct for microbial contamination when assessing in situ protein degradability of fresh forages. J. Anim. Sci. 92:5053-5062.

Karlsson, L., M. Hetta, P. Udén, and K. Martinsson. 2009. New methodology for estimating rumen protein degradation using the in vitro gas production technique. Anim. Feed Sci. Technol. 153:193202.

Keeney, M., I. Katz, and M. J. Allison. 1962. On the probable origin of some milk fat acids in rumen microbial lipids. J. Am. Oil Chem. Soc. 39:198-201.

Kennedy, P. M. 1980. The effects of dietary sucrose and the concentration of plasma urea and rumen ammonia on the degradation of urea in the gastrointestinal tract of cattle. Br. J. Nutr. 43:125-140.

Klevenhusen, F., M. Kreuzer, and C. R. Soliva. 2011. Enteric and manure-derived methane and nitrogen emissions as well as metabolic energy losses in cows fed balanced diets based on maize, barley or grass hay. Animal 5:450-461.

Klopfenstein, T. J., R. A. Mass, K. W. Creighton, and H. H. Patterson. 2001. Estimating forage protein degradation in the rumen. J. Anim. Sci. 79(E. Suppl.):E208-E217.

Kozloski, G. V., C. M. Stefanello, F. R. Mesquita, T. P. Alves, H. M. Ribeiro Filho, J. G. Almeida, and T. C. Moraes Genro. 2014. Technical note: Evaluation of markers for estimating duodenal digesta flow and ruminal digestibility: Acid detergent fiber, sulfuric acid detergent lignin, and n-alkanes. J. Dairy Sci. 97:1730-1735.

Krishnamoorthy, U., C. J. Sniffen, M. D. Stern, and P. J. Van Soest. 1983. Evaluation of a mathematical model of rumen digestion and an in vitro simulation of rumen proteolysis to estimate the rumenundegraded nitrogen content of feedstuffs. Br. J. Nutr. 50:555-568.

Krizsan, S. J., S. Ahvenjärvi, and P. Huhtanen. 2010a. A meta-analysis of passage rate estimated by rumen evacuation with cattle and evaluation of passage rate prediction models. J. Dairy Sci. 93:5890-5901.

Krizsan, S. J., S. Ahvenjärvi, H. Volden, and G. A. Broderick. 2010b. Estimation of rumen outflow in dairy cows fed grass silage-based diets by use of reticular sampling as an alternative to sampling from the omasal canal. J. Dairy Sci. 93:1138-1147.

Krizsan, S. J., M. Rinne, L. Nyholm, and P. Huhtanen. 2015. New recommendations for the ruminal in situ determination of indigestible neutral detergent fibre. Anim. Feed Sci. Technol. 205:31-41.

Külling, D. R., F. Dohme, H. Menzi, F. Sutter, P. Lischer, and M. Kreuzer. 2002. Methane emissions of differently fed dairy cows and corresponding methane and nitrogen emissions from their manure during Storage. Environ. Monit. Assess. 79:129-150.

Külling, D. R., H. Menzi, T. F. Kröber, A. Neftel, F. Sutter, P. Lischer, and M. Kreuzer. 2001. Emissions of ammonia, nitrous oxide and methane from different types of dairy manure during storage as affected by dietary protein content. J. Agric. Sci. 137:235-250.

Külling, D. R., H. Menzi, F. Sutter, P. Lischer, and M. Kreuzer. 2003. Ammonia, nitrous oxide and methane emissions from differently stored dairy manure derived from grass- and hay-based rations. Nutr. Cycl. Agroecosyst. 65:13-22.

Lapierre, H., and G. E. Lobley. 2001. Nitrogen recycling in the ruminant: A review. J. Dairy Sci. 84:E223-E236.

Lapierre, H., D. R. Ouellet, R. Berthiaume, C. Girard, P. Dubreuil, M. Babkine, and G. E. Lobley. 2004. Effect of urea supplementation on urea kinetics and splanchnic flux of amino acids in dairy cows. J. Anim. Feed Sci. 13:319-322.

Lapierre, H., D. R. Ouellet, L. Doepel, G. Holtrop, and G. E. Lobley. 2008. Histidine, lysine and methionine: From metabolism to balanced dairy rations. Pages 19-36 in Proc. 44th Eastern Nutrition Conference of the Animal Nutrition Association of Canada (ANAC), University of Guelph, Guelph, ON, Canada. University of Guelph, Guelph, ON, Canada.

Lapierre, H., D. Pacheco, R. Berthiaume, D. R. Ouellet, C. G. Schwab, P. Dubreuil, G. Holtrop, and G. E. Lobley. 2006. What is the true supply of amino acids for a dairy cow? J. Dairy Sci. 89(Suppl. 1):E1-E14.

Lascano, G. J., G. I. Zanton, A. J. Heinrichs, and W. P. Weiss. 2010. Technical note: A noninvasive urine collection device for female cattle: Modification of the urine cup collection method. J. Dairy Sci. 93:2691-2694.

Laubach, J., A. Taghizadeh-Toosi, S. J. Gibbs, R. R. Sherlock, F. M. Kelliher, and S. P. P. Grover. 2013. Ammonia emissions from cattle urine and dung excreted on pasture. Biogeosciences 10:327-338.

Lee, C., R. C. Araujo, K. M. Koenig, M. L. Hile, E. E. Fabian-Wheeler, and K. A. Beauchemin. 2016. Effects of feeding encapsulated nitrate to beef cattle on ammonia and greenhouse gas emissions from their manure in a short-term manure storage system. J. Environ. Qual. 45:1979-1987.

Lee, C., G. W. Feyereisen, A. N. Hristov, C. J. Dell, J. Kaye, and D. Beegle. 2014. Effects of dietary protein concentration on ammonia volatilization, nitrate leaching, and plant nitrogen uptake from dairy manure applied to lysimeters. J. Environ. Qual. 43:398-408.

Lee, C., F. Giallongo, A. N. Hristov, H. Lapierre, T. W. Cassidy, K. S. Heyler, G. A. Varga, and C. Parys. 2015. Effect of dietary protein level and rumen protected amino acid supplementation on amino acid utilization for milk protein in lactating dairy cows. J. Dairy Sci. 98:1885-1902.

Lee, C., and A. N. Hristov. 2014. Short communication: Comparison of 3 solid digesta passage markers in dairy cows. J. Dairy Sci. 97:1725-1729

Lee, C., A. N. Hristov, T. Cassidy, and K. Heyler. 2011. Nitrogen isotope fractionation and origin of ammonia nitrogen volatilized from cattle manure in simulated storage. Atmosphere 2:256-270.

Lee, C., A. N. Hristov, T. W. Cassidy, K. S. Heyler, H. Lapierre, G. A. Varga, M. J. de Veth, R. A. Patton, and C. Parys. 2012c. Rumen-protected lysine, methionine, and histidine increase milk protein yield in dairy cows fed metabolizable protein-deficient diet. J. Dairy Sci. 95:6042-6056.

Lee, C., A. N. Hristov, C. J. Dell, G. W. Feyereisen, J. Kaye, and D. Beegle. 2012a. Effect of dietary protein concentration on ammonia and greenhouse gas emitting potential of dairy manure. J. Dairy Sci. 95:1930-1941.

Lee, C., A. N. Hristov, K. S. Heyler, T. W. Cassidy, H. Lapierre, G. A. Varga, and C. Parys. 2012b. Effects of metabolizable protein 
supply and amino acids supplementation on nitrogen utilization, production and ammonia emissions from manure in dairy cows. J. Dairy Sci. 95:5253-5268.

Leite, R. F., S. J. Krizsan, F. O. Figueiredo, V. B. Carvalho, I. A. Teixeira, and P. Huhtanen. 2015. Contribution of different segments of the gastrointestinal tract to digestion in growing Saanen goats. J. Anim. Sci. 93:1802-1814.

Lemosquet, S., G. E. Lobley, R. Koopman, L. J. C. van Loon, A. K. Kies, and H. Lapierre. 2010. A large supply of phenylalanine is not oxidised by the mammary gland of dairy cows. Pages 137-138 in Energy and Protein Metabolism and Nutrition in Sustainable Animal Production. G. M. Crovetto, ed. Wageningen Academic Publishers, Wageningen, the Netherlands.

Leng, J. A., and J. V. Nolan. 1984. Nitrogen metabolism in the rumen. J. Dairy Sci. 67:1072-1089.

Levitt, M. D., J. Furne, and E. G. DeMaster. 1994. Magnitude, origin and implications of the discrepancy between blood ethanol concentrations of tail vein and arterial blood of the rat. Alcohol. Clin. Exp. Res. 18:1237-1241.

Linzell, J. L. 1974. Mammary blood flow and methods of identifying and measuring precursors of milk. Pages 143-225 in Lactation, a comprehensive treatise. B. L. Larson and V. R. Smith, ed. Academic Press, New York, NY.

Lobley, G. E., D. M. Bremner, and G. Zuur. 2000. Effects of diet quality on urea fates in sheep as assessed by refined, non-invasive [15N15N]urea kinetics. Br. J. Nutr. 84:459-468.

Lockyer, D. R. 1984. A system for the measurement in the field of losses of ammonia through volatilisation. J. Sci. Food Agric. 35:837-848.

Lopez, S., J. France, M. S. Dhanoa, F. Mould, and J. Dijkstra. 1999. Comparison of mathematical models to describe disappearance curves obtained using the polyester bag technique for incubating feeds in the rumen. J. Anim. Sci. 77:1875-1888.

Ludden, P. A., T. L. Wechter, and B. W. Hess. 2002. Effects of oscillating dietary protein on nutrient digestibility, nitrogen metabolism, and gastrointestinal organ mass in sheep. J. Anim. Sci. 80:3021-3026.

Lykos, T., and G. A. Varga. 1997. Varying degradation rates of total nonstructural carbohydrates: effects on nutrient uptake and utilization by the mammary gland in high producing Holstein cows. J. Dairy Sci. 80:3356-3367.

Machado, M. G., E. Detmann, H. C. Mantovani, S. C. Valadares Filho, C. B. P. Bento, M. I. Marcondes, and A. S. Assunção. 2016. Evaluation of the length of adaptation period for changeover and crossover nutritional experiments with cattle fed tropical forage-based diets. Anim. Feed Sci. Technol. 222:132-148.

Machmüller, A., D. A. Ossowski, and M. Kreuzer. 2006. Effect of fat supplementation on nitrogen utilisation of lambs and nitrogen emission from their manure. Livest. Sci. 101:159-168.

MacRae, J. C., L. A. Bruce, D. S. Brown, and A. G. Calder. 1997a. Amino acid use by the gastrointestinal tract of sheep given lucerne forage. Am. J. Physiol. 273:G1200-G1207.

MacRae, J. C., L. A. Bruce, D. S. Brown, D. A. Farningham, and M. Franklin. 1997b. Absorption of amino acids from the intestine and their net flux across the mesenteric- and portal-drained viscera of lambs. J. Anim. Sci. 75:3307-3314.

Madsen, J. 1985. The basis for the proposed Nordic protein evaluation system for ruminants. The AAT-PBV system. Acta Agric. Scand. 25(Suppl.):9-20.

Madsen, J., and T. Hvelplund. 1994. Prediction of in situ protein degradability in the rumen. Results of a European ringtest. Livest. Prod. Sci. 39:201-212.

Marais, J. P. 2000. Use of markers. Pages 255-277 in Farm Animal Metabolism and Nutrition. J. P. F. D'Mello, ed. CABI Publishing, Wallingford, UK.

Marini, J. C., D. G. Fox, and M. R. Murphy. 2008. Nitrogen transactions along the gastrointestinal tract of cattle: A meta-analytical approach. J. Anim. Sci. 86:660-679.

Martin, A. K. 1966. Some errors in the determination of nitrogen retention of sheep by nitrogen balance studies. Br. J. Nutr. 20:325-337.

Mason, V. C. 1969. Some observations on the distribution and origin of nitrogen in sheep faeces. J. Agric. Sci. 73:99-111.
Mason, V. C. 1979. The quantitative importance of bacterial residues in the non-dietary faecal nitrogen of sheep. I. Methodology studies. Z. Tierphysiol. Tierernahr. Futtermittelkd. 41:131-139.

Mathison, G. W., and L. P. Milligan. 1971. Nitrogen metabolism in sheep. Br. J. Nutr. 25:351-366.

Mathot, M., V. Decruyenaere, D. Stilmant, and R. Lambert. 2012. Effect of cattle diet and manure storage conditions on carbon dioxide, methane and nitrous oxide emissions from tie-stall barns and stored solid manure. Agric. Ecosyst. Environ. 148:134-144.

Maynard, L. A., and J. K. Loosli. 1975. Animal Nutrition. 6th ed. McGraw-Hill Book Company, New York, NY.

McAllan, A. B., and R. H. Smith. 1973. Degradation of nucleic acid derivatives by rumen bacteria in vitro. Br. J. Nutr. 29:467-474.

McDowell, G. H., J. M. Gooden, D. Leenanuruksa, M. Jois, and A. W. English. 1987. Effects of exogenous growth hormone on milk production and nutrient uptake by muscle and mammary tissues of dairy cows in mid-lactation. Aust. J. Biol. Sci. 40:295-306.

McNamara, J. P., M. D. Hanigan, and R. R. White. 2016. Invited review: Experimental design, data reporting, and sharing in support of animal systems modeling research. J. Dairy Sci. 99:9355-9371.

Meijer, G. A., J. van der Meulen, and A. M. van Vuuren. 1993. Glutamine is a potentially limiting amino acid for milk production in dairy cows: A hypothesis. Metabolism 42:358-364.

Melgar, A., and A. N. Hristov. 2004. Rate of release of nitrogen from alfalfa hay fractions into ammonia nitrogen pool in vitro. Page 154 in Proc. Pacific Northwest Animal Nutrition Conference. Seattle, WA.

Mepham, T. B. 1982. Amino acid utilization by lactating mammary gland. J. Dairy Sci. 65:287-298.

Metcalf, J. A., S. J. Roberts, and J. D. Sutton. 1992. Variations in blood flow to and from the bovine mammary gland measured using transit time ultrasound and dye dilution. Res. Vet. Sci. 53:59-63.

Metcalf, J. A., D. Wray-Cahen, E. E. Chettle, J. D. Sutton, D. E. Beever, L. A. Crompton, J. C. MacRae, B. J. Bequette, and F. R. C. Backwell. 1996. The effect of dietary crude protein as protected soybean meal on mammary metabolism in the lactating dairy cow. J. Dairy Sci. 79:603-611.

Michalowski, T., J. Harmeyer, and G. Breves. 1986. The passage of protozoa from the reticulo-rumen through the omasum of sheep. Br. J. Nutr. 56:625-634.

Misselbrook, T. H., J. M. Powell, G. A. Broderick, and J. H. Grabber. 2005. Dietary manipulation in dairy cattle: Laboratory experiments to assess the influence on ammonia emissions. J. Dairy Sci. 88:1765-1777.

Mohamed, R., and A. S. Chaudhry. 2008. Methods to study degradation of ruminant feeds. Nutr. Res. Rev. 21:68-81.

Mohammed, R., S. M. McGinn, and K. A. Beauchemin. 2011. Prediction of enteric methane output from milk fatty acid concentrations and rumen fermentation parameters in dairy cows fed sunflower, flax, or canola seeds. J. Dairy Sci. 94:6057-6068.

Mohn, J., K. Zeyer, M. Keck, M. Keller, M. Zähner, J. Poteko, L. Emmenegger, and S. Schrade. 2018. A dual tracer ratio method for comparative emission measurements in an experimental dairy housing. Atmos. Environ. 179:12-22.

Monteils, V., M. Rey, M. Silberberg, L. Cauquil, and S. Combes. 2012. Modification of activities of the ruminal ecosystem and its bacterial and protozoan composition during repeated dietary changes in cows. J. Anim. Sci. 90:4431-4440.

Moorby, J. M., R. J. Dewhurst, R. T. Evans, and W. J. Fishert. 2002. Effects of level of concentrate feeding during the second gestation of Holstein-Friesian dairy cows. 2. Nitrogen balance and plasma metabolites. J. Dairy Sci. 85:178-189.

Morris, T. R. 1999. Experimental Design and Analysis in Animals Sciences. CABI Publishing, Wallingford, UK.

Mosier, A. R. 1989. Chamber and isotope techniques. Pages 175-187 in Exchange of Trace Gases between Terrestrial Ecosystems and the Atmosphere. M. O. Andreae and D. S. Schimel, ed. John Wiley \& Sons, New York, NY.

Müller, D. W., J. Caton, D. Codron, A. Schwarm, R. Lentle, W. J. Streich, J. Hummel, and M. Clauss. 2011. Phylogenetic constraints on digesta separation: Variation in fluid throughput in the diges- 
tive tract in mammalian herbivores. Comp. Biochem. Physiol. A Mol. Integr. Physiol. 160:207-220.

Ndegwa, P. M., V. K. Vaddella, A. N. Hristov, and H. S. Joo. 2009. Measuring concentrations of ammonia in ambient air or exhaust air stream using acid traps. J. Environ. Qual. 38:647-653.

Nichols, K., J. Dijkstra, H. van Laar, S. Pacheco, H. J. van Valenberg, and A. Bannink. 2019. Energy and nitrogen partitioning in dairy cows at low or high metabolizable protein levels is affected differently by post-rumen glucogenic and lipogenic substrates. J. Dairy Sci. 102:395-412.

Nocek, J. E. 1988. In situ and other methods to estimate ruminal protein and energy digestibility: a review. J. Dairy Sci. 71:2051-2069.

Nozière, P., W. Steinberg, M. Silberberg, and D. Morgavi. 2014. Amylase addition increases starch ruminal digestion in first-lactation cows fed high and low starch diets. J. Dairy Sci. 97:2319-2328.

NRC (National Research Council). 1968. Body Composition in Animals and Man. Natl. Acad. Sci., Washington, DC.

NRC (National Research Council). 2000. Nutrient Requirements of Beef Cattle. 7th rev. ed. Natl. Acad. Sci., Washington, DC.

NRC (National Research Council). 2001. Nutrient Requirements of Dairy Cattle. 7th rev. ed. Natl. Acad. Sci., Washington, DC.

NRC (National Research Council). 2016. Nutrient Requirements of Beef Cattle. 8th rev. ed. Natl. Acad. Sci., Washington, DC.

Olaisen, V., T. Mejdell, H. Volden, and N. Nesse. 2003. Simplified in situ method for estimating ruminal dry matter and protein degradability of concentrates. J. Anim. Sci. 81:520-528.

Orskov, E. R., and P. McDonald. 1979. Estimation of protein degradability in the rumen from incubation measurements weighed according to rate of passage. J. Agric. Sci. 92:499-503.

Ouellet, D. R., M. Demers, G. Zuur, G. E. Lobley, J. R. Seoane, J. V. Nolan, and H. Lapierre. 2002. Effect of dietary fiber on endogenous nitrogen flows in lactating dairy cows. J. Dairy Sci. 85:3013-3025.

Owen, E. C. 1967. Nitrogen balances. Proc. Nutr. Soc. 26:116-124.

Owens, F. N., S. Qi, and D. A. Sapienza. 2014. Invited Review: Applied protein nutrition of ruminants - Current status and future directions. Prof. Anim. Sci. 30:150-179.

Pacheco-Rios, D., D. D. S. Mackenzie, and W. C. McNabb. 2001. Comparison of two variants of the Fick principle for estimation of mammary blood flow in dairy cows fed two levels of dry matter intake. Can. J. Anim. Sci. 81:57-63.

Pappenheimer, J. R., and B. P. Setchell. 1972. The measurement of cerebral blood flow in the rabbit and sheep. J. Physiol. 226:48P-50P.

Paquay, R., R. De Baere, and A. Lousse. 1972. The capacity of the mature cow to lose and recover nitrogen and the significance of protein reserves. Br. J. Nutr. 27:27-37.

Patience, J. F., D. W. Friend, K. E. Hartin, and M. S. Wolynetz. 1987. A comparison of two urine collection methods for female swine. Can. J. Anim. Sci. 67:859-863.

Paul, J. W., N. E. Dinn, T. Kannangara, and L. J. Fisher. 1998. Protein content in dairy cattle diets affects ammonia losses and fertilizer nitrogen value. J. Environ. Qual. 27:528-534.

Peeters, G., A. Houvenaghel, E. Roets, A. M. Massart-Leen, R. Verbeke, G. Dhondt, and F. Verschooten. 1979. Electromagnetic blood flow recording and balance of nutrients in the udder of lactating cows. J. Anim. Sci. 48:1143-1153.

Pell, J. M., E. M. Caldarone, and E. N. Bergman. 1983. Importance of sites of tracer administration and blood sampling in relation to leucine metabolism. Practical considerations. Biochem. J. $214: 1015-1018$.

Perez, J. F., J. Balcells, J. A. Guada, and C. Castrillo. 1997. Contribution of dietary nitrogen and purine bases to the duodenal digesta: Comparison of duodenal and polyester-bag measurements. Anim. Sci. 65:237-245.

Pilgrim, A. F., R. A. Weller, F. V. Gray, and C. B. Belling. 1970. Synthesis of microbial protein from ammonia in the sheep's rumen and the proportion of dietary nitrogen converted into microbial nitrogen. Br. J. Nutr. 24:589-598.

Pollet, I., J. Christiaens, and H. Van Langenhove. 1998. Determination of the ammonia emission from cubicle houses for dairy cows based on a mass balance. J. Agric. Eng. Res. 71:239-248.

Poncet, C., B. Michalet-Doreau, T. McAllister, and D. Remond. 1995. Dietary compounds escaping rumen digestion. Pages 167-204 in
Recent Developments in the Nutrition of Herbivores. M. Journet, E. Grenet, M.-H. Farce, M. Theriez, and C. Demarquilly, ed. INRA Editions, Paris, France.

Powell, J. M., M. J. Aguerre, and M. A. Wattiaux. 2011. Dietary crude protein and tannin impact dairy manure chemistry and ammonia emissions from incubated soils. J. Environ. Qual. 40:1767-1774.

Powell, J. M., M. A. Wattiaux, G. A. Broderick, V. R. Moreira, and M. D. Casler. 2006. Dairy diet impacts on fecal chemical properties and nitrogen cycling in soils. Soil Sci. Soc. Am. J. 70:786-794.

Powell, M., P. R. Cusick, T. Misselbrook, and B. J. Holmes. 2007. Design and calibration of chambers for measuring ammonia emissions from tie-stall dairy barns. Trans. ASABE 49:1139-1149.

Prosser, C. G., and S. R. Davis. 1992. Milking frequency alters the milk yield and mammary blood flow response to intra-mammary infusion of insulin-like growth factor-I in the goat. J. Endocrinol. 135:311-316.

Raab, L., B. Cafantaris, T. Jilg, and K. H. Menke. 1983. Rumen protein degradation and biosynthesis. 1. A new method for determination of protein degradation in rumen fluid in vitro. Br. J. Nutr. 50:569-582.

Rajczyk, Z. K., A. Sweeting, I. J. Lean, and J. M. Gooden. 1995. Postural effects on mammary blood flow and nutrient uptake. Proc. Nutr. Soc. Aust. 19:119. (Abstr.)

Reijs, J. W., M. P. W. Sonneveld, P. Sørensen, R. L. M. Schils, J. C. J. Groot, and E. A. Lantinga. 2007. Effects of different diets on utilization of nitrogen from cattle slurry applied to grassland on a sandy soil in The Netherlands. Agric. Ecosyst. Environ. 118:65-79.

Reynal, S. M., G. A. Broderick, and C. Bearzi. 2005. Comparison of four markers for quantifying microbial protein flow from the rumen of lactating dairy cows. J. Dairy Sci. 88:4065-4082.

Reynolds, C. K. 2002. Economics of visceral energy metabolism in ruminants: Toll keeping or internal revenue service? J. Anim. Sci. 80:E74-E84.

Reynolds, C. K., B. J. Bequette, J. S. Caton, D. J. Humphries, P. C. Aikman, B. Lupoli, and J. D. Sutton. 2001b. Effects of intake and lactation on absorption and metabolism of leucine and phenylalanine by splanchnic tissues of dairy cows. J. Dairy Sci. 84(Suppl. 1):362. (Abstr.)

Reynolds, C. K., S. B. Cammell, D. J. Humphries, D. E. Beever, J. D. Sutton, and J. R. Newbold. 2001a. Effects of postrumen starch infusion on milk production and energy metabolism in dairy cows. J. Dairy Sci. 84:2250-2259.

Reynolds, C. K., L. A. Crompton, J. A. N. Mills, D. J. Humphries, P. Kirton, A. E. Relling, T. H. Misselbrook, D. R. Chadwick, and D. I. Givens. 2010. Effects of diet protein level and forage source on energy and nitrogen balance and methane and nitrogen excretion in lactating dairy cows. Pages 463-464 in Proc. the 3rd International Symposium on Energy and Protein Metabolism. G. M. Corvetto, ed. EAAP Publ. No. 127. Wageningen Academic Publishers, Wageningen, the Netherlands.

Reynolds, C. K., D. L. Harmon, and M. J. Cecava. 1994. Absorption and delivery of nutrients for milk protein synthesis by portaldrained viscera. J. Dairy Sci. 77:2787-2808.

Reynolds, C. K., D. J. Humphries, S. B. Cammell, J. Benson, J. D Sutton, and D. E. Beever. 1998. Effects of abomasal wheat starch infusion on splanchnic metabolism and energy balance of lactating dairy cows. Page 39 in Energy Metabolism of Farm Animals. K. J. McCracken, E. F. Unsworth, and A. R. G. Wylie, ed. Proc. the 14th Symposium on Energy Metabolism. CAB International, Wallingford, UK.

Reynolds, C. K., D. J. Humphries, P. Kirton, M. Kindermann, S. Duval, and W. Steinberg. 2014. Effects of 3-nitrooxypropanol on methane emission, digestion, and energy and nitrogen balance of lactating dairy cows. J. Dairy Sci. 97:3777-3789.

Reynolds, C. K., D. J. Humphries, A. M. van Vuuren, J. Dijkstra, and A. Bannink. 2015. Considerations for feeding starch to high yielding dairy cows. Pages 27-47 in Recent Advances in Animal Nutrition 2014. P. C. Garnsworthy and J. Wiseman, ed. Context Products Ltd., Packington, UK.

Reynolds, C. K., and G. B. Huntington. 1988. Partition of portaldrained visceral net flux in beef steers. 1. Blood flow and net flux 
of oxygen, glucose and nitrogenous compounds across stomach and post-stomach tissues. Br. J. Nutr. 60:539-551.

Reynolds, C. K., and N. B. Kristensen. 2008. Nitrogen recycling through the gut and the nitrogen economy of ruminants: An asynchronous symbiosis. J. Anim. Sci. 86:E293-E305.

Reynolds, M. 1964. Use of nitrous oxide to measure mammary blood flow in anesthetized lactating goats. Am. J. Physiol. 206:183-188.

Reynolds, M., J. L. Linzell, and F. Rasmussen. 1968. Comparison of four methods for measuring mammary blood flow in conscious goats. Am. J. Physiol. 214:1415-1424.

Richard, O. K., D. Codron, K. B. Hagen, K. H. Sudekum, and M. Clauss. 2017. Little differences in digestive efficiency for protein and fat in mammals of different trophic guilds and digestive strategies: Data constraints or fundamental functional similarity? J. Anim. Physiol. Anim. Nutr. (Berl.) 101(Suppl. 1):127-141.

Robinson, P. H. 2016. Letter to the Editor: Comments on Journal of Dairy Science statistical unit policy as it relates to pen-based animal studies. J. Dairy Sci. 99:2435-2436.

Robinson, P. H., E. K. Okine, and J. J. Kennelly. 1992. Measurement of protein digestion in ruminants. Pages 121-144 in Modern Methods in Protein Nutrition and Metabolism. S. Nissen, ed. Academic Press, San Diego, CA.

Robinson, P. H., S. Tamminga, and A. M. van Vuuren. 1987. Influence of declining level of feed intake and varying the proportion of starch in the concentrate on rumen ingesta quantity, composition and kinetics of ingesta turnover in dairy cows. Livest. Prod. Sci. $17: 37-62$.

Rodríguez, C. A., J. Gonzalez, M. R. Alvir, J. L. Repetto, C. Centeno, and F. Lamrani. 2000. Composition of bacteria harvested from the liquid and solid fractions of the rumen of sheep as influenced by feed intake. Br. J. Nutr. 84:369-376.

Røjen, B. A., and N. B. Kristensen. 2012. Effect of time duration of ruminal urea infusions on ruminal ammonia concentrations and portal-drained visceral extraction of arterial urea- $\mathrm{N}$ in lactating Holstein cows. J. Dairy Sci. 95:1395-1409.

Røjen, B. A., P. K. Theil, and N. B. Kristensen. 2011. Effects of nitrogen supply on inter-organ fluxes of urea-N and renal urea-N kinetics in lactating Holstein cows. J. Dairy Sci. 94:2532-2544.

Roman-Garcia, Y., R. R. White, and J. L. Firkins. 2016. Meta-analysis of postruminal microbial nitrogen flows in dairy cattle. I. Derivation of equations. J. Dairy Sci. 99:7918-7931.

Ross, D. A., M. Gutierrez-Botero, and M. E. Van Amburgh. 2013. Development of an in vitro intestinal digestibility assay for ruminant feeds. Pages 190-202 in Proc. Cornell Nutrition Conference, Cornell University, Ithaca, NY.

Rossi, G., S. Schiavon, G. Lomolino, C. Cipolat-Gotet, A. Simonetto, G. Bittante, and F. Tagliapietra. 2018. Garlic (Allium sativum L.) fed to dairy cows does not modify the cheese-making properties of milk but affects the color, texture, and flavor of ripened cheese. J. Dairy Sci. 101:2005-2015.

Rotta, P. P., S. C. Valadares Filho, E. Detmann, L. F. Costa e Silva, M. F. Paulino, M. I. Marcondes, A. A. Lobo, and F. A. Villadiego. 2014. Digesta sampling sites and marker methods for estimation of ruminal outflow in bulls fed different proportions of corn silage or sugarcane. J. Anim. Sci. 92:2996-3006.

Rutherfurd, S. M. 2009. Accurate determination of the amino acid content of selected feedstuffs. Int. J. Food Sci. Nutr. 60(Suppl. 7):53-62.

Rymer, C. 2000. The measurement of forage digestibility in vivo. Pages 113-134 in Forage Evaluation in Ruminant Nutrition. D. I. Givens, E. Owen, R. F. E. Axford, and H. M. Ohmed, ed. CAB International, Wallingford, UK.

Salter, D. N., and R. H. Smith. 1977. Digestibilities of nitrogen compounds in rumen bacteria and in other components of digesta in the small intestine of the young steer. Br. J. Nutr. 38:207-216.

Sangaré, M., A. Bationo, P. Hiernaux, S. Fernández-Rivera, and V. Pandey. 2002. Effect of type and level of roughage offered to sheep and urine addition on compost quality and millet growth and production in the Sahel. Nutr. Cycl. Agroecosyst. 62:203-208.

Sauvant, D., and P. Nozière. 2016. Quantification of the main digestive processes in ruminants: the equations involved in the renewed energy and protein feed evaluation systems. Animal 10:755-770.
Schager, W. M., J. H. Harrison, C. T. Gaskins, and D. Davidson. 2003. Factors affecting application of milk allantoin as an estimator of microbial protein flow to the duodenum under commercial conditions. J. Dairy Sci. 86:1716-1721.

Schneider, B. H., and W. P. Flatt. 1975. The Evaluation of Feeds Through Digestibility Experiments. The University of Georgia Press, Athens.

Schwab, C. G., and G. A. Broderick. 2017. A 100-Year Review: Protein and amino acid nutrition in dairy cows. J. Dairy Sci. 100:1009410112.

Schwab, C. G., P. Huhtanen, C. W. Hunt, and T. Hvelplund. 2005. Nitrogen requirements of cattle. Pages 13-70 in Nitrogen and Phosphorus Nutrition of Cattle and the Environment. E. Pfeffer and A. N. Hristov, ed. CAB International, Wallingford, UK.

Schwarm, A., S. Ortmann, C. Wolf, W. J. Streich, and M. Clauss 2008. Excretion patterns of fluid and different sized particle passage markers in banteng (Bos javanicus) and pygmy hippopotamus (Hexaprotodon liberiensis): Two functionally different foregut fermenters. Comp. Biochem. Physiol. A Mol. Integr. Physiol. 150:32-39.

Schwarm, A., S. Ortmann, C. Wolf, W. J. Streich, and M. Clauss. 2009a. More efficient mastication allows increasing intake without compromising digestibility or necessitating a larger gut: Comparative feeding trials in banteng (Bos javanicus) and pygmy hippopotamus (Hexaprotodon liberiensis). Comp. Biochem. Physiol. A Mol. Integr. Physiol. 152:504-512.

Schwarm, A., M. Schweigel-Rontgen, M. Kreuzer, S. Ortmann, F. Gill, B. Kuhla, U. Meyer, M. Loholter, and M. Derno. 2015. Methane emission, digestive characteristics and faecal archaeol in heifers fed diets based on silage from brown midrib maize as compared to conventional maize. Arch. Anim. Nutr. 69:159-176.

Schwarm, A., M. Schweigert, S. Ortmann, J. Hummel, G. P. J. Janssens, W. J. Streich, and M. Clauss. 2009b. No easy solution for the fractionation of faecal nitrogen in captive wild herbivores: Results of a pilot study. J. Anim. Physiol. Anim. Nutr. (Berl.) 93:596-605.

Schwarting, G., and W. Kaufmann. 1978. Die Verdaulichkeit des Proteins beim Wiederkäuer. Z. Tierphysiol. Tierernahr. Futtermittelkd. 40:6-18.

Seal, C. J., and C. K. Reynolds. 1993. Nutritional implications of gastrointestinal and liver metabolism in ruminants. Nutr. Res. Rev. $6: 185-208$

Shingfield, K. J., and N. W. Offer. 1998. Evaluation of milk allantoin excretion as an index of microbial protein supply in lactating dairy cows. Anim. Sci. 67:371-385.

Siddons, R. C., D. E. Beever, and J. V. Nolan. 1982. A comparison of methods for the estimation of microbial nitrogen in duodenal digesta of sheep. Br. J. Nutr. 48:377-389.

Śliwiński, B. J., M. Kreuzer, F. Sutter, A. Machmüller, and H.-R. Wettstein. 2004. Performance, body nitrogen conversion and nitrogen emission from manure of dairy cows fed diets supplemented with different plant extracts. J. Anim. Feed Sci. 13:73-91.

Śliwiński, B. J., M. Kreuzer, H. R. Wettstein, and A. Machmuller. 2002. Rumen fermentation and nitrogen balance of lambs fed diets containing plant extracts rich in tannins and saponins, and associated emissions of nitrogen and methane. Arch. Tierernahr. $56: 379-392$

Smith, M. E., and D. G. Morton. 2010. The Digestive System - Basic Science and Clinical Conditions, Churchill Livingstone, London, UK.

Smith, R. H., and A. B. McAllan. 1970. Nucleic acid metabolism in the ruminant. 2. Formation of microbial nucleic acids in the rumen in relation to the digestion of food nitrogen, and the fate of dietary nucleic acids. Br. J. Nutr. 24:545-556.

Smith, T. 1979. The collection of faeces and urine from steers. J. Sci. Food Agric. 30:215-217.

Sniffen, C. J., C. S. Ballard, M. P. Carter, K. W. Cotanch, H. M. Danna, R. J. Grant, P. Mandebvu, M. Suekawa, and S. A. Martin. 2006. Effects of malic acid on microbial efficiency and metabolism in continuous culture of rumen contents and on performance of mid-lactation dairy cows. Anim. Feed Sci. Technol. 127:13-31.

Sniffen, C. J., J. D. O'Connor, P. J. Van Soest, D. G. Fox, and J. B. Russell. 1992. A net carbohydrate and protein system for evaluat- 
ing cattle diets: II. Carbohydrate and protein availability. J. Anim. Sci. 70:3562-3577.

Sok, M., D. R. Ouellet, J. L. Firkins, D. Pellerin, and H. Lapierre. 2017. Amino acid composition of rumen bacteria and protozoa in cattle. J. Dairy Sci. 100:5241-5249.

Spanghero, M., and Z. M. Kowalski. 1997. Critical analysis of N balance experiments with lactating cows. Livest. Prod. Sci. 52:113122.

Spek, J. W., A. Bannink, G. Gort, W. H. Hendriks, and J. Dijkstra. 2012. Effect of sodium chloride intake on urine volume, urinary urea excretion, and milk urea concentration in lactating dairy cattle. J. Dairy Sci. 95:7288-7298.

Spek, J. W., A. Bannink, G. Gort, W. H. Hendriks, and J. Dijkstra. 2013b. Interaction between dietary content of protein and sodium chloride on milk urea concentration, urinary urea excretion, renal recycling of urea, and urea transfer to the gastrointestinal tract in dairy cows. J. Dairy Sci. 96:5734-5745.

Spek, J. W., J. Dijkstra, G. Van Duinkerken, and A. Bannink. 2013a. A review of factors influencing milk urea concentration and its relationship with urinary urea excretion in lactating dairy cattle. J. Agric. Sci. 151:407-423.

Spires, H. R., J. H. Clark, R. G. Derrig, and C. L. Davis. 1975. Milk production and nitrogen utilization in response to postruminal infusion of sodium caseinate in lactating cows. J. Nutr. 105:11111121.

St-Pierre, N. R. 2007. Design and analysis of pen studies in the animal sciences. J. Dairy Sci. 90(Suppl. 1):E87-E99.

St-Pierre, N. R., and W. P. Weiss. 2015. Partitioning variation in nutrient composition data of common feeds and mixed diets on commercial dairy farms. J. Dairy Sci. 98:5004-5015.

Steingaß, H., D. Nibbe, K.-H. Südekum, P. Lebzien, and H. Spiekers. 2001. Schätzung des nXP-Gehaltes mit Hilfe des modifizierten Hohenheimer Futterwerttests und dessen Anwendung zur Bewertung von Raps- und Sojaextraktionsschroten. VDLUFA-Kongress 113 Berlin, Kurzfassungen der Vorträge, 114 (Abstr.).

Steingaß, H., and K. H. Südekum. 2013. Proteinbewertung beim Wiederkäuer - Grundlagen, analytische Entwicklungen und Perspektiven. Übers. Tierernähr. 41:51-73.

Stern, M. D., A. Bach, and S. Calsamiglia. 1997. Alternative techniques for measuring nutrient digestion in ruminants. J. Anim. Sci. 75:2256-2276.

Stern, M. D., G. A. Varga, J. H. Clark, J. L. Firkins, J. T. Huber, and D. L. Palmquist. 1994. Evaluation of chemical and physical properties of feeds that affect protein metabolism in the rumen. J. Dairy Sci. 77:2762-2786.

Stoll, B., D. G. Burrin, J. Henry, H. Yu, F. Jahoor, and P. J. Reeds. 1999. Substrate oxidation by the portal drained viscera of fed piglets. Am. J. Physiol. 277:E168-E175.

Storm, E., D. S. Brown, and E. R. Orskov. 1983a. The nutritive value of rumen micro-organisms in ruminants. 3 . The digestion of microbial amino and nucleic acids in, and losses of endogenous nitrogen from, the small intestine of sheep. Br. J. Nutr. 50:479-485.

Storm, E., E. R. Ørskov, and R. Smart. 1983b. The nutritive value of rumen micro-organisms in ruminants: 2 . The apparent digestibility and net utilization of microbial $\mathrm{N}$ for growing lambs. Br. J. Nutr. 50:471-478.

Sylvester, J. T., S. K. Karnati, Z. Yu, M. Morrison, and J. L. Firkins. 2004. Development of an assay to quantify rumen ciliate protozoal biomass in cows using real-time PCR. J. Nutr. 134:3378-3384.

Sylvester, J. T., S. K. Karnati, Z. Yu, C. J. Newbold, and J. L. Firkins. 2005. Evaluation of a real-time PCR assay quantifying the ruminal pool size and duodenal flow of protozoal nitrogen. J. Dairy Sci. 88:2083-2095.

Tajima, K., S. Arai, K. Ogata, T. Nagamine, H. Matsui, M. Nakamura, and Y. Benno. 2000. Rumen bacterial community transition during adaptation to high-grain diet. Anaerobe 6:273-284.

Tamminga, S. 1979. Protein degradation in the forestomachs of ruminants. J. Anim. Sci. 49:1615-1630.

Tamminga, S., and X. B. Chen. 2000. Animal-based techniques for the estimation of protein value of forages. Pages 215-231 in Forage Evaluation in Ruminant Nutrition. D. I. Givens, E. Owen, R. R.
E. Axford, and H. M. Omed, ed. CAB International, Wallingford, UK.

Tamminga, S., W. M. Van Straalen, A. P. J. Subnel, R. G. M. Meijer, A. Steg, C. J. G. Wever, and M. C. Blok. 1994. The Dutch protein evaluation system: The DVE/OEB-system. Livest. Prod. Sci. 40:139-155.

Tas, B. M., and A. Susenbeth. 2007. Urinary purine derivates excretion as an indicator of in vivo microbial $\mathrm{N}$ flow in cattle: A review. Livest. Sci. 111:181-192.

Tas, M. V., R. A. Evans, and R. F. Axford. 1981. The digestibility of amino acids in the small intestine of the sheep. Br. J. Nutr. 45:167-174.

Tedeschi, L. O., L. F. L. Cavalcanti, M. A. Fonseca, M. Herrero, and P. K. Thornton. 2014. The evolution and evaluation of dairy cattle models for predicting milk production: An agricultural model intercomparison and improvement project (AgMIP) for livestock. Anim. Prod. Sci. 54:2052-2067.

Tempelman, R. J. 2004. Experimental design and statistical methods for classical and bioequivalence hypothesis testing with an application to dairy nutrition studies. J. Anim. Sci. 82(E-Suppl.):E162E172

Thivierge, M. C., D. Petitclerc, J. F. Bernier, Y. Couture, and H. Lapierre. 2000. External pudic venous reflux into the mammary vein in lactating dairy cows. J. Dairy Sci. 83:2230-2238.

Thivierge, M. C., D. Petitclerc, J. F. Bernier, Y. Couture, and H. D. Lapierre. 2002. Variations in mammary protein metabolism during the natural filling of the udder with milk over a 12-h period between two milkings: Leucine kinetics. J. Dairy Sci. 85:2974-2985.

Thomas, C. 2004. Feed into Milk: A New Applied Feeding System for Dairy Cows. Nottingham University Press, Nottingham, UK.

Tiemann, T., B. Hincapie, E. Frossard, M. Kreuze, and H. Hess. 2009. Effect of supplementing tropical tannin-free and tanniniferous legumes to grass-fed sheep on the utility of their manure as nitrogen fertiliser. Livest. Res. Rural Dev. 21:1-8.

Timmermans, S. J., L. M. Johnson, J. H. Harrison, and D. Davidson. 2000. Estimation of the flow of microbial nitrogen to the duodenum using milk uric acid or allantoin. J. Dairy Sci. 83:1286-1299.

Titgemeyer, E. C. 1997. Design and interpretation of nutrient digestion studies. J. Anim. Sci. 75:2235-2247.

Titgemeyer, E. C., N. R. Merchen, and L. L. Berger. 1989. Evaluation of soybean meal, corn gluten meal, blood meal and fish meal as sources of nitrogen and amino acids disappearing from the small intestine of steers. J. Anim. Sci. 67:262-275.

Topps, J. H., and R. C. Elliott. 1965. Relationship between concentrations of ruminal nucleic acids and excretion of purine derivatives by sheep. Nature 205:498-499.

Tvedten, H., M. Kopcia, and C. Haines. 2000. Mixed venous and arterial blood in bovine coccygeal vessel samples for blood gas analysis. Vet. Clin. Pathol. 29:4-6.

Tyrrell, H. F., P. J. Reynolds, and P. W. Moe. 1979. Effect of diet on partial efficiency of acetate use for body tissue synthesis by mature cattle. J. Anim. Sci. 48:598-606.

Vagnoni, D. B., G. A. Broderick, M. K. Clayton, and R. D. Hatfield. 1997. Excretion of purine derivatives by Holstein cows abomasally infused with incremental amounts of purines. J. Dairy Sci. 80:1695-1702.

van der Stelt, B., P. C. J. van Vliet, J. W. Reijs, E. J. M. Temminghoff, and W. H. van Riemsdijk. 2008. Effects of dietary protein and energy levels on cow manure excretion and ammonia volatilization. J. Dairy Sci. 91:4811-4821.

Van Dorland, H. A., H. R. Wettstein, H. Leuenberger, and M. Kreuzer. 2007. Effect of supplementation of fresh and ensiled clovers to ryegrass on nitrogen loss and methane emission of dairy cows. Livest. Sci. 111:57-69.

Van Duinkerken, G., M. C. Blok, A. Bannink, J. W. Cone, J. Dijkstra, A. M. Van Vuuren, and S. Tamminga. 2011. Update of the Dutch protein evaluation system for ruminants: The DVE/OEB2010 system. J. Agric. Sci. 149:351-367.

van Gastelen, S., M. Visker, J. E. Edwards, E. C. Antunes-Fernandes, K. A. Hettinga, S. J. J. Alferink, W. H. Hendriks, H. Bovenhuis, H. Smidt, and J. Dijkstra. 2017. Linseed oil and DGAT1 K232A 
polymorphism: Effects on methane emission, energy and nitrogen metabolism, lactation performance, ruminal fermentation, and rumen microbial composition of Holstein-Friesian cows. J. Dairy Sci. 100:8939-8957.

Van Kessel, J. A., J. B. Reeves, and J. J. Meisinger. 1999. Storage and handling can alter the mineralization characteristics of manure. J. Environ. Qual. 28:1984-1990.

Van Soest, P. J. 1994. Nutritional Ecology of the Ruminant. 2nd ed. Cornell University Press, Ithaca, NY.

Van Straalen, W. M., and S. Tamminga. 1990. Protein degradation of ruminant feedstuffs. Pages 55-59 in Feedstuffs Evaluation. J. Wiseman and D. J. A. Cole, ed. Butterworths, London, UK.

van Vliet, P. C., J. W. Reijs, J. Bloem, J. Dijkstra, and R. G. de Goede. 2007. Effects of cow diet on the microbial community and organic matter and nitrogen content of feces. J. Dairy Sci. 90:5146-5158.

Velthof, G. L., P. J. Kuikman, and O. Oenema. 2003. Nitrous oxide emission from animal manures applied to soil under controlled conditions. Biol. Fertil. Soils 37:221-230.

Verbeke, R., E. Roets, A.-M. Massart-Leën, and G. Peeters. 1972. Metabolism of [U-14C]-l-threonine and [U-14C]-l-phenylalanine by the isolated perfused udder. J. Dairy Res. 39:239-250.

Vercoe, J. E. 1976. Urinary allantoin excretion and digestible drymatter intake in cattle and buffalo. J. Agric. Sci. 86:613-615.

Vérité, R., M. Journet, and R. Jarrige. 1979. A new system for the protein feeding of ruminants: The PDI system. Livest. Prod. Sci. 6:349-367. https://doi.org/10.1016/0301-6226(79)90003-4.

Vérité, R., and J. L. Peyraud. 1989. Protein: The PDI system. Pages 33-48 in Ruminant Nutrition. R. Jarrige, ed. Recommended Allowances and Feed Tables. INRA, France.

Verloop, J., G. J. Hilhorst, J. Oenema, H. Van Keulen, L. B. J. Sebek, and M. K. Van Ittersum. 2014. Soil N mineralization in a dairy production system with grass and forage crops. Nutr. Cycl. Agroecosyst. 98:267-280.

Vicente, F., J. A. Guada, J. Surra, J. Balcells, and C. Castrillo. 2004. Microbial contribution to duodenal purine flow in fattening cattle given concentrate diets, estimated by purine $\mathrm{N}$ labelling $(15 \mathrm{~N})$ of different microbial fractions. Anim. Sci. 78:159-167.

Vlaeminck, B., V. Fievez, A. R. J. Cabrita, A. J. M. Fonseca, and R. J. Dewhurst. 2006. Factors affecting odd- and branched-chain fatty acids in milk: A review. Anim. Feed Sci. Technol. 131:389-417.

Volden, H. 2011. NorFor - The Nordic feed evaluation system. EAAP Publications No. 130, Wageningen Academic Publishers, Wageningen University, Wageningen, the Netherlands.

Volden, H., L. T. Mydland, and V. Olaisen. 2002. Apparent ruminal degradation and rumen escape of soluble nitrogen fractions in grass and grass silage administered intraruminally to lactating dairy cows. J. Anim. Sci. 80:2704-2716.

Wainman, F. W., and D. Paterson. 1963. A note on the collection of urine from male cattle and sheep. J. Agric. Sci. 61:253-254.

Walz, L. S., W. C. Ellis, T. W. White, J. H. Matis, H. G. Bateman, C. C. Williams, J. M. Fernandez, and L. R. Gentry. 2004. Flow paths of plant tissue residues and digesta through gastrointestinal segments in Spanish goats and methodological considerations. J. Anim. Sci. 82:508-520.

Wang, S., M. Terranova, M. Kreuzer, S. Marquardt, L. Eggerschwiler, and A. Schwarm. 2018. Supplementation of pelleted hazel (Corylus avellana) leaves decreases methane and urinary nitrogen emissions by sheep at unchanged forage intake. Sci. Rep. 8:5427.

Warner, D., J. Dijkstra, W. H. Hendriks, and W. F. Pellikaan. 2013b. Passage of stable isotope-labeled grass silage fiber and fiber-bound protein through the gastrointestinal tract of dairy cows. J. Dairy Sci. 96:7904-7917.

Warner, D., L. M. Ferreira, M. J. Breuer, J. Dijkstra, and W. F. Pellikaan. 2013a. Stable isotope labeled n-alkanes to assess digesta passage kinetics through the digestive tract of ruminants. PLoS One 8:e75496.

Waterlow, J. C. 1999. The mysteries of nitrogen balance. Nutr. Res. Rev. 12:25-54.

Weimer, P. J., D. M. Stevenson, H. C. Mantovani, and S. L. Man. 2010. Host specificity of the ruminal bacterial community in the dairy cow following near-total exchange of ruminal contents. J. Dairy Sci. 93:5902-5912.

White, R. R., P. J. Kononoff, and J. J. Firkins. 2017. Technical note: Methodological and feed factors affecting prediction of ruminal degradability and intestinal digestibility of essential amino acids. J. Dairy Sci. 100:1946-1950.

White, R. R., Y. Roman-Garcia, and J. L. Firkins. 2016. Meta-analysis of postruminal microbial nitrogen flows in dairy cattle. II. Approaches to and implications of more mechanistic prediction. J. Dairy Sci. 99:7932-7944.

Wilkerson, V. A., T. J. Klopfenstein, and W. W. Stroup. 1995. A collaborative study of in situ forage protein degradation. J. Anim. Sci. 73:583-588.

Wonsil, B. J. 1993. Influence of dietary fat and protein on nutrient supply and utilization by the lactating bovine mammary gland. PhD Dissertation. Department of Dairy Science, Virginia Polytechnic Institute and State University, Blacksburg, VA.

Wu, Z., and L. D. Satter. 2000. Milk production during the complete lactation of dairy cows fed diets containing different amounts of protein. J. Dairy Sci. 83:1042-1051.

Yáñez-Ruiz, D. R., A. Bannink, J. Dijkstra, E. Kebreab, D. Morgavi, P. O'Kiely, C. K. Reynolds, A. Schwarm, K. Shingfield, Z. T. Yu, and A. N. Hristov. 2016. Design, implementation and interpretation of in vitro batch culture experiments to assess methane mitigation in ruminants - a review. Anim. Feed Sci. Technol. 216:1-18.

Yang, G., D. P. Bu, J. Q. Wang, E. Khas, L. Y. Zhou, and J. J. Loor. 2012. Duodenal infusion of alpha-linolenic acid affects fatty acid metabolism in the mammary gland of lactating dairy cows. J. Dairy Sci. 95:5821-5830.

Yu, F., L. A. Bruce, A. G. Calder, E. Milne, R. L. Coop, F. Jackson, G. W. Horgan, and J. C. MacRae. 2000. Subclinical infection with the nematode Trichostrongylus colubriformis increases gastrointestinal tract leucine metabolism and reduces availability of leucine for other tissues. J. Anim. Sci. 78:380-390.

Zanton, G. I. 2016. Analysis of production responses to changing crude protein levels in lactating dairy cow diets when evaluated in continuous or change-over experimental designs. J. Dairy Sci. 99:4398-4410.

Zhang, Y. D., D. P. Bu, S. C. Li, N. Zheng, X. Q. Zhou, M. Zhao, S. G. Zhao, S. L. Li, and J. Q. Wang. 2016. Technical Note: Can tail arterial or tail venous blood represent external pudic arterial blood to measure amino acid uptake by mammary gland of cows? Livest. Sci. 188:9-12.

Zierler, K. 2000. Indicator dilution methods for measuring blood flow, volume, and other properties of biological systems, a brief history and memoir. Ann. Biomed. Eng. 28:836-848.

Zinn, R. A., and F. N. Owens. 1986. A rapid procedure for purine measurement and its use for estimating net ruminal protein synthesis. Can. J. Anim. Sci. 66:157-166. 